San Jose State University

SJSU ScholarWorks

Master's Theses

Master's Theses and Graduate Research

Fall 2013

\title{
Characterization of Silver Nanoparticle-Infused Tissue Adhesive for Ophthalmic Use
}

William Yee

San Jose State University

Follow this and additional works at: https://scholarworks.sjsu.edu/etd_theses

\section{Recommended Citation}

Yee, William, "Characterization of Silver Nanoparticle-Infused Tissue Adhesive for Ophthalmic Use" (2013). Master's Theses. 4406.

DOI: https://doi.org/10.31979/etd.2btn-qkw6

https://scholarworks.sjsu.edu/etd_theses/4406

This Thesis is brought to you for free and open access by the Master's Theses and Graduate Research at SJSU ScholarWorks. It has been accepted for inclusion in Master's Theses by an authorized administrator of SJSU ScholarWorks. For more information, please contact scholarworks@sjsu.edu. 


\title{
CHARACTERIZATION OF SILVER NANOPARTICLE-INFUSED TISSUE \\ ADHESIVE FOR OPHTHALMIC USE
}

\author{
A Thesis \\ Presented to \\ San José State University \\ In Partial Fulfillment \\ of the Requirements for the Degree \\ Master of Science
}

The Faculty of the Department of Biomedical, Chemical, and Materials Engineering

by

William Yee

December 2013 
(C) 2013

William Yee

ALL RIGHTS RESERVED 
The Designated Thesis Committee Approves the Thesis Titled

CHARACTERIZATION OF SILVER NANOPARTICLE-INFUSED TISSUE

ADHESIVE FOR OPHTHALMIC USE

by

William Yee

APPROVED FOR THE DEPARTMENT OF BIOMEDICAL, CHEMICAL, AND

MATERIALS ENGINEERING

SAN JOSÉ STATE UNIVERSITY

December 2013

Dr. Benjamin Hawkins

Department of Biomedical, Chemical, and Materials

Engineering

Dr. Guna Selvaduray

Department of Biomedical, Chemical, and Materials

Engineering

Dr. Jon Nunes

Roche Molecular Systems 


\section{ABSTRACT}

CHARACTERIZATION OF SILVER NANOPARTICLE-INFUSED TISSUE

\section{ADHESIVE FOR OPHTHALMIC USE}

by William Yee

This research examined if the infusion of silver nanoparticles into a 2-octyl cyanoacrylate tissue adhesive alters the antibacterial effectiveness and mechanical properties of the adhesive. Silver nanoparticle size and concentration combinations were varied to determine the effects of these factors. Uniform distribution of the silver nanoparticles was achieved before proceeding to testing. Antibacterial effectiveness of the composite adhesive was determined via the Kirby-Bauer disk diffusion susceptibility test and by CFU counting. Doping the adhesive with silver nanoparticles resulted in an order of magnitude reduction in bacterial growth. The greatest antibacterial effect came from imbuing $10 \mu \mathrm{g} / \mathrm{mL}$ of $4 \mathrm{~nm}$ silver nanoparticles into the tissue adhesive. Despite the noticeable reduction of bacterial growth for the doped adhesives, the difference among the varying silver nanoparticle size and concentration combinations was minimal.

The breaking strength of the adhesive increased when silver nanoparticles were added. The adhesive strength of the composite adhesive attached to an incised porcine sclera was also greater than the unaltered adhesive. The greatest breaking load and adhesive force was the $10 \mu \mathrm{g} / \mathrm{mL}$ of $10 \mathrm{~nm}$ silver nanoparticle-doped adhesive. The increased mechanical strength of the doped adhesive expands the possible applications of treatment on different areas of the body. 


\section{ACKNOWLEDGEMENTS}

I would like to thank God for the opportunity and provision to allow me to complete this research. I would also like to express my gratitude to my family for the continual support and patience during this entire process. Thanks to Dr. Benjamin Hawkins for his guidance, insight, and effort throughout this research, especially for exposing me to better techniques and more suitable equipment for my experiments. Thanks to Dr. Guna Selvaduray for his feedback on how to develop my research and experiments after I determined my research area of interest. I would like to appreciate Dr. Jon Nunes for instilling the idea of uniformity and the perspective of how the medical device industry thinks when developing products. I would also like to thank Neil Peters and Jason von Linsowe for their efforts in creating parts and training me to use certain equipment. Thanks to Intuitive Surgical for partial funding of this research. Lastly, I would like to thank Dr. Melanie McNeil and Dr. Arthur Diaz for teaching me how to effectively write and present my thesis research. 


\section{TABLE OF CONTENTS}

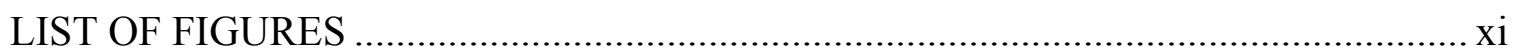

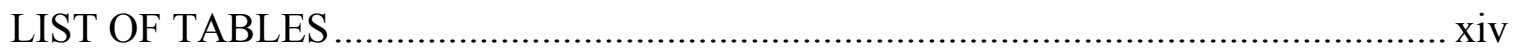

CHAPTER ONE INTRODUCTION ................................................................. 1

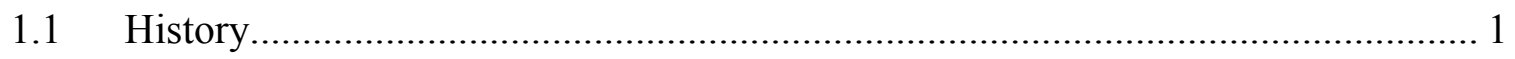

1.1.1 History of Tissue Adhesives.................................................................... 1

1.1.2 History of Silver Nanoparticles .............................................................. 3

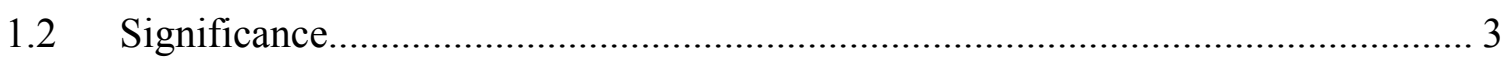

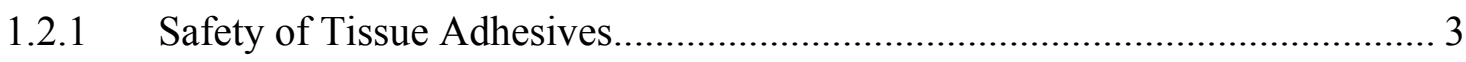

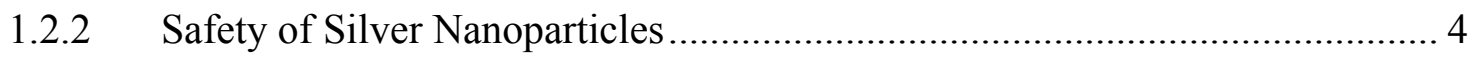

1.2.3 Technical Importance of Tissue Adhesives ................................................... 5

1.2.4 Technical Importance of Silver Nanoparticles ................................................. 6

1.2.5 Economic Relevance of Tissue Adhesives .................................................... 6

1.2.6 Economic Relevance of Silver Nanoparticles ............................................. 8

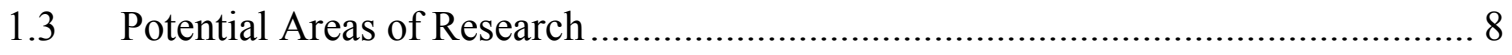

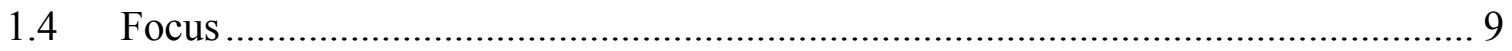

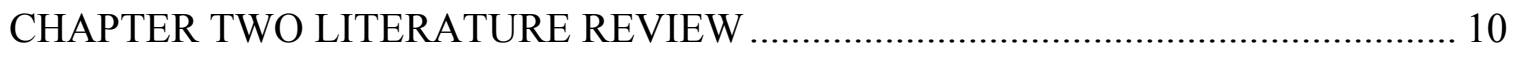

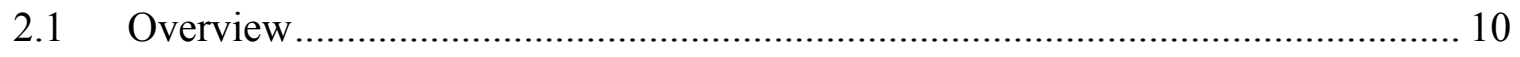

2.2 Tissue Adhesives for Ophthalmic Use............................................................... 10 


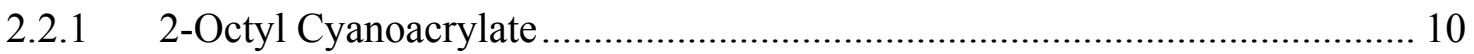

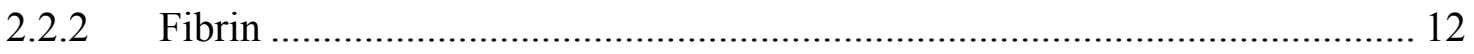

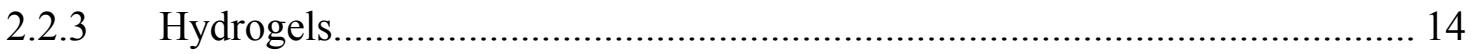

2.3 Generating Silver Nanoparticles ............................................................... 15

2.3.1 Silver Salt Precursors Used in Silver Nanoparticle Synthesis........................ 16

2.3.2 Solvents Used in Silver Nanoparticle Synthesis........................................... 17

2.3.3 Reducing Agents Used in Silver Nanoparticle Synthesis............................... 18

2.3.4 Stabilizing Agents Used in Silver Nanoparticle Synthesis.......................... 19

2.4 Silver Nanoparticle Size and Concentration ........................................................ 20

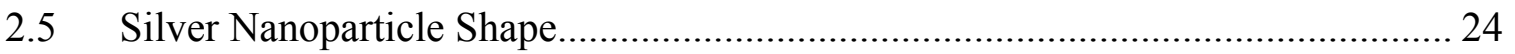

2.6 Infusing Silver Nanoparticles into a Polymer ................................................... 25

2.7 Bacteria Culturing and Types of Bacteria....................................................... 28

2.8 Antibacterial Efficacy of Silver Nanoparticle-Infused Polymers .......................... 28

2.8.1 Kirby-Bauer Disk Diffusion Susceptibility Technique ................................ 28

2.8.2 Measurement of the Colony-Forming Unit ............................................... 29

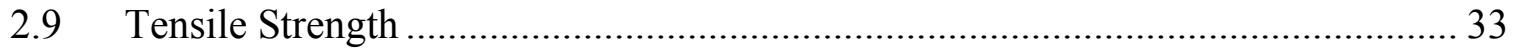

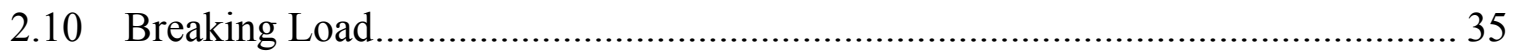

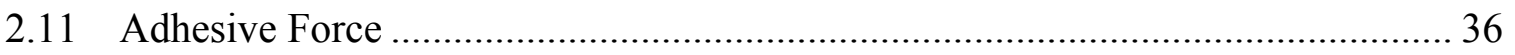

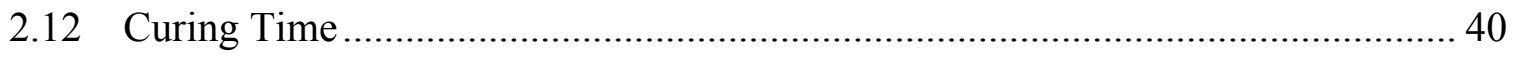




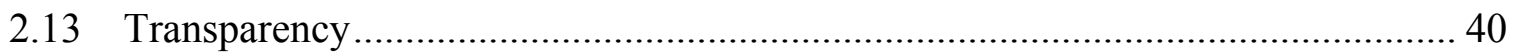

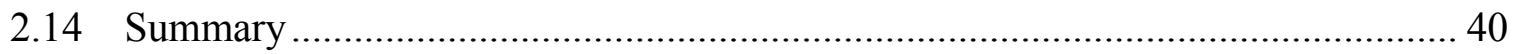

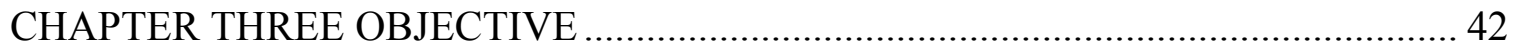

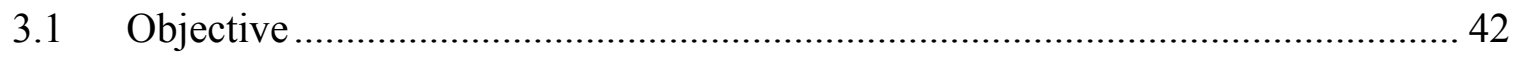

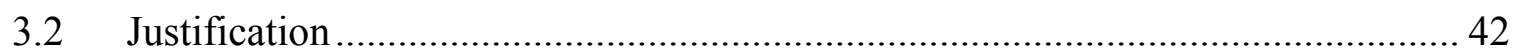

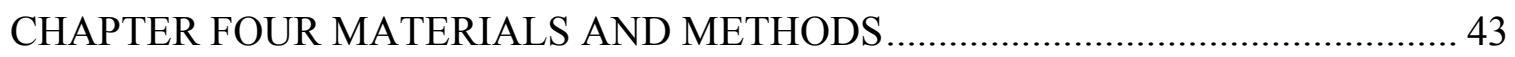

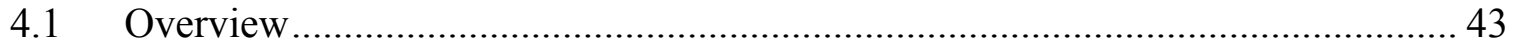

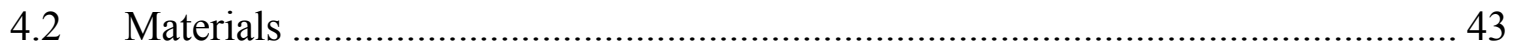

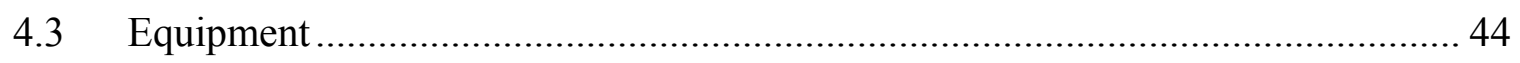

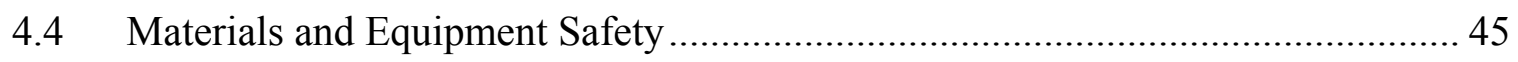

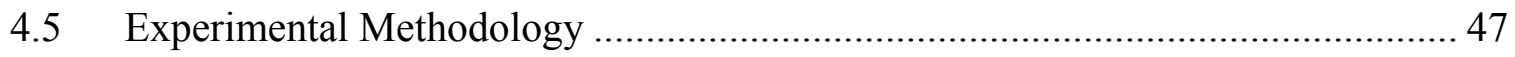

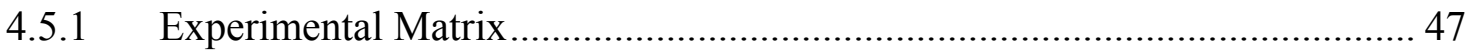

4.5.2 Infusion of Silver Nanoparticles into the Tissue Adhesive ……………........ 50

4.5.3 Silver Nanoparticle Distribution Within Adhesive ……………………….... 53

4.5.4 Preparing Samples in Polyacrylamide Mold .............................................. 54

4.5.5 Antibacterial Effectiveness Testing .......................................................... 56

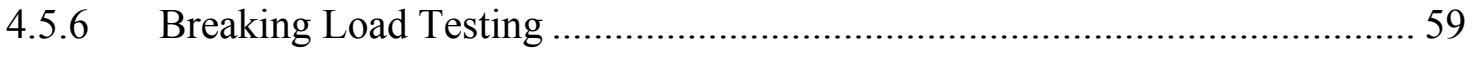

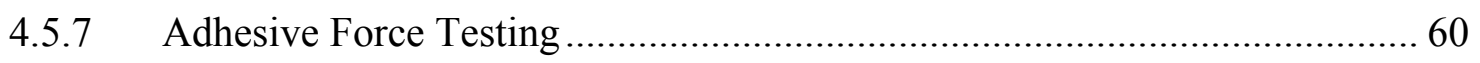

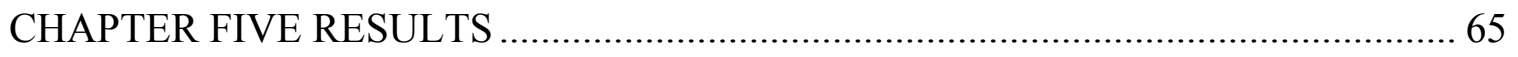


5.1 Silver Nanoparticle Distribution within Tissue Adhesive 65

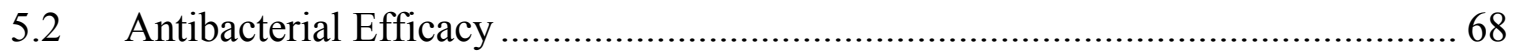

5.2.1 Kirby-Bauer Disk Diffusion Susceptibility Test ...................................... 68

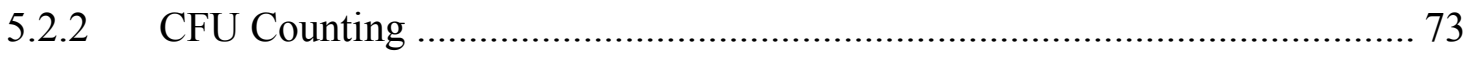

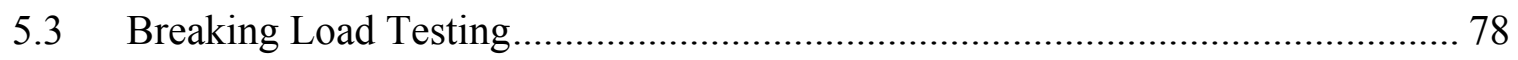

5.4 Adhesive Force Testing on Porcine Eyes .................................................... 79

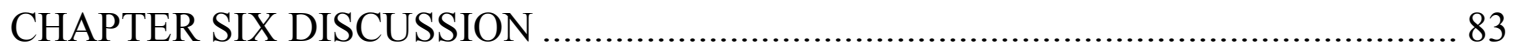

6.1 Silver Nanoparticle Distribution within Tissue Adhesive ................................ 83

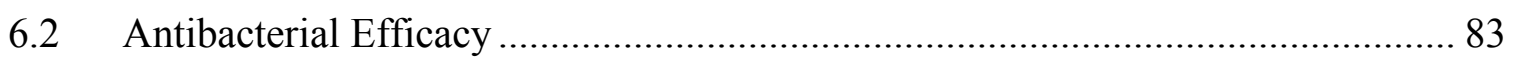

6.2.1 Kirby-Bauer Disk Diffusion Susceptibility Test .................................... 84

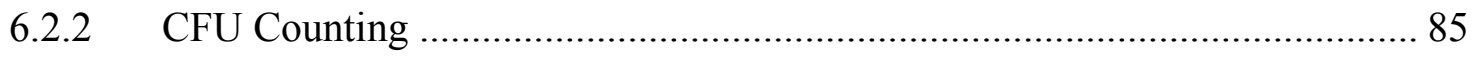

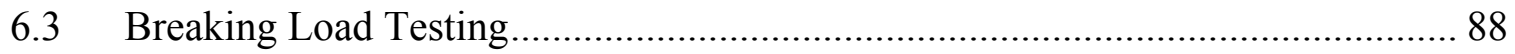

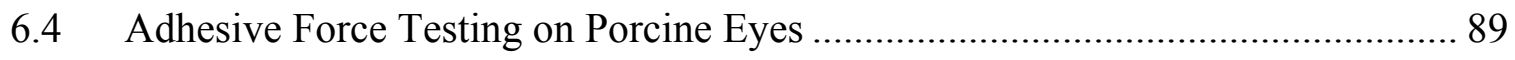

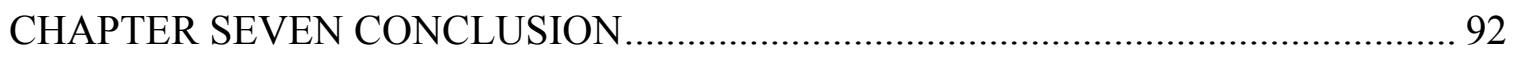

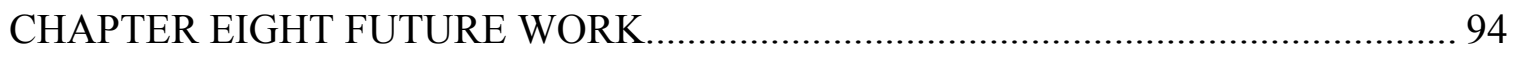

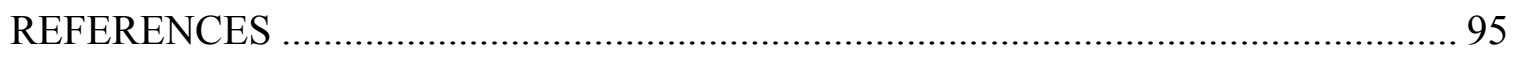

APPENDIX A DISTANCES BETWEEN SILVER NANOPARTICLES ..................... 101

APPENDIX B KIRBY-BAUER DISK DIFFUSION SUSCEPTIBILITY TEST ......... 102

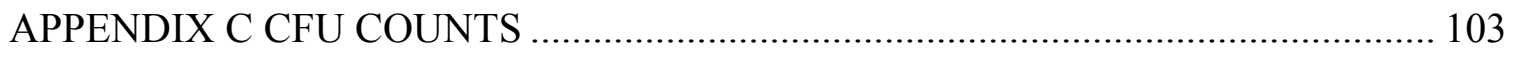


APPENDIX E ADHESIVE FORCE TESTING ...................................................... 105 


\section{LIST OF FIGURES}

Figure 1. Experimental setup that allowed adjustment of intraocular pressure in the anterior chamber of the eye

Figure 2. The silver salt precursors used in scientific literature to synthesize silver nanoparticles 16

Figure 3. The solvents used in scientific literature to synthesize silver nanoparticles ..... 17

Figure 4. The reducing agents used in scientific literature to synthesize silver nanoparticles

Figure 5. The stabilizing agents used in scientific literature to synthesize silver nanoparticles.

Figure 6 . The stirring rate affected the particle size under different silver nitrate concentrations in 1-vinyl-2-pyrrolidinone solution at $30^{\circ} \mathrm{C}$

Figure 7. The mean silver particle size versus various AgNO3/VP concentration weight ratios with a stirring rate of $300 \mathrm{rpm}$ at $30^{\circ} \mathrm{C}$ and was reduced by ultraviolet irradiation.

Figure 8 . The size of synthesized silver nanoparticles used in scientific literature

Figure 9. The deactivation of $E$. coli in relation to the interval incubation times of the composite materials.

Figure 10. The growth inhibition curves of $E$. coli in LB medium with different silver concentrations.

Figure 11. The growth inhibition curves of $S$. aureus in LB medium with different silver concentrations.

Figure 12. A stress-strain curve depicting the increased tensile strength of the polyurethane when mixed with silver nanoparticles

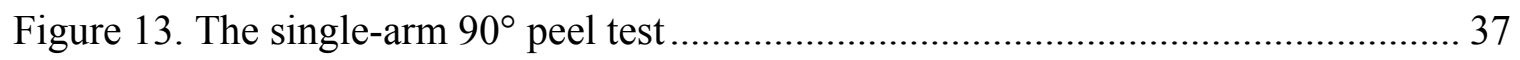

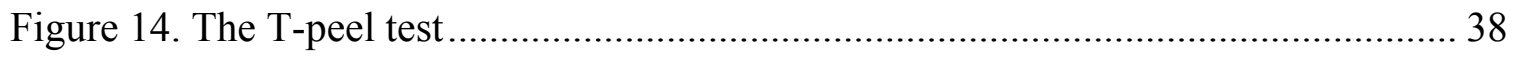

Figure 15. Flowchart illustrating the steps involved with this experiment. 
Figure 16. The addition of silver nanoparticles to the tissue adhesive prior (top) and after (bottom) vortexing and sonication

Figure 17. Machined high-density polyethylene (HDPE) solid mold used to form the polyacrylamide mold for preparing samples for the breaking load test

Figure 18. The polyacrylamide mold used to form the samples used for breaking load testing

Figure 19. Dog-bone shaped specimen clamped by the grips of the universal testing machine

Figure 20. The T-structure adhered to the porcine sclera prior to placing into the vacuum eye holder ....

Figure 21. The eye holder that held the eye in the pipe adapter 62

Figure 22. The adhesive force experimental setup 63

Figure 23. TEM image of the $10 \mathrm{~nm}$ silver nanoparticles distributed within 2-octyl cyanoacrylate. 66

Figure 24. TEM image of the $4 \mathrm{~nm}$ silver nanoparticles to confirm the particle size ...... 67

Figure 25. TEM image of the $10 \mathrm{~nm}$ silver nanoparticles to confirm the particle size .... 67

Figure 26. An inhibition halo was not formed around the unaltered adhesive 69

Figure 27. Magnified view of an unaltered adhesive sample at $2 \mathrm{X}$ magnification 69

Figure 28. A composite sample displaying the presence of an inhibition halo 71

Figure 29. Magnified view of a composite adhesive sample's inhibition halo at $2 \mathrm{X}$ magnification.

Figure 30. The average inhibition halo diameter for various silver nanoparticle-doped and undoped adhesives. 72

Figure 31. CFU counts for each of the different tested samples.................................. 74

Figure 32. The serial dilution of an undoped tissue adhesive .................................... 75

Figure 33. The serial dilution of a silver nanoparticle-doped adhesive ......................... 75 
Figure 34. The average CFU counts of various silver nanoparticle concentration and size combinations within the 2-octyl cyanoacrylate tissue adhesive

Figure 35. The breaking load results of the different silver nanoparticle concentration and size combinations within the tissue adhesive

Figure 36. The broken adhesive bonds after adhesive force testing .............................. 80

Figure 37 . The adhesive force results of the various doped and undoped adhesives ....... 81 


\section{LIST OF TABLES}

Table 1. The surface area of the examined nanosilver shapes

Table 2. The growth inhibition rates of the nanosilver shapes against $S$. aureus and $E$. coli

Table 3. The tensile strength of each polyurethane sample containing different concentrations of silver nanoparticles .................................................... 33

Table 4. The mean breaking loads with the standard deviations measured in grams ....... 36

Table 5. The adhesive force for various concentrations of silver nanoparticles in the hydrogel

Table 6 . The mean adhesive force for the three adhesives bonded to the three different substrates.

Table 7. Safety precautions for each material used in this experiment ............................ 46

Table 8. The experimental matrix containing varying levels of each factor .................. 48

Table 9. The average diameter of the inhibition halos around the various samples ........ 72

Table 10. The results of a 2-way ANOVA test from the responses generated in the Kirby-Bauer disk diffusion susceptibility test

Table 11. The average logarithmic amount of $E$. coli colonies for the different types of samples

Table 12. The results of a 2-way ANOVA test from the responses produced in the CFU counting 77

Table 13. The average breaking loads for the different factor combinations 78

Table 14. The results of a 2-way ANOVA test from the responses generated in the breaking load testing 79

Table 15. The average adhesive forces for the various factor combinations. 81

Table 16. The results of a 2-way ANOVA test from the responses produced in the adhesive force testing 


\section{CHAPTER ONE}

\section{INTRODUCTION}

The repair of wounds occurring from traumatic injuries and surgical procedures can be addressed by several wound closing methods. Some notable wound closing methods are mechanical fasteners, such as sutures, wires, and staples [1]. As with all medical treatments and tools, there is constant research and development of safer and more efficient ways of treating the ailment. Thus, the development and application of tissue adhesives became an alternative to conventional mechanical fasteners. These tissue adhesives needed to demonstrate comparable mechanical properties as mechanical fasteners and also prove to be an antimicrobial agent.

\subsection{History}

\subsubsection{History of Tissue Adhesives}

Tissue adhesives have been developed and applied since the $19^{\text {th }}$ century [2]. At that time, methyl-2-cyanoacrylate was the first tissue adhesive used for surgical application. In 1909, fibrin was first applied as a hemostatic agent [3]. Fibrinogen was then used as an adhesive in 1940 and later was developed into a biologic glue in 1944 [3]. The initial work on modern cyanoacrylates in 1949 greatly advanced the field of tissue adhesives, which then led to the characterization of the adhesive properties of modern cyanoacrylate in 1959 [3]. The research and progress on cyanoacrylates allowed the adhesive to become clinically used in ophthalmic applications in 1963 and for tympanic membrane repair in 1965 [3,4]. In addition to the use of cyanoacrylate in clinical 
settings, this adhesive was used heavily during the Vietnam War [1]. Cyanoacrylate allowed soldiers to quickly seal their wounds and ultimately aided in recovery.

In 1964, a gelatin-resorcinol-formol adhesive was created and tested and led to its application in treating aortic dissections in 1977 [3]. This clinical application was the first of its kind and was applied to the most important artery in the human body, which distributes oxygenated blood to all tissue. Gelatin-resorcinol-formol was a good adhesive that also improved hemostasis; however, this material did not promote wound healing [3]. The next major introduction to the tissue adhesive field was the United States Food and Drug Administration's (FDA) approval of a synthetic skin adhesive called Dermabond ${ }^{\circledR}$ in 1998 [1]. Chemically designated as 2-octyl-cyanoacrylate, Dermabond ${ }^{\circledR}$ has been widely accepted by surgeons and physicians for use in cosmetic surgery and in the emergency room [1]. Dermabond ${ }^{\circledR}$ has been used to treat small lacerations and wounds in a variety of areas on the body. The FDA approval and success of Dermabond ${ }^{\circledR}$ spawned the development of other synthetic tissue adhesives, using different chemical formulations, and also the discovery of further uses for natural adhesives. Despite some "off-label" use of certain tissue adhesives, the range of applications of modern adhesives has been expanded to almost every tissue in the body. This range of applications includes nerve anastomosis, bone fixation, and corneal wound repair among many others [1]. Along with sealing various wounds, tissue adhesives also prevent infection. The addition of an antimicrobial agent, such as parabens or silver nanoparticles, to tissue adhesives has been investigated. Silver nanoparticles are a promising antimicrobial agent that has recently been heavily examined. 


\subsubsection{History of Silver Nanoparticles}

For thousands of years, silver has been widely used for various functions, such as utensils, dental alloys, and photography. Hippocrates, the father of modern medicine, believed silver had anti-disease and healing properties and noted it as a treatment for

ulcers [5]. In 1884, the first documented medical use of silver recorded $1 \%$ silver nitrate as an eye treatment for neonatal conjunctivitis [5]. For serious burn wounds, topically applied silver sulfadiazine cream became the standard antibacterial treatment; its effectiveness aids in its prevalent usage today [5]. Until antibiotics were developed, silver compounds were major combatants of wound infection in World War I [5].

As antibiotics replaced silver compounds as the main antibacterial agent, silver was not used as heavily in medical applications until the advent of modern science and technology. The next major milestone for silver was the engineering of silver nanoparticles. These nanoparticles have multiple functions and have been used in various consumer products such as water purifiers, laundry detergents, and textiles [5]. Extensive research and development has been done to create marketable medical products that utilize the antimicrobial properties of silver nanoparticles in applications such as wound dressings, surgical instruments, and contraceptive devices [5].

\subsection{Significance}

\subsubsection{Safety of Tissue Adhesives}

Tissue adhesives offer many safety benefits over the use of sutures, wires, and staples. Mechanical fasteners are inherently invasive and pose potential damage to tissue. Not only do sutures and the like inflict trauma on a patient's operated tissue, but 
there is also the risk of needlestick injury to the surgeon or operating room personnel $[1,6,7]$. Suture areas can also be a site for infection and inflammation, which will lead to more complications and require additional treatment [6]. After operations, sutures and other fasteners have a tendency to loosen and possibly break, which entails extra treatment to fix these problems [1]. Tissue adhesives reduce or eliminate the risk of the aforementioned safety hazards. Tissue adhesives also provide a less traumatic closure, a reduction of blood loss by the patient, no suture removal, and less pain compared to mechanical fasteners [1].

Despite some of the safety risks associated with mechanical fasteners, fasteners are safer in some aspects than certain tissue adhesives. If the thrombin and fibrinogen in fibrin glues that were obtained from human blood were not properly screened, they can carry human viruses and other diseases $[1,4]$. In contrast, mechanical fasteners do not carry the risk of transmitting diseases and viruses.

\subsubsection{Safety of Silver Nanoparticles}

A nanoparticle has at least one dimension that ranges between 1 and $100 \mathrm{~nm}$. Nanoparticles possess an extra-large surface area to volume ratio, which is one of the reasons why nanoparticles display distinct physiochemical and biological properties. The extra-large surface area to volume ratio of silver nanoparticles imbues unique antimicrobial interactions with bacteria and viruses [5].

There is strong research evidence that supports the safety of silver nanoparticles; however, a small fraction of research has shown that silver nanoparticles are potentially cytotoxic. Chen and Schluesener point out that silver nanoparticles facilitate the creation 
of free radicals and reactive oxygen species (ROS) [5]. An over accumulation of ROS can elicit an inflammatory response [5]. Long-term occupational exposure can also lead to argyria, which is the irreversible bluish-grey pigmentation of the skin and even the eyes $[5,8]$. Despite these relevant toxicological implications, most of the research data that support silver nanoparticle cytotoxicity has been carried out by in vitro experiments. However, cells may behave differently when they are under in vivo conditions.

\subsubsection{Technical Importance of Tissue Adhesives}

Tissue adhesives are highly versatile and can be used in various applications. They are easy to use, fast to apply, do not require removal, and provide sufficient seal quality and strength [1]. Alternatively, mechanical fasteners do pose some technical disadvantages. Sutures, staples, and wires are not suitable for more complicated procedures, such as sealing leaks of bodily fluids and air in blood vessels and tissues [1]. Also, there are some areas of the body that are not easily accessible for the application of fasteners; thus, the accuracy of positioning the fasteners will be compromised. Successful suturing involves acquired skill that only comes with talent and practice [6]. Different suturing skill levels influence the time and success of the operation.

Compared to mechanical methods, tissue adhesives are aesthetically pleasing and the preferred choice for plastic surgeons performing cosmetic surgeries [1]. For ocular surgeries, suturing corneas often produces asymmetrical healing which results in a regular or an irregular astigmatism [6]. Treating this astigmatism would require more complicated surgery or a pair of corrective spectacles. 
Mechanical fasteners have clear benefits in certain applications in the body. For deep tissue wounds and lacerations, the use of deep support sutures promote the healing process and provide more than adequate mechanical strength to join two tissues together [1]. Some wounds and lacerations are large and wide, requiring fasteners instead of tissue adhesives because of the possibility that the wound reopens and takes a longer time to heal. Mechanical fasteners can also complement tissue adhesives in appropriate situations by assisting with the healing process. In the end, the suitable treatment is dependent on the type of wound and the doctor's preference of treatment.

\subsubsection{Technical Importance of Silver Nanoparticles}

When compared to their antibiotic counterparts, silver nanoparticles are highly effective against organisms that have developed a resistance to multiple drugs [8]. Additionally, these nanoparticles have a multilevel antibacterial effect on cells, which allows the silver to interact with organisms and reduce their chance of developing resistance to treatment [8]. Silver nanoparticles are bactericidal because they bind to the bacteria's cell wall, alter their cytoplasmic DNA and proteins, and modify the enzymes involved in essential cellular processes [8]. Furthermore, latest research has found that silver nanoparticles possess anti-inflammatory properties that might be due to the reduction of cytokine release and the decrease infiltration of mast cells and lymphocytes [8].

\subsubsection{Economic Relevance of Tissue Adhesives}

There are more than 12 million procedures done annually throughout the world that require the use of nylon sutures to close ocular wounds alone [6]. Since the eyes are 
commonly operated on, it is safe to say that there are many more millions of procedures that require wound closure. Non-dissolvable mechanical fasteners require removal by the doctor. Trauma occurs and the opportunity for infection is present every time sutures are removed [6]. The need for patients to come back to the doctors to have mechanical fasteners removed and the chance that further complications might arise requiring subsequent treatments is highly undesirable and ultimately uneconomical. Visiting the doctor for follow-up medical attention will incur additional costs to patients and potentially the government via Medicare or Medicaid. Alternatively, tissue adhesives eliminate the need for mechanical fastener removal and the possibility of additional trauma and infection. From a doctor's perspective, adhesives will reduce the surgery time, allowing the doctor to operate on more patients and ultimately earn more money.

The large volume of procedures that require wound closure presents a viable market for tissue adhesives. While mechanical fasteners remain the most common method for wound closure, recent advances are making tissue adhesives a viable alternative and potential replacement wound closure technique. Hence, there is a growing amount of research and development for the application of various natural, synthetic, semisynthetic, and biomimetic tissue adhesives [1]. Despite the fact that some adhesives are more expensive than typical sutures, the favorable properties and the development of more commercial adhesives establishes tissue adhesives as an economical option for wound care management. 


\subsubsection{Economic Relevance of Silver Nanoparticles}

The commercial nanotechnology industry is expected to reach $\$ 3$ trillion by 2015 [9]. Because nanomaterials have been incorporated in many sectors of society, there is no doubt that there is a massive economic impact. Silver nanoparticles are the most commercialized nanomaterial in the medical field [5]. Current and future research of silver nanoparticles will further expand the market for medical products containing the effective antimicrobial property of the nanoparticle.

\subsection{Potential Areas of Research}

Injury can occur at every part of the body, which necessitates doctors to care for them with different treatments and tools. The past century featured many advances in the field of wound care management, as evidenced by the various fields utilizing tissue adhesives. Some of these fields include hematology, gynecology, neurology, cardiology, urology, dentistry, dermatology, and ophthalmology [1]. Even though all these fields vary in the type of procedures performed, repairing wounds requires a tissue adhesive that possesses ideal properties.

First, the tissue adhesive needs to hold together two sides of tissue until the body can properly heal the wound [1]. Second, the adhesive should be able to polymerize in a moist environment within a reasonable curing time $[1,2]$. Third, the adhesive must be steadily metabolized by the surrounding tissue without generating an inflammatory response or be a site for infection $[1,6]$. Lastly, the adhesive should not deform the tissue and cause discomfort to the patient postoperatively $[1,2]$. All of these features are what all tissue adhesives should essentially share in common. 
Silver nanoparticles must have low systemic toxicity and be effective as a bactericide. There has been minimal research on the infusion of silver nanoparticles into a tissue adhesive. To the author's knowledge, there has been no research on the application of silver nanoparticle-infused tissue adhesives for ophthalmic use. The eyes are important organs of the body and are subjected to various procedures. As a result, the eyes have the potential to be a site for infection and inflammation.

\section{$1.4 \quad$ Focus}

This research focused on the infusion of silver nanoparticles in tissue adhesives for ophthalmic use. The effectiveness of the antimicrobial property of silver nanoparticles mixed with the adhesive was studied. Furthermore, the mixture adhesive was examined to determine if the silver nanoparticles alter the mechanical properties of the adhesive. 


\section{CHAPTER TWO \\ LITERATURE REVIEW}

\subsection{Overview}

Tissue adhesives offer many benefits in repairing traumatic and surgical wounds. To be effective, tissue adhesives need to be nontoxic, have a rapid curing time, and possess favorable mechanical properties. The mechanical properties of tissue adhesives changes when silver nanoparticles are infused into the adhesive. Furthermore, the antibacterial efficacy is affected when silver nanoparticles are infused into a polymer. This chapter discusses the previous research performed that evaluates the mechanical and antibacterial properties of the infusion of silver nanoparticles into a polymer. Despite the research conducted in the addition of silver nanoparticles to a polymer, there are no studies on the infusion of silver nanoparticles into a tissue adhesive for ophthalmic use. This literature review investigates the areas needed to develop this tissue adhesive for the use in the eye.

\subsection{Tissue Adhesives for Ophthalmic Use}

\subsubsection{2-Octyl Cyanoacrylate}

Multiple types of tissue adhesives have been tested for various ophthalmic wounds and conditions. A common adhesive is 2-octyl cyanoacrylate. Ritterband et al. used this adhesive to seal clear cataract wounds. Due to the influx of surface bacteria present in extraocular fluid before wound epithelialization, a $3.0 \mathrm{~mm}$ clear corneal incision is a possible site of infection and inflammation [10]. Ritterband et al. studied the effectiveness of 2-octyl cyanoacrylate (Liquid Bandage ${ }^{\mathrm{TM}}$, Johnson \& Johnson) in sealing 
a clear corneal incision by testing the influx of India ink with varying intraocular pressures and manual wound manipulations. India ink was used because the opaque fluid particle size is comparable to the size of bacteria [10]. The dynamic flow of fluid at varying intraocular pressures and wound manipulations attempts to simulate the unpredictability of the eye environment.

This study by Ritterband and his group had two phases to prove the sealing efficacy of the adhesive. In the first phase, the researchers created corneal incisions in seven human cadaver eyes to test the influx of India ink by adjusting the intraocular pressure from $4 \mathrm{mmHg}$ to $22 \mathrm{mmHg}$ and manipulating the wound by manually applying $70 \mathrm{mmHg}$ of pressure to the wound [10]. The second phase consisted of the same experiment as phase one, but this time the corneal incisions were sealed with 2-octyl cyanoacrylate. For phase one, one eye demonstrated the ingress of fluid when the intraocular pressure was less than $5 \mathrm{mmHg}$, while India ink leaked into the anterior chamber of the other eyes when more than $70 \mathrm{mmHg}$ of manual pressure was applied on the incision [10]. In contrast, all of the human eyes with the 2-octyl cyanoacrylate sealed corneal incisions did not experience any influx of India ink when the same tests were applied.

Meskin et al. confirmed the sealing efficacy of the same 2-octyl cyanoacrylate tissue adhesive used in the Ritterband et al. study. Instead of using human cadaver eyes, the Meskin et al. study was assessed in vivo in 51 eyes of 51 cataract surgery patients. After the cataract surgery and before the application of the adhesive, all incisions were hydrated with a balanced saline solution and were examined for leakage by applying 
gentle pressure to the wound with a cellulose sponge. Out of the 51 eyes, seven of the eyes displayed leakage [11]. There was no leakage present in all 51 eyes when the adhesive was applied.

In other research, Duffy et al. created and tested a scaffold-enhanced 2-octyl cyanoacrylate adhesive composite that was intended for correcting strabismus.

Strabismus is the misalignment of the eyes due to the lack of synchronization between the extraocular muscles, which results in the inability of both eyes to focus on the same point [12]. Duffy et al. evaluated the breaking loads of extraocular muscles to ocular tissues or other extraocular muscles using the scaffold-enhanced adhesive. A scaffold was added to the 2-octyl cyanoacrylate adhesive because the scaffold increased the breaking load of the adhesive [7]. The scaffolds used were made out of either poly(L-lactic-co-glycolic acid) (PLGA) or porcine small intestine submucosa. The 2-octyl cyanoacrylate used was Dermabond ${ }^{\circledR}$. As a reference, Duffy and his group analyzed the breaking loads of an unoperated eye and its extraocular muscles. Next was the testing of the breaking loads between the ocular tissues and extraocular muscles with 2-octyl cyanoacrylate alone and also with the scaffold-enhanced composite adhesive. The breaking load was found to be greatest with the composite adhesive, while the breaking load of 2-ocytl cyanoacrylate was the next highest and the unoperated eye was the lowest [7]. Further details of this study are discussed in the Section 2.10.

\subsubsection{Fibrin}

Fibrin is another common tissue adhesive for ophthalmic use. Banitt et al. compared the sealing ability of a fibrin adhesive (Tisseel®, Baxter Healthcare 
Corporation), n-butyl-2-cyanoacrylate (Histoacryl ${ }^{\circledR}$, TissueSeal) adhesive, and 10-0 nylon sutures on clear corneal incisions. The research focused on the relation between incision size and the intraocular pressure when leakage occurred after an adhesive or suture was applied. Using porcine eyes, Banitt et al. gradually increased the intraocular pressure from $20 \mathrm{mmHg}$ to $700 \mathrm{mmHg}$. The results of the study showed that regardless of the incision size, the n-butyl-2-cyanoacrylate adhesive was far superior in sealing clear corneal incisions because of the high pressures the adhesive can withstand before liquid seeps in [13]. Fibrin was generally the second best adhesive when sealing clear corneal incisions; however, as the incision size increased, the sealed corneas that used 10-0 nylon sutures were able to withstand a similar intraocular pressure as their fibrin counterparts. The intraocular pressure that the n-butyl-2-cyanoacrylate adhesive can tolerate before the corneal incision leaked was about two to three times more than the intraocular pressure that the fibrin adhesive or 10-0 nylon sutures can handle.

Fibrin is also used as a tissue adhesive to secure a lamellar graft and to attach amniotic tissue to a bare scleral wound. Kaufman et al. used a fibrin adhesive (Tisseel ${ }^{\circledR}$ VH Fibrin Sealant, Baxter Healthcare Corporation) to fasten a lamellar graft and found that all five of the patients' lamellar grafts were healed and transparent. In addition, the amniotic tissue was affixed securely onto the bare sclera of a patient. Based on the successful results of the study, Kaufman et al. concluded that the adhesive should be effective in sealing LASIK corneal flaps, conjunctival grafts, and clear corneal incisions [4]. However, in agreement with Banitt et al., Kaufman and his colleagues noted the lengthy 20 min preparation time of mixing the fibrin ingredients and the high cost of the 
adhesive (\$121 for $2 \mathrm{~mL}$ ) compared to sutures $(\$ 15)[4,13]$. Also, if not properly screened, fibrin adhesives obtained from human blood can carry viruses and other diseases $[1,4]$.

\subsubsection{Hydrogels}

Hovanesian tested the sealing effectiveness of a polyethylene glycol hydrogel adhesive (I-ZIP® Ocular Bandage, I-Therapeutix). Clear corneal incisions were made on 24 human cadaver eyes and were tested for India ink leakage under low pressure conditions and with external wound manipulations. Twelve eyes were treated with the hydrogel adhesive and reported no fluid ingress when the intraocular pressure was at 33 $\mathrm{mmHg}$, which is similar to the intraocular pressure of an incision during cataract surgery [14]. Furthermore, no fluid leakage was observed when there was external manipulation

of the incision. The other twelve eyes were set apart as controls. Nine of the control eyes experienced fluid influx with varying intraocular pressures, while eleven of the control eyes leaked India ink with external manipulation of the wound [14].

Strehin et al. evaluated the sealing ability of a chondroitin sulfate-polyethylene glycol adhesive. To test the sealing effectiveness of the synthesized adhesive, the researchers measured the intraocular pressure when the excised porcine eyes began to leak. The experiment was set up to allow the variation of intraocular pressure with a pressure sensor and a 20 -gauge needle connected to a syringe pump that was inserted into the anterior chamber of the eye [15]. Once the eye was in equilibrium, Strehin and his group increased the pumping of fluid into the eye to ensure a non-self-sealing incision that aided in demonstrating the functionality of the adhesive. This experimental setup is 
exhibited in Figure 1. Two out of the three adhesive treated eyes maintained wound sealing integrity at intraocular pressures greater than $200 \mathrm{mmHg}$. One eye experienced leakage at $200 \mathrm{mmHg}$.

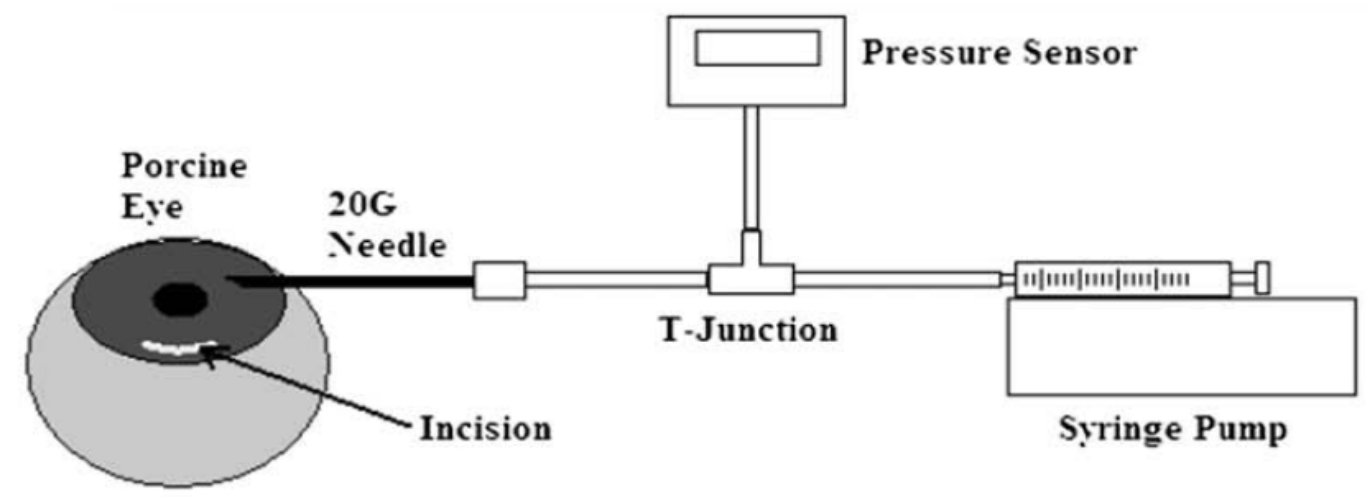

Figure 1. Experimental setup that allowed adjustment of intraocular pressure in the anterior chamber of the eye. The intraocular pressure was increased until fluid leaked through the incision [15]. (Reprinted from J. Cataract Refractive Surg., 35, I. Strehin, W.M. Ambrose, O. Schein, A. Salahuddin and J. Elisseeff, Synthesis and characterization of a chondroitin sulfate-polyethylene glycol corneal adhesive, 567-576, 2009, with permission from Elsevier)

\subsection{Generating Silver Nanoparticles}

Silver nanoparticles are synthesized by either the top-down or bottom-up techniques [16]. The top-down approach mechanically reduces bulk silver to the nanoscale size via laser ablation and lithography [17]. Conversely, the bottom-up approach is the dissolution of silver salt into a solvent [16]. The addition of a reducing agent and stabilizing agent precipitates formation of silver nanoparticles [16]. The bottom-up technique is the preferred and predominant method to synthesize silver nanoparticles primarily because the mechanical reduction of the top-down technique produces surface imperfections, which impacts the applicability of the silver nanoparticles $[16,18]$. 


\subsubsection{Silver Salt Precursors Used in Silver Nanoparticle Synthesis}

In the bottom-up method, silver salt precursors are dissolved in a solvent to produce ionic silver as part of the synthesis of silver nanoparticles [16]. When compared to other silver salt precursors, silver nitrate $\left(\mathrm{AgNO}_{3}\right)$ is the predominant silver salt precursor used in research due to its chemical stability and low cost $[16,19]$. In a scientific literature review conducted by Tolaymat et al., 200 pertinent articles referenced the statistics involved with the synthesis of silver nanoparticles. The percentage of certain silver salt precursors used in the scientific literature review in relation to other salts is portrayed in Figure 2.

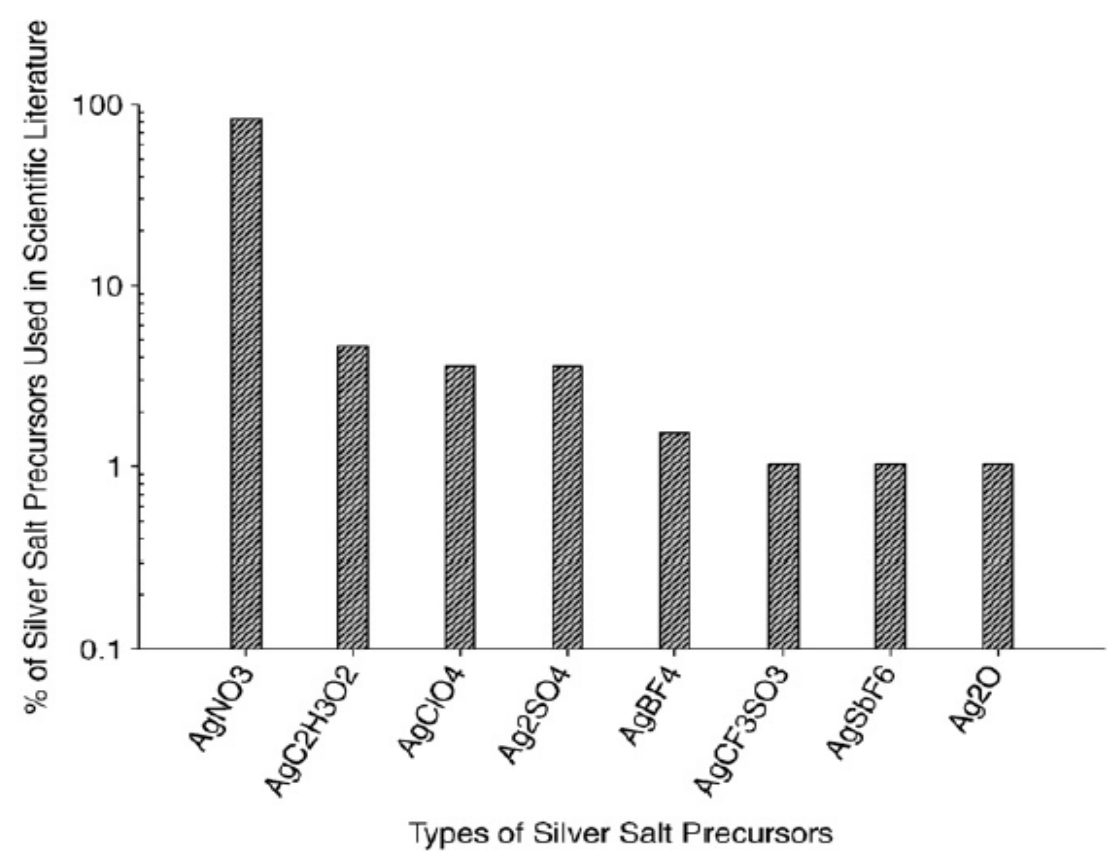

Figure 2. The silver salt precursors used in scientific literature to synthesize silver nanoparticles. Silver nitrate accounted for $83 \%$ of the silver salt precursors in the review [16]. (Reprinted from Sci. Total Environ., 408, T.M. Tolaymat, A.M. El Badawy, A. Genaidy, K.G. Scheckel, T.P. Luxton and M. Suidan, An evidence-based environmental perspective of manufactured silver nanoparticle in syntheses and applications: A systematic review and critical appraisal of peer-reviewed scientific papers, 999-1006, 2010, with permission from Elsevier) 


\subsubsection{Solvents Used in Silver Nanoparticle Synthesis}

In the bottom-up method, organic and inorganic solvents are used to dissolve the silver salt precursors as part of the silver nanoparticle synthesis process [16]. Organic solvents are heavily used for the production of high particle concentrations with a predefined shape and size $[20,21]$. Due to the low cost and availability of water, it is the prime solvent used in the synthesis of silver nanoparticles [16]. Water is used to generate stable and mobile silver nanoparticles in an aqueous environment [16]. The number of researchers using water as a solvent in comparison to other solvents is shown in Figure 3.

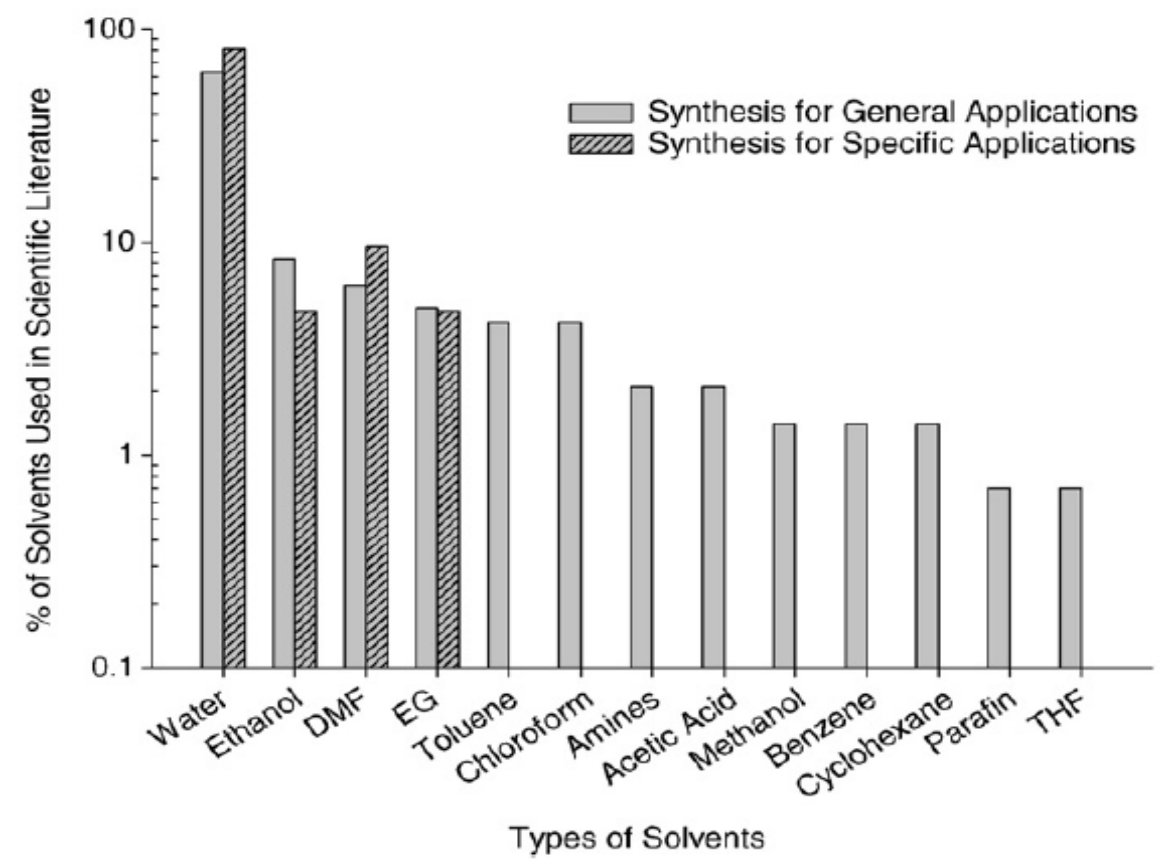

Figure 3. The solvents used in scientific literature to synthesize silver nanoparticles. Water accounted for about $60 \%$ of the solvents in the review. The diagonal-shaded bars depict the solvents used for the synthesis of silver nanoparticles for certain applications [16]. (Reprinted from Sci. Total Environ., 408, T.M. Tolaymat, A.M. El Badawy, A. Genaidy, K.G. Scheckel, T.P. Luxton and M. Suidan, An evidence-based environmental perspective of manufactured silver nanoparticle in syntheses and applications: A systematic review and critical appraisal of peer-reviewed scientific papers, 999-1006, 2010, with permission from Elsevier) 


\subsubsection{Reducing Agents Used in Silver Nanoparticle Synthesis}

The use of a reducing agent is necessary for the bottom-up approach of synthesizing silver nanoparticles. Reducing agents offer free electrons to reduce the silver ions that will eventually form the nanoparticles [16]. These agents can be a chemical or biological agent, plant extract, or an irradiation method [16]. Sodium borohydride $\left(\mathrm{NaBH}_{4}\right)$ and sodium citrate are the prevalent reducing agents used to form silver nanoparticles, which is shown in Figure 4 of the Tolaymat et al. study. Sodium borohydride is a strong reducing agent that typically generates a narrow range of small, uniform particles [16]. To form larger particles, a weaker reducing agent is used such as ascorbic acid [22]. 


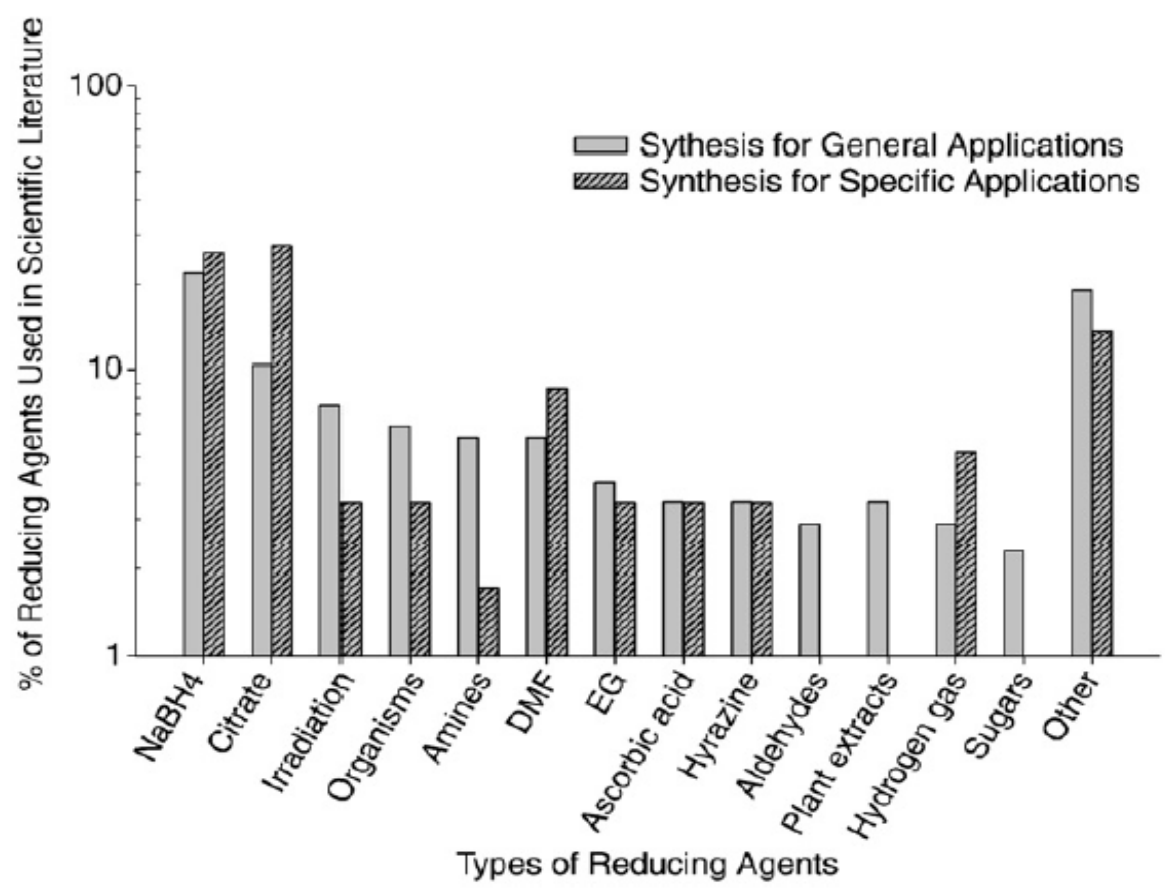

Figure 4. The reducing agents used in scientific literature to synthesize silver nanoparticles. Sodium borohydride $\left(\mathrm{NaBH}_{4}\right)$ and sodium citrate accounted for about $33 \%$ of the reducing agents in the review. The diagonal-shaded bars depict the reducing agents used for the synthesis of silver nanoparticles for certain applications. The "other" category was composed of reducing agents that were rarely used in the literature review [16]. (Reprinted from Sci. Total Environ., 408, T.M. Tolaymat, A.M. El Badawy, A. Genaidy, K.G. Scheckel, T.P. Luxton and M. Suidan, An evidence-based environmental perspective of manufactured silver nanoparticle in syntheses and applications: A systematic review and critical appraisal of peer-reviewed scientific papers, 999-1006, 2010, with permission from Elsevier)

\subsubsection{Stabilizing Agents Used in Silver Nanoparticle Synthesis}

In the bottom-up approach, stabilizing agents are used to control the size of the nanoparticle and to prevent nanoparticle agglomeration [16]. According to the research of Olenin et al., the aggregation of nanoparticles is due to the high thermodynamic instability and extra surface energy on the particle surface [23]. Stabilizing agents can be surfactants or polymers containing functional groups $[16,23]$. The concentration of a 
stabilizing agent also determines the reactivity, solubility, stability, shape, and size of the nanoparticle [24]. The different types of stabilizing agents are illustrated in Figure 5.

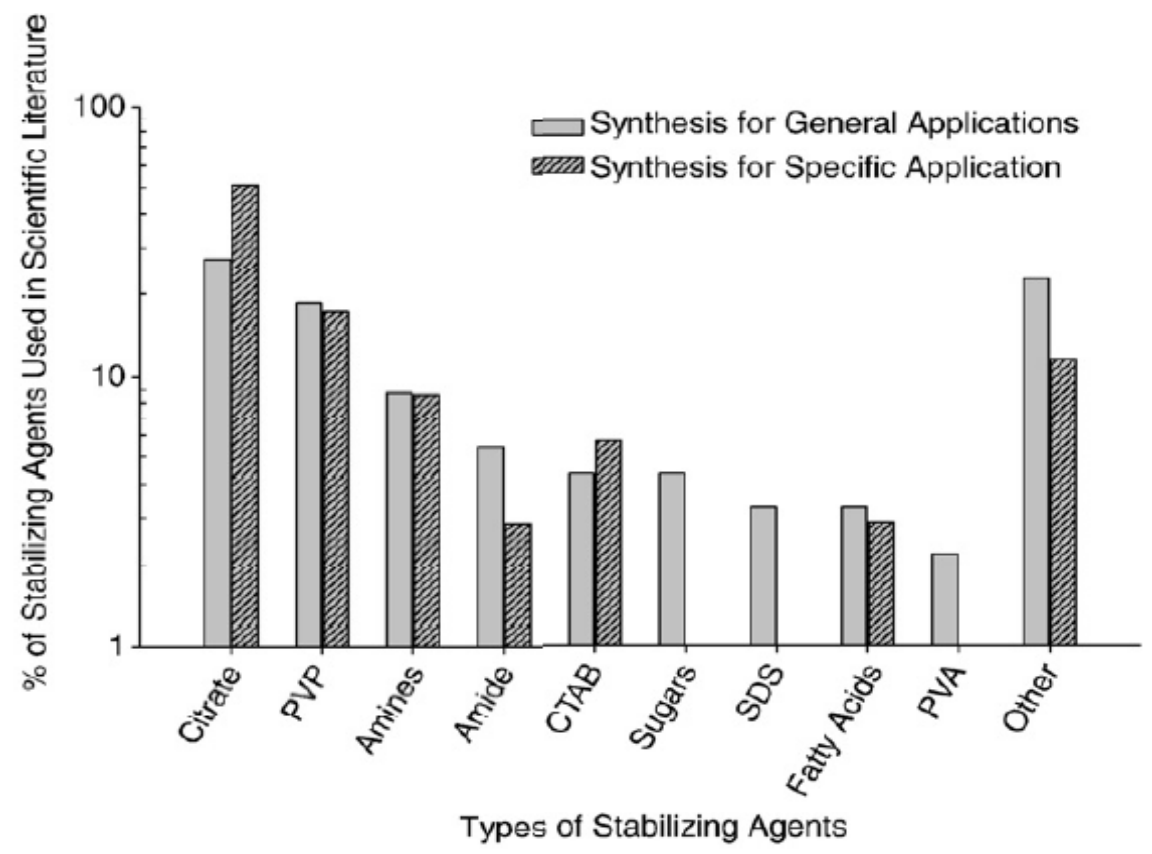

Figure 5. The stabilizing agents used in scientific literature to synthesize silver nanoparticles. Sodium citrate accounted for about $27 \%$ of the stabilizing agents in the review. The diagonal-shaded bars depict the stabilizing agents used for the synthesis of silver nanoparticles for certain applications. The "other" category was composed of stabilizing agents rarely used in the literature review [16]. (Reprinted from Sci. Total Environ., 408, T.M. Tolaymat, A.M. El Badawy, A. Genaidy, K.G. Scheckel, T.P. Luxton and M. Suidan, An evidence-based environmental perspective of manufactured silver nanoparticle in syntheses and applications: A systematic review and critical appraisal of peer-reviewed scientific papers, 999-1006, 2010, with permission from Elsevier)

\subsection{Silver Nanoparticle Size and Concentration}

In a study performed by Lee and Tsao, they examined the factors that effected silver nanoparticle diameter size. A particle size analyzer was used to measure the silver nanoparticle size. The study used $100 \mathrm{~mL}$ of $100 \mathrm{ppm}$ silver nitrate solution as the silver salt precursor and mixed it with $1 \mathrm{~g}$ of 1-vinyl-2-pyrrolidinone in $100 \mathrm{~mL}$ of water at 


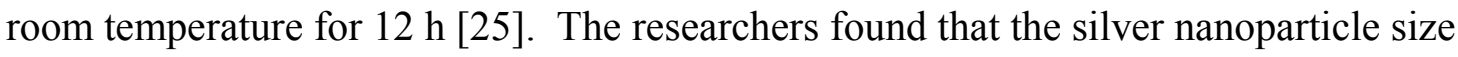
increased as the concentration of the silver nitrate solution in 1-vinyl-2-pyrrolidinone mixture increased [25]. Lee and Tsao recognized that the increase of particle size was the result of an agglomeration of silver nanoparticles due to the lack of a stabilizing agent when the concentration of the silver aqueous mixture increased [25]. This finding supports the research of Olenin et al., which also found that the aggregation of particles was prevented by the addition of a stabilizing agent.

Additionally, the results demonstrated that the silver particle size was notably affected by the stirring rate and the silver nitrate/1-vinyl-2-pyrrolidinone $\left(\mathrm{AgNO}_{3} / \mathrm{VP}\right)$ mixture concentration ratio [25]. Figure 6 shows that a higher stirring rate means a smaller particle size; however, the increased concentration of silver nitrate in the $\mathrm{AgNO}_{3} / \mathrm{VP}$ mixture also means an increase of particle size, regardless of the higher stirring rate. The $300 \mathrm{~nm}$ particle size with the higher stirring rate depicted in Figure 6 cannot be considered a nanoparticle because a nanoparticle is between 1 and $100 \mathrm{~nm}$ in size [5]. Nevertheless, the study does reveal that a higher stirring rate translates to the generation of a smaller particle. 


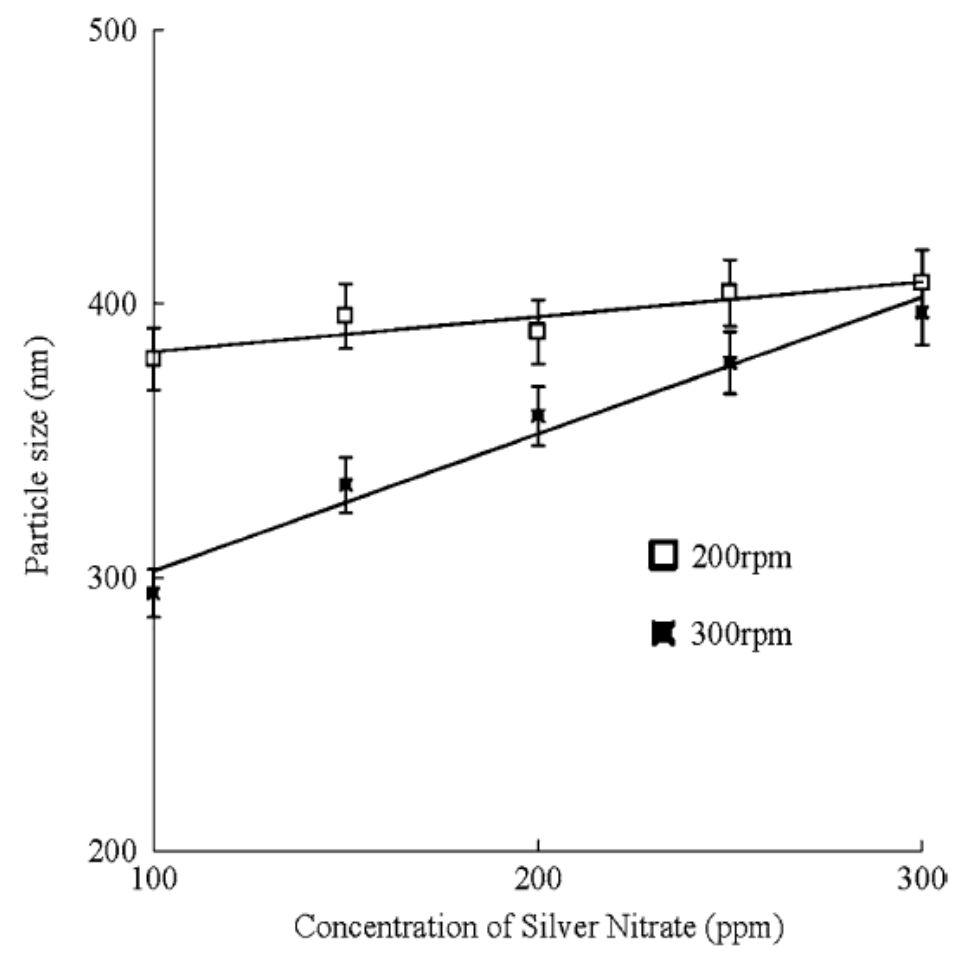

Figure 6. The stirring rate affected the particle size under different silver nitrate concentrations in 1-vinyl-2-pyrrolidinone solution at $30^{\circ} \mathrm{C}$ [25]. (Reprinted from J. Mater. Sci., 45, W-F. Lee and K-T. Tsao, Effect of silver nanoparticles content on the various properties of nanocomposite hydrogels by in situ polymerization, 89-97, 2010, with permission from Springer Science and Business Media)

The $\mathrm{AgNO}_{3} / \mathrm{VP}$ mixture weight ratio was also an important factor that was considered to produce appropriate sized silver nanoparticles. Figure 7 shows that silver particle size was affected by different silver nitrate concentrations under varying $\mathrm{AgNO}_{3} / \mathrm{VP}$ weight ratios. With a lower $\mathrm{AgNO}_{3} / \mathrm{VP}$ weight ratio, the silver particle size decreased to become equal or less than $100 \mathrm{~nm}$, which is in the size range of a nanoparticle $[5,25]$. Lee and Tsao concluded that when the $\mathrm{AgNO}_{3} / \mathrm{VP}$ weight ratio was lowered to $1 / 10$, the extra 1-vinyl-2-pyrrolidinone chelated the dispersible silver ions to form the smallest silver particle diameter size at $72 \mathrm{~nm}$ [25]. 


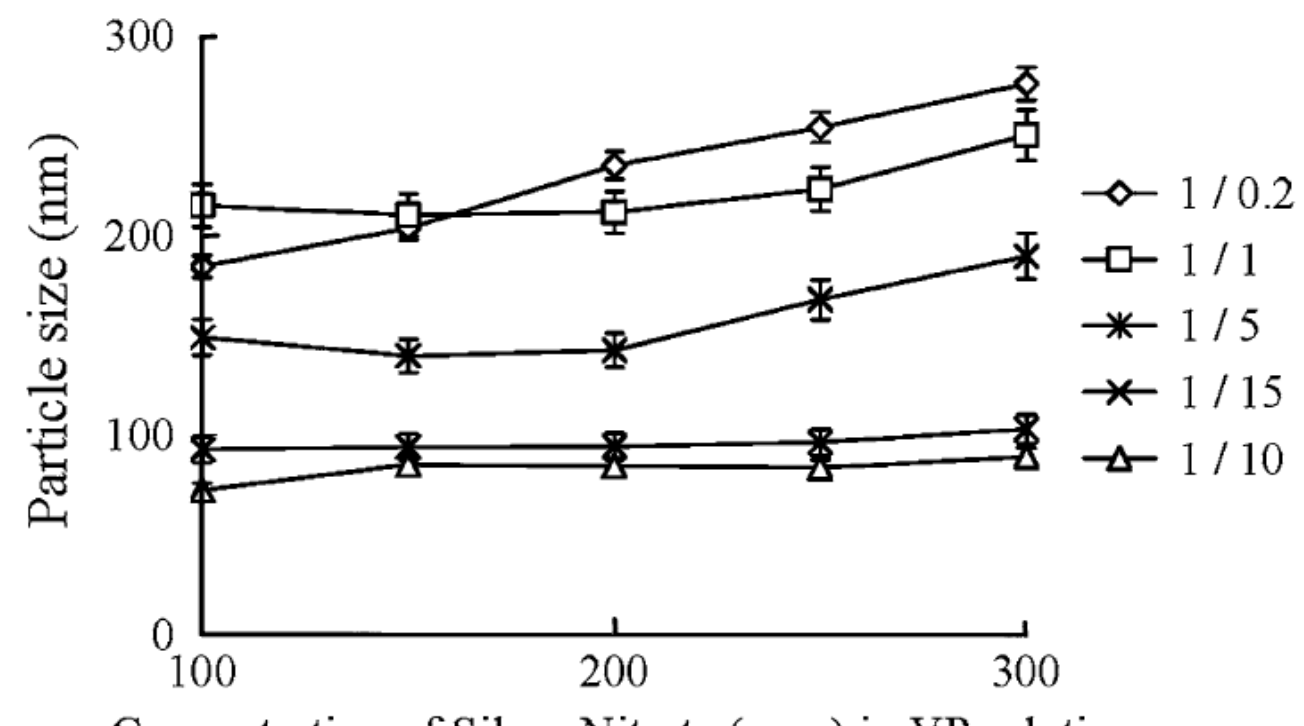

Concentration of Silver Nitrate (ppm) in VP solution

Figure 7. The mean silver particle size versus various AgNO3/VP concentration weight ratios with a stirring rate of $300 \mathrm{rpm}$ at $30^{\circ} \mathrm{C}$ and was reduced by ultraviolet irradiation. When the $\mathrm{AgNO}_{3} / \mathrm{VP}$ weight ratio was lowered to $1 / 10$, the smallest particle size can be formed to be $72 \mathrm{~nm}$ [25]. (Reprinted from J. Mater. Sci., 45, W-F. Lee and K-T. Tsao, Effect of silver nanoparticles content on the various properties of nanocomposite hydrogels by in situ polymerization, 89-97, 2010, with permission from Springer Science and Business Media)

The review conducted by Tolaymat's group concluded that researchers preferred to use smaller sized particles, especially between 0 and $10 \mathrm{~nm}$ [16]. Different nanoparticle sizes were chosen based on what was more suitable for the application. In Figure 8 , the nanoparticle size of $0-10 \mathrm{~nm}$ is shown to be used in $45 \%$ of general applications, which is almost double the percentage of the next most commonly used particle size of 11-20 nm [16]. 


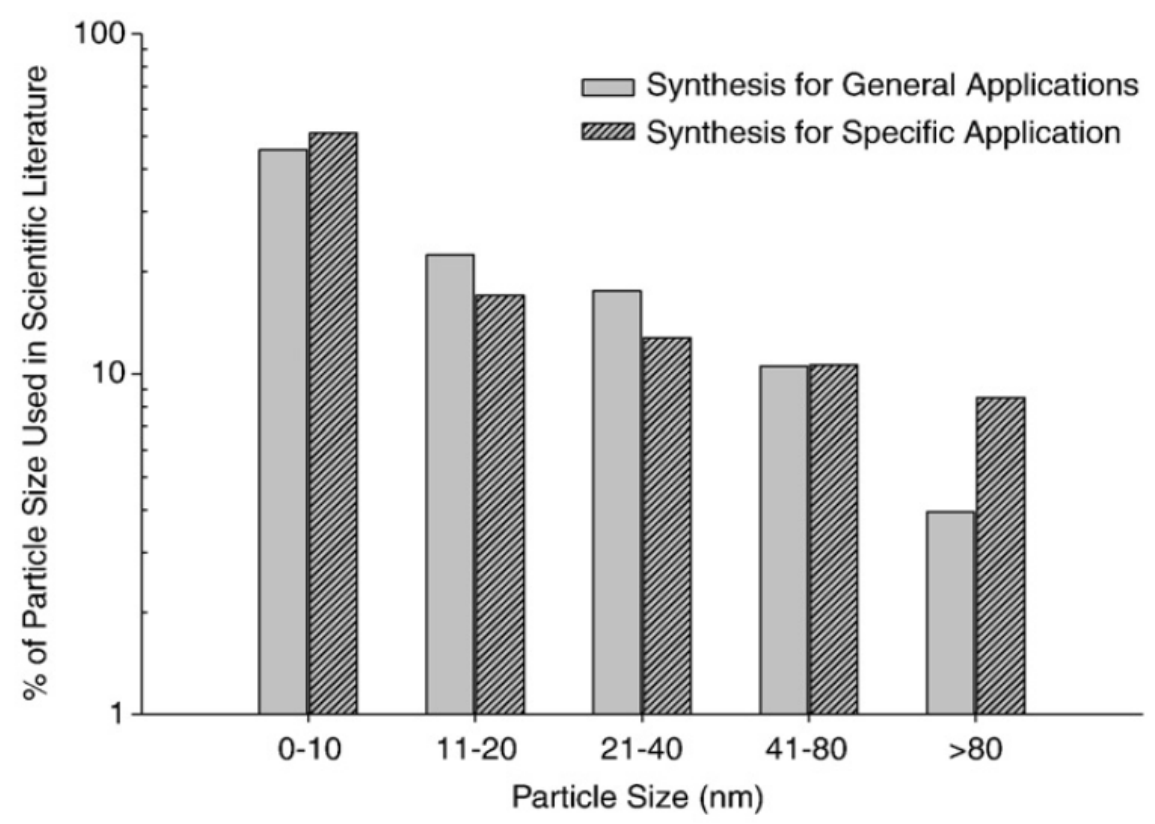

Figure 8 . The size of synthesized silver nanoparticles used in scientific literature. The range of 0 to $10 \mathrm{~nm}$ accounted for about $45 \%$ of the nanoparticle sizes in the review. The diagonal-shaded bars depict the silver nanoparticle sizes used in specific applications [16]. (Reprinted from Sci. Total Environ., 408, T.M. Tolaymat, A.M. El Badawy, A. Genaidy, K.G. Scheckel, T.P. Luxton and M. Suidan, An evidence-based environmental perspective of manufactured silver nanoparticle in syntheses and applications: A systematic review and critical appraisal of peer-reviewed scientific papers, 999-1006, 2010, with permission from Elsevier)

\subsection{Silver Nanoparticle Shape}

Silver nanoparticles are formed into many different shapes such as plates, rods, spheres, triangles, and hexagons [16,26]. Sadeghi et al. studied the antibacterial effectiveness of a few of these various shapes. They used N-N'-dimethyl formamide to reduce silver nitrate and poly(N-vinyl-2-pyrrolidone) to stabilize the mixture to produce uniform, non-agglomerated particles [26,27]. The results showed that the antibacterial efficacy of silver nanoparticles was highly dependent on the amount of surface area of the particle that the bacteria can interact with [26]. Table 1 displays the surface area of the 
nanosilver shapes examined by Sadeghi's group, which includes hexagonal nanoparticles, nanorods, and nanoplates. Table 2 presents the growth inhibition rates of the nanosilver shapes against Staphylococcus aureus (S. aureus) and Escherichia coli (E. coli). This table supports the study's conclusion that a larger nanoparticle surface area increases the antibacterial efficacy.

Table 1. The surface area of the examined nanosilver shapes [26]. (Reprinted from Adv. Powder Technol., 23, B. Sadeghi, F.S. Garmaroudi, M. Hashemi, H.R. Nezhad, A. Nasrollahi, S. Ardalan and S. Ardalan, Comparison of the anti-bacterial activity on the nanosilver shapes: Nanoparticles, nanorods and nanoplates, 22-26, 2012, with permission from Elsevier)

\begin{tabular}{|l|l|}
\hline Nanosilver Shapes & Surface Area $\left(\mathrm{m}^{2} / \mathrm{g}\right)$ \\
\hline Silver Hexagonal Nanoparticles & 17.8 \\
\hline Silver Nanorods & 38.8 \\
\hline Silver Nanoplates & 121.1 \\
\hline
\end{tabular}

Table 2. The growth inhibition rates of the nanosilver shapes against $S$. aureus and $E$. coli. Note that the growth inhibition rates of all nanosilver shapes were high, which means that regardless of the shape chosen, the antibacterial property of nanosilver was effective [26]. (Reprinted from Adv. Powder Technol., 23, B. Sadeghi, F.S. Garmaroudi, M. Hashemi, H.R. Nezhad, A. Nasrollahi, S. Ardalan and S. Ardalan, Comparison of the anti-bacterial activity on the nanosilver shapes: Nanoparticles, nanorods and nanoplates, 22-26, 2012, with permission from Elsevier)

\begin{tabular}{|l|l|l|}
\hline Sample (10 ppm) & Growth Inhibition Rate $(\%)$ \\
\hline & S. aureus & E. coli \\
\hline Silver Hexagonal Nanoparticles & 95.5 & 92.5 \\
\hline Silver Nanorods & 97.3 & 93.4 \\
\hline Silver Nanoplates & 98.5 & 94.2 \\
\hline
\end{tabular}

2.6 Infusing Silver Nanoparticles into a Polymer

The incorporation of silver nanoparticles into a polymer can be done by a few approaches, such as in situ, ex situ, melt processing, and sonication [25,28,29]. The ex 
situ approach is when the silver nanoparticles are generated via soft-chemistry routes and then spread throughout a polymer matrix [25]. The in situ approach is when the silver nanoparticles are produced inside a polymer matrix via decomposition or chemical reduction of the silver salt precursor dissolved into the polymer [25]. The melt processing method is when the silver nanoparticles and polymer are mixed together at high temperatures while being spun at a constant speed [30]. For the melting process, Radheshkumar and Münstedt produced the melted compound with an internal mixer at $230^{\circ} \mathrm{C}$ while rotating at $60 \mathrm{rpm}$ for $7 \mathrm{~min}$ [30]. Sonication uses ultrasonic energy to evenly disperse nanoparticles within a liquid or polymer [29]. The two methods of sonication are direct and indirect sonication. Direct sonication is the production of ultrasonic waves in the polymer by immersing an ultrasonic probe within the polymer suspension [29]. Indirect sonication is the propagation of ultrasonic waves through a liquid bath surrounding the nanoparticle-doped polymer sample container [29].

The in situ method is a commonly used technique in the scientific literature to generate a polymer containing silver nanoparticles. Lee and Tsao applied this method to produce a silver nanoparticle-infused hydrogel that was used as a bioadhesive for hard and soft tissue applications [25]. The first step of creating the silver nanoparticle-infused hydrogel was the addition of a 1-vinyl-2-pyrrolidinone/silver ion precursor solution into a monomer solution containing $1 \mathrm{~mol} \%$ of ethylene glycol dimethacrylate (EGDMA) and 1 mol\% of 2,2-diethoxyacetophenone (DEAP) [25]. EGDMA was a crosslinker and DEAP was a photoinitiator [25]. Lastly, the mixture was polymerized and reduced simultaneously by exposing the solution to $600 \mathrm{~W}$ of ultraviolet radiation for $2 \mathrm{~h} \mathrm{[25].}$ 
Deka et al. used an in situ polymerization technique to create a silver nanoparticle-infused polyurethane [31]. A silver nitrate solution was reduced by N,N'dimethylformamide (DMF) and was added to a hyperbranched polyurethane matrix at

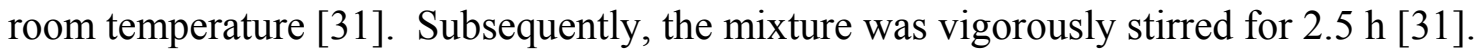
The researchers found that the nature of the atmosphere has no effect on the formation of the silver nanoparticle-infused polyurethane [31]. Uniform distribution of the silver nanoparticles in the polyurethane was confirmed via transmission electron microscopy (TEM).

Zhou et al. used the in situ approach to synthesize a silver nanoparticle-doped gelatin and carboxymethyl chitosan (CM-chitosan) hydrogel [32]. These generated hydrogels proved to be stable and have homogenous distribution of the silver nanoparticles in the polymer matrix [32]. The first step in preparing the infused hydrogels was dissolving silver nitrate powder into deionized water. Next, a $10 \mathrm{wt} \%$ total concentration of a 2:3 weight ratio of gelatin and CM-chitosan powders were mixed into the silver solution at $50^{\circ} \mathrm{C}$ with an ARE-310 hybrid mixer for 20 min to produce a homogenous polymer solution [32]. Zhou et al. used $30 \mathrm{kGy}$ of gamma radiation at ambient temperature located in a ${ }^{60} \mathrm{Co}$ facility as a crosslinker and reducing agent [32].

Lin et al. examined the dispersion of silver nanoparticles with sonication. They observed the dispersion of the nanoparticles with a field emission scanning electron microscope (FE-SEM). The ultrasonic energy delivered at various power intensities was sufficient in dispersing the nanoparticles. Greater ultrasonic power delivered to 
agglomerated silver nanoparticles provided better dispersion [33]. However, greater ultrasonic energy also signified that more heat was imparted to the sample.

\subsection{Bacteria Culturing and Types of Bacteria}

Two of the most common bacteria used in determining the antibacterial properties of silver nanoparticles are $S$. aureus and E. coli [26,28,31]. Despite multiple methods of culturing bacteria, there are some commonalities in the bacterial culturing process. Zhou et al. cultivated their E. coli bacterial culture at $37^{\circ} \mathrm{C}$ in a sterilized Luria-Bertani (LB) broth [32]. The mixture was placed into a rotary shaker and shaken at $150 \mathrm{rpm}$ for $16 \mathrm{~h}$ [32]. Lee and Tsao also used a similar preparation method for their bacterial culture. E. coli was preserved on LB agar, which was composed of a LB medium and $15 \mathrm{~g} / \mathrm{L}$ of agar [25]. The bacterial cells were added to $100 \mathrm{~mL}$ of $\mathrm{LB}$ medium and were placed into a $37^{\circ} \mathrm{C}$ incubator to be shaken at $170 \mathrm{rpm}$ for 12 to $16 \mathrm{~h}$ [25]. Likewise, Deka et al. incubated $S$. aureus and E. coli bacteria at $37^{\circ} \mathrm{C}$ for $24 \mathrm{~h}$ by adding it to a Mueller Hinton broth [31].

\subsection{Antibacterial Efficacy of Silver Nanoparticle-Infused Polymers}

\subsubsection{Kirby-Bauer Disk Diffusion Susceptibility Technique}

Zhou et al. used the Kirby-Bauer disk diffusion susceptibility test to assess the antibacterial performance of the silver nanoparticle-infused hydrogel [32]. They first dispensed $50 \mu \mathrm{L}$ of bacteria medium containing a concentration of $10^{6}$ colony-forming units per milliliter $(\mathrm{CFU} / \mathrm{mL})$ of $E$. coli onto an agar plate. A disk-shaped sample of the silver nanoparticle-infused hydrogel was then placed on the agar plate and incubated at $37^{\circ} \mathrm{C}$ for $12 \mathrm{~h} \mathrm{[32].} \mathrm{After} \mathrm{the} \mathrm{incubation} \mathrm{period,} \mathrm{the} \mathrm{diameter} \mathrm{of} \mathrm{the} \mathrm{bacterial} \mathrm{growth}$ 
inhibition halo around each composite sample was measured to determine the antibacterial efficacy of the composite [32]. A larger inhibition halo diameter signified the bacteria having a larger susceptibility to the antibacterial composite.

Sadeghi et al. also used the Kirby-Bauer technique by placing nanosilver-filled disks onto separate $S$. aureus and $E$. coli-filled agar plates and incubated the sample mediums for $24 \mathrm{~h}$ at $37^{\circ} \mathrm{C}$ [26]. During the incubation period, the samples were supposed to absorb water from the agar plate while the antibacterial silver diffused into the surrounding agar $[26,34]$. The diameters of the inhibition halos were measured to detect the effectiveness of the antibacterial samples.

\subsubsection{Measurement of the Colony-Forming Unit}

Lee and Tsao assessed the antibacterial activity of their silver nanoparticleinfused hydrogel by adding the bacterial culture to the composite samples in sterile water and incubated it in a $37^{\circ} \mathrm{C}$ shaker [25]. The samples were removed in $20 \mathrm{~min}$ intervals between 20 and $120 \mathrm{~min}$ [25]. This solution was diluted between $10^{3}$ and $10^{5}$ fold with a $0.85 \%$ saline solution and was mixed with LB broth [25]. After gentle shaking of the mixture, the contents remained untouched until solidified. Following two days of incubation at $37^{\circ} \mathrm{C}$, the developed colonies were counted to determine their viability in the antibacterial environment [25]. The viability was represented by the log of the colony-forming unit per milliliter [25]. Figure 9 illustrates the deactivation of E. coli by comparing the change in viability during the interval incubation times. The deactivation

of the bacteria was greatest when the silver nanoparticle concentration was the highest $[25]$. 


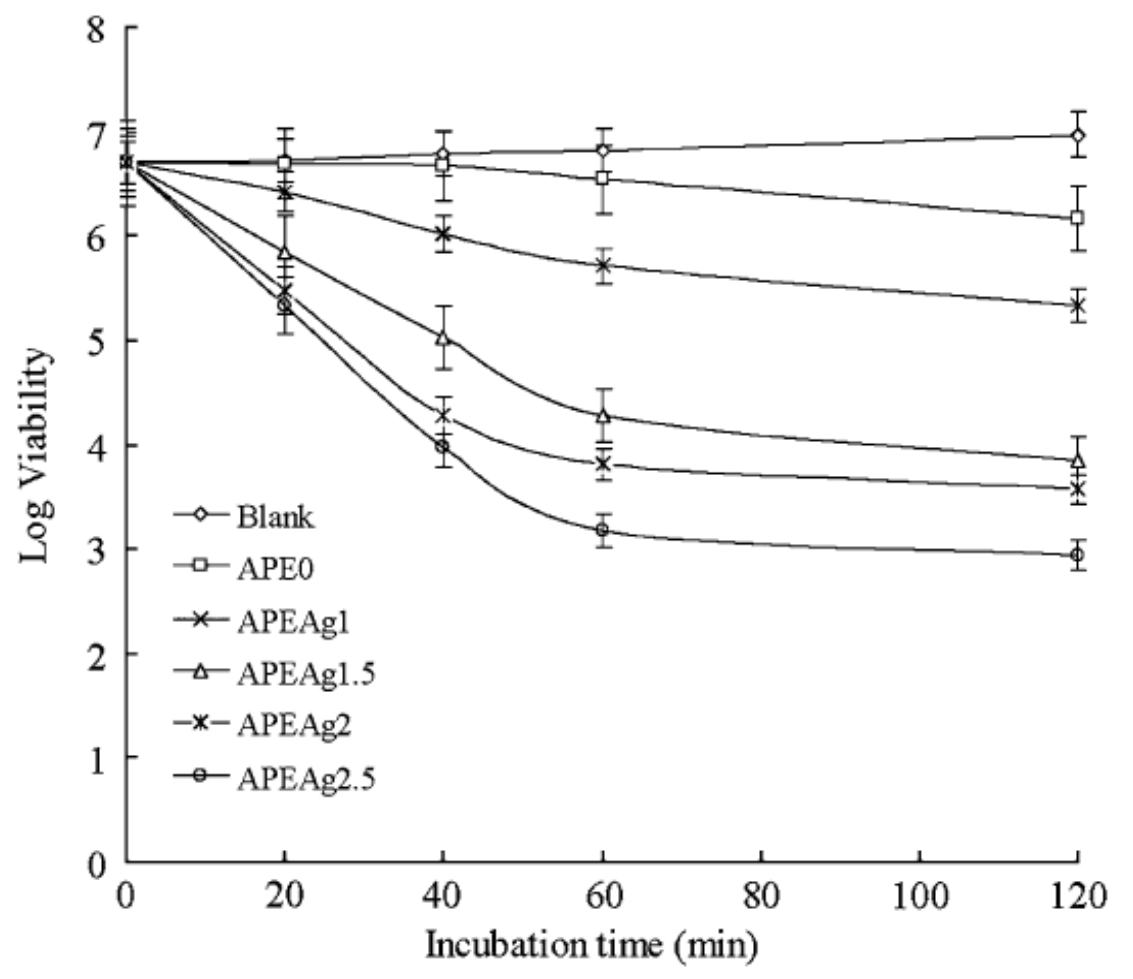

Figure 9. The deactivation of $E$. coli in relation to the interval incubation times of the composite materials. APEAg is the sample code prefix, while the subsequent sample numbers denote the multiples of $55.6 \mathrm{ppm}$ silver nanoparticles in the sample. The viability corresponds to the log of the colony-forming unit per milliliter [25]. (Reprinted from J. Mater. Sci., 45, W-F. Lee and K-T. Tsao, Effect of silver nanoparticles content on the various properties of nanocomposite hydrogels by in situ polymerization, 89-97, 2010, with permission from Springer Science and Business Media)

Sadeghi et al. also measured the colony-forming unit in their study. A mixture of nanosilver and $1.5 \times 10^{5}$ colony-forming units of $S$. aureus and E. coli were cultured at $37^{\circ} \mathrm{C}$ in a shaking incubator for $12 \mathrm{~h} \mathrm{[26].} \mathrm{This} \mathrm{mixture} \mathrm{was} \mathrm{then} \mathrm{seeded} \mathrm{onto} \mathrm{a} \mathrm{LB} \mathrm{agar}$ plate and incubated for $24 \mathrm{~h}$ at $37^{\circ} \mathrm{C} \mathrm{[26].} \mathrm{After} \mathrm{the} \mathrm{incubation} \mathrm{time,} \mathrm{the} \mathrm{colony-forming}$ units were counted. The counted number was used in Equation 1 to calculate the antibacterial efficacy of the nanosilver samples.

$$
\operatorname{ABE}(\%)=\left[\left(\mathrm{V}_{\mathrm{c}}-\mathrm{V}_{\mathrm{t}}\right) / \mathrm{V}_{\mathrm{c}}\right] * 100 \quad \text { Equation } 1
$$


$\mathrm{V}_{\mathrm{c}}$ and $\mathrm{V}_{\mathrm{t}}$ symbolize the number of viable bacterial colonies of the silver nitrate blank control and nanosilver samples, respectively [26]. Figure 10 and Figure 11 shows the growth inhibition curves of E. coli and $S$. aureus in LB medium with different silver concentrations, respectively.

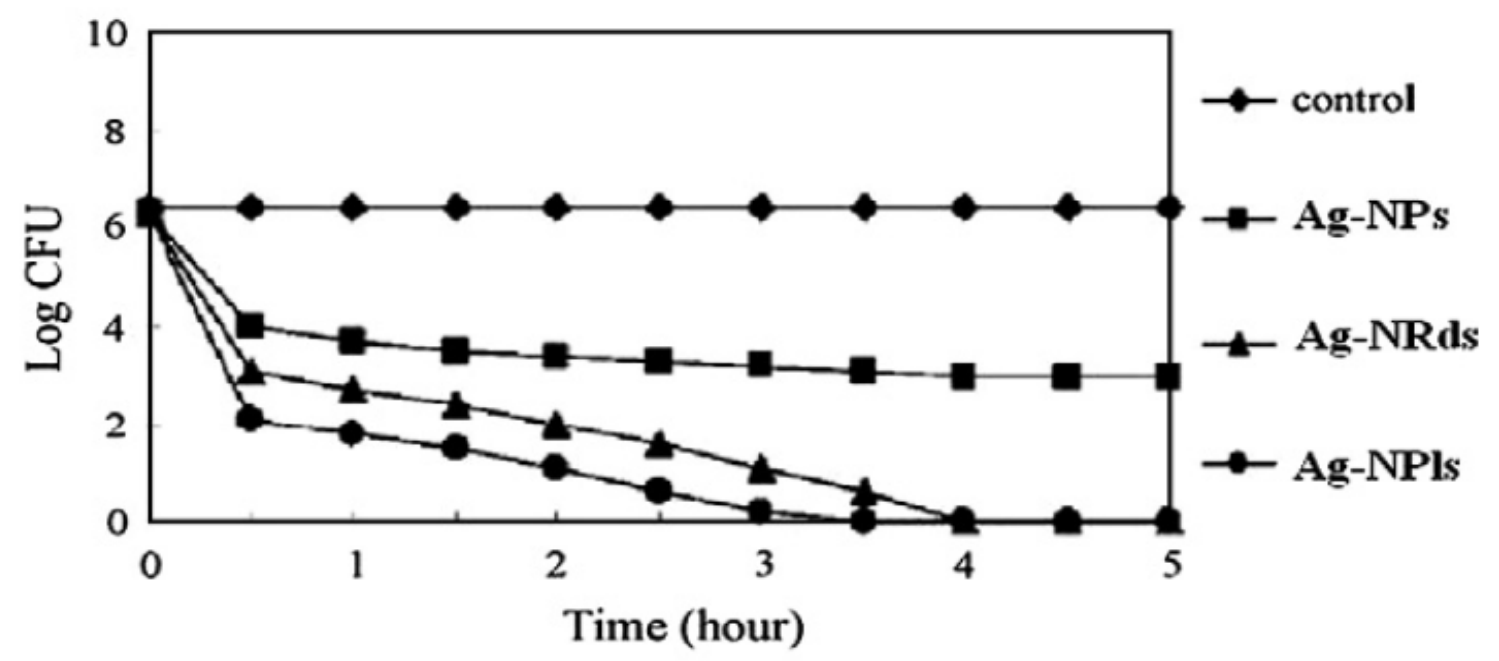

Figure 10. The growth inhibition curves of $E$. coli in LB medium with different silver concentrations. Note the effectiveness of the nanosilver samples in decreasing the number of bacterial colonies over time. Ag-NPs, Ag-NRds, and Ag-NPls denote silver nanoparticles, silver nanorods, and silver nanoplates, respectively [26]. (Reprinted from Adv. Powder Technol., 23, B. Sadeghi, F.S. Garmaroudi, M. Hashemi, H.R. Nezhad, A. Nasrollahi, S. Ardalan and S. Ardalan, Comparison of the anti-bacterial activity on the nanosilver shapes: Nanoparticles, nanorods and nanoplates, 22-26, 2012, with permission from Elsevier) 


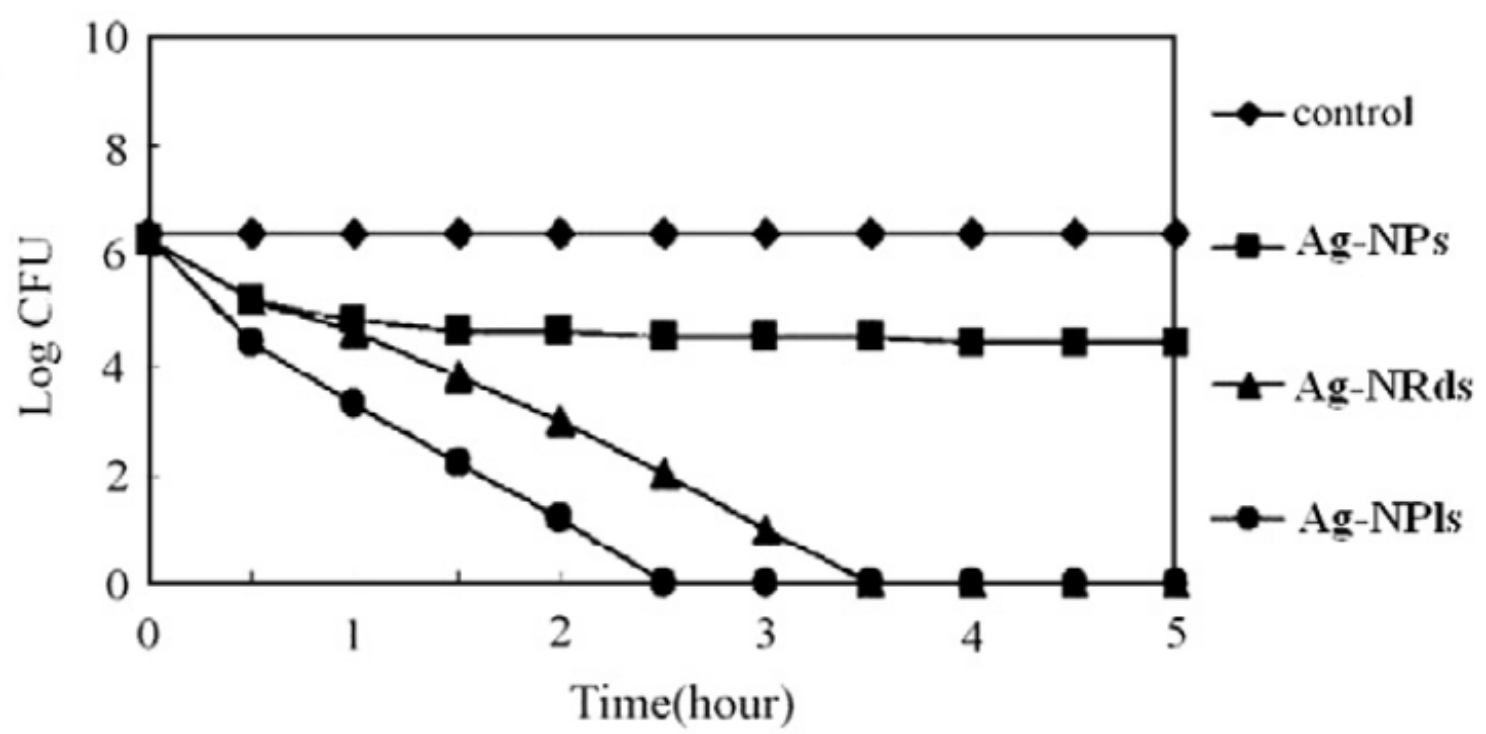

Figure 11. The growth inhibition curves of $S$. aureus in LB medium with different silver concentrations. Note the effectiveness of the nanosilver samples in decreasing the number of bacterial colonies over time. Ag-NPs, Ag-NRds, and Ag-NPls denote silver nanoparticles, silver nanorods, and silver nanoplates, respectively [26]. (Reprinted from Adv. Powder Technol., 23, B. Sadeghi, F.S. Garmaroudi, M. Hashemi, H.R. Nezhad, A. Nasrollahi, S. Ardalan and S. Ardalan, Comparison of the anti-bacterial activity on the nanosilver shapes: Nanoparticles, nanorods and nanoplates, 22-26, 2012, with permission from Elsevier)

Liu et al. embedded three average sizes of silver nanoparticles within polyurethane. The average sizes were 3,6, and $25 \mathrm{~nm}$. They performed a CFU count test and found that a smaller average silver nanoparticle size demonstrated the greatest antibacterial effect [35]. As the nanoparticle size increased, the antibacterial effectiveness decreased. The smaller silver nanoparticles were characterized by a larger surface area to volume ratio to interact with the bacteria and impart its bactericidal property [35]. Liu et al. also found that increasing the silver nanoparticle concentration increased the antibacterial efficacy of the polyurethane. 


\section{$2.9 \quad$ Tensile Strength}

The tensile strength of a material is typically tested by a universal testing machine [7,31]. Deka et al. created polymers that contained $1,2.5$, and $5 \mathrm{wt} \%$ of silver nanoparticles to see if the silver nanoparticles influenced the tensile strength of the polyurethane [31]. The group used a universal testing machine that had a $10 \mathrm{kN}$ load cell and a $50 \mathrm{~mm} / \mathrm{min}$ crosshead speed to test the tensile strength [31]. They found that the increased concentration of the silver nanoparticles increased the tensile strength of the composite material. The values obtained from the universal testing machine are displayed in Table 3. In Figure 12, a stress-strain curve depicts the improved tensile strength of the polyurethane when mixed with silver nanoparticles. Deka et al. suggested that the improved tensile strength was due to the increased interactions of the silver nanoparticles with the hard segment of the polyurethane matrix [31].

Table 3. The tensile strength of each polyurethane sample containing different concentrations of silver nanoparticles. Tensile strengths were measured and expressed as the mean \pm standard deviation. HBPU stands for hyperbranched polyurethane. HBPUAg + number stands for a hyperbranched polyurethane containing a weight percent of silver nanoparticles. LPU stands for linear polyurethane. LPUAg + number stands for a linear polyurethane containing a weight percent of silver nanoparticles [31]. (Reprinted from Polym. Degrad. Stab., 95, H. Deka, N. Karak, R.D. Kalita and A.K. Buragohain, Bio-based thermostable, biodegradable and biocompatible hyperbranched polyurethane/Ag nanocomposites with antimicrobial activity, 1509-1517, 2010, with permission from Elsevier)

\begin{tabular}{|l|l|l|l|l|l|l|}
\hline & HBPU & HBPU Ag1 & HBPU Ag2.5 & HBPU Ag5 & LPU & LPU Ag2.5 \\
\hline $\begin{array}{l}\text { Tensile } \\
\text { Strength } \\
\text { (MPa) }\end{array}$ & $6.80 \pm 1.2$ & $8.13 \pm 1.4$ & $9.42 \pm 1.1$ & $11.51 \pm 1.5$ & $5.31 \pm 0.95$ & $9.60 \pm 1.1$ \\
\hline
\end{tabular}




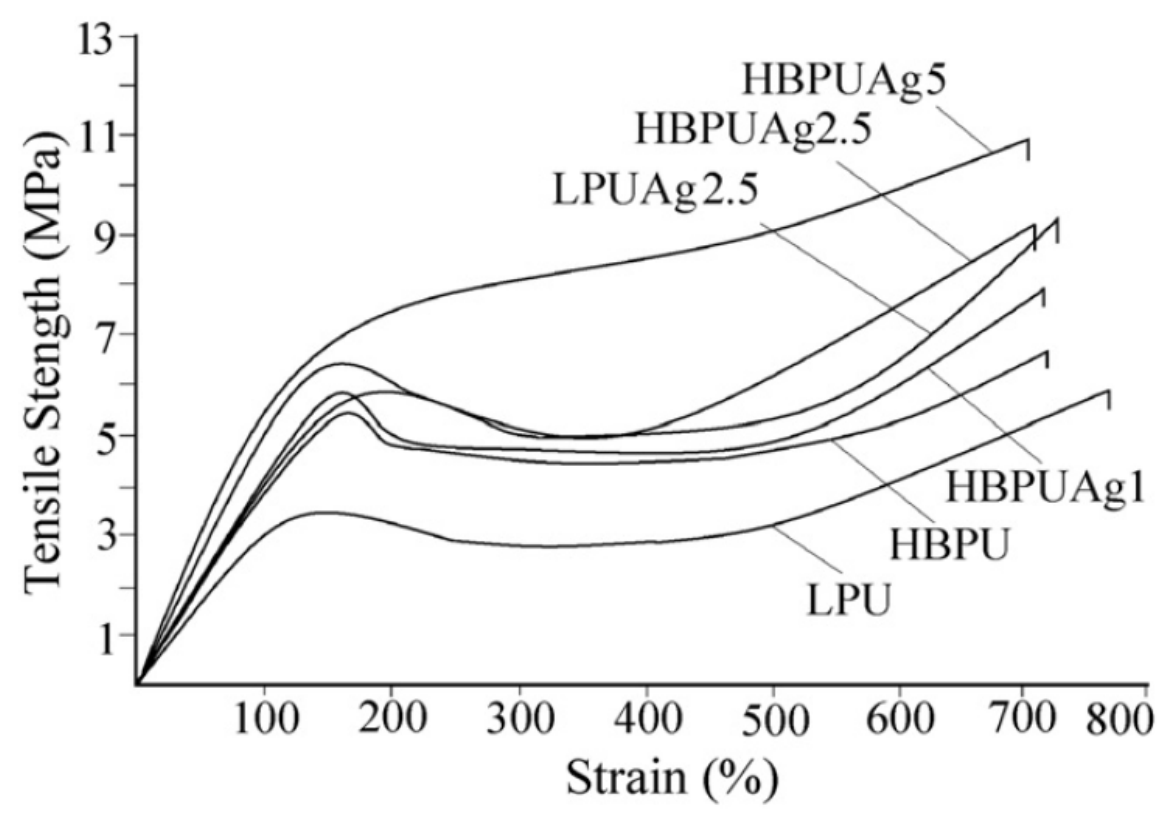

Figure 12. A stress-strain curve depicting the increased tensile strength of the polyurethane when mixed with silver nanoparticles [31]. (Reprinted from Polym. Degrad. Stab., 95, H. Deka, N. Karak, R.D. Kalita and A.K. Buragohain, Bio-based thermostable, biodegradable and biocompatible hyperbranched polyurethane/Ag nanocomposites with antimicrobial activity, 1509-1517, 2010, with permission from Elsevier)

Liu et al. measured the tensile strength of their silver nanoparticle-embedded polyurethane. Their specimens were cut to a length and width of $20 \mathrm{~mm}$ by $1 \mathrm{~mm}$ and tested on a universal testing machine. The specimens were pulled at $1 \mathrm{~mm} / \mathrm{min}$ until fracturing. The tensile strength noticeably increased for the polyurethane prepared without a crosslinker than the polyurethane prepared with a crosslinker [35]. The polyurethane prepared without a crosslinker had an average tensile strength of $10.5 \mathrm{MPa}$ [35]. The polyurethane prepared with a crosslinker had an average tensile strength of $20.5 \mathrm{MPa}[35]$. 


\subsection{Breaking Load}

Kull et al. evaluated the breaking strength of a n-butyl-2-cyanoacrylate adhesive called Glubran2 and a fibrin glue called Tissucol. A dog-bone shaped silicone rubber mold mounted on a Teflon plate was created to prepare the dog-bone shaped specimen used for testing. An activator was sprayed on the Teflon plate to trigger polymerization of the adhesive. The adhesive was dispensed into the dog-bone shaped mold and allowed to polymerize for $24 \mathrm{~h}$ at $25^{\circ} \mathrm{C}$ room temperature. The samples were attached to a material testing machine equipped with a $100 \mathrm{~N}$ load cell and pulled until breakage occurred at the reduced section of the dog-bone shaped specimen. Based on testing three samples each of the cyanoacrylate and fibrin glue, the average breaking strength of the cyanoacrylate was about 150 times greater than the fibrin glue [36]. However, the flexibility of the fibrin glue was vastly better than the cyanoacrylate. The results of this study showed that the n-butyl-2-cyanoacrylate glue was characterized by a greater mechanical strength than its fibrin counterpart but lacked the flexibility to conform to the shape of tissue.

Duffy et al. used a MTS Material Strength Testing Machine to evaluate the breaking loads of extraocular muscles adhered to other ocular tissues with 2-octyl cyanoacrylate, a scaffold-enhanced 2-octyl cyanoacrylate adhesive, and the natural adhesion of the two tissues [7]. Two to five minutes after the tissue adhesion preparation, the samples were clamped to the strength testing machine with pneumatic grips and attached to a $100 \mathrm{~N}$ load cell [7]. The samples were pulled at a constant rate of one gravitational force per second until complete separation of the two tissues [7]. The 
maximum load was obtained when the two tissues completely separated [7]. Table 4 shows the average breaking loads of extraocular muscle-to-sclera, sclera-to-sclera, and extraocular muscle-to-extraocular muscle adhesions when certain sample adhesives were and were not applied. All three adhesions indicate that the scaffold-enhanced 2-octyl cyanoacrylate adhesive required a larger load to break the adhesion between the tissues than 2-octyl cyanoacrylate alone. The native extraocular muscle-to-extraocular muscle adhesion required a larger load to completely separate the two tissues than 2-octyl cyanoacrylate alone and a scaffold-enhanced 2-octyl cyanoacrylate adhesive [7].

Table 4. The mean breaking loads with the standard deviations measured in grams. PLGA and SIS were scaffolds used in conjunction with the 2-octyl cyanoacrylate adhesive that required a higher breaking load to separate the two tissues [7]. (Reprinted from J. AAPOS, 9, M.T. Duffy, J.N. Bloom, K.M. McNally-Heintzelman, D.L. Heintzelman, E.C. Soller and G.T. Hoffman, Sutureless Ophthalmic Surgery: A Scaffold-Enhanced Bioadhesive Technique, 315-320, 2005, with permission from Elsevier)

\begin{tabular}{|l|l|l|l|l|}
\hline & $\begin{array}{l}2 \text {-Octyl } \\
\text { Cyanoacrylate } \\
\text { Alone }\end{array}$ & $\begin{array}{l}2 \text {-Octyl } \\
\text { Cyanoacrylate } \\
\text { + PLGA }\end{array}$ & $\begin{array}{l}\text { 2-Octyl } \\
\text { Cyanoacrylate } \\
\text { + SIS }\end{array}$ & Native Muscle \\
\hline $\begin{array}{l}\text { Extraocular Muscle-to- } \\
\text { Sclera Adhesions (g) }\end{array}$ & $248 \pm 43$ & $432 \pm 21$ & $424 \pm 23$ & $257 \pm 41$ \\
\hline $\begin{array}{l}\text { Sclera-to-Sclera } \\
\text { Adhesions (g) }\end{array}$ & $251 \pm 37$ & $404 \pm 21$ & $399 \pm 24$ & $\mathrm{~N} / \mathrm{A}$ \\
\hline $\begin{array}{l}\text { Extraocular Muscles- } \\
\text { to-Extraocular Muscle } \\
\text { Adhesions (g) }\end{array}$ & $369 \pm 35$ & $561 \pm 21$ & $571 \pm 24$ & $631 \pm 36$ \\
\hline
\end{tabular}

\subsection{Adhesive Force}

When assessing the adhesive force of a tissue adhesive not on tissue, two types of peel tests are commonly performed. The first type of test is the single-arm $90^{\circ}$ peel test. This version of the peel test has a rigid base plate bolted onto a linear bearing, which is 
mounted on a universal testing machine [37]. The free part of the peel arm is bent around a roller so that it can be clamped by the upper grip of the testing machine and can provide a $90^{\circ}$ peel angle [37]. The peel test is conducted by peeling the peel arm with a constant crosshead speed measured in millimeters per minute [37]. The force required to fracture the adhesive bond is obtained at the conclusion of this test. Figure 13 portrays the concept of a single-arm $90^{\circ}$ peel test.

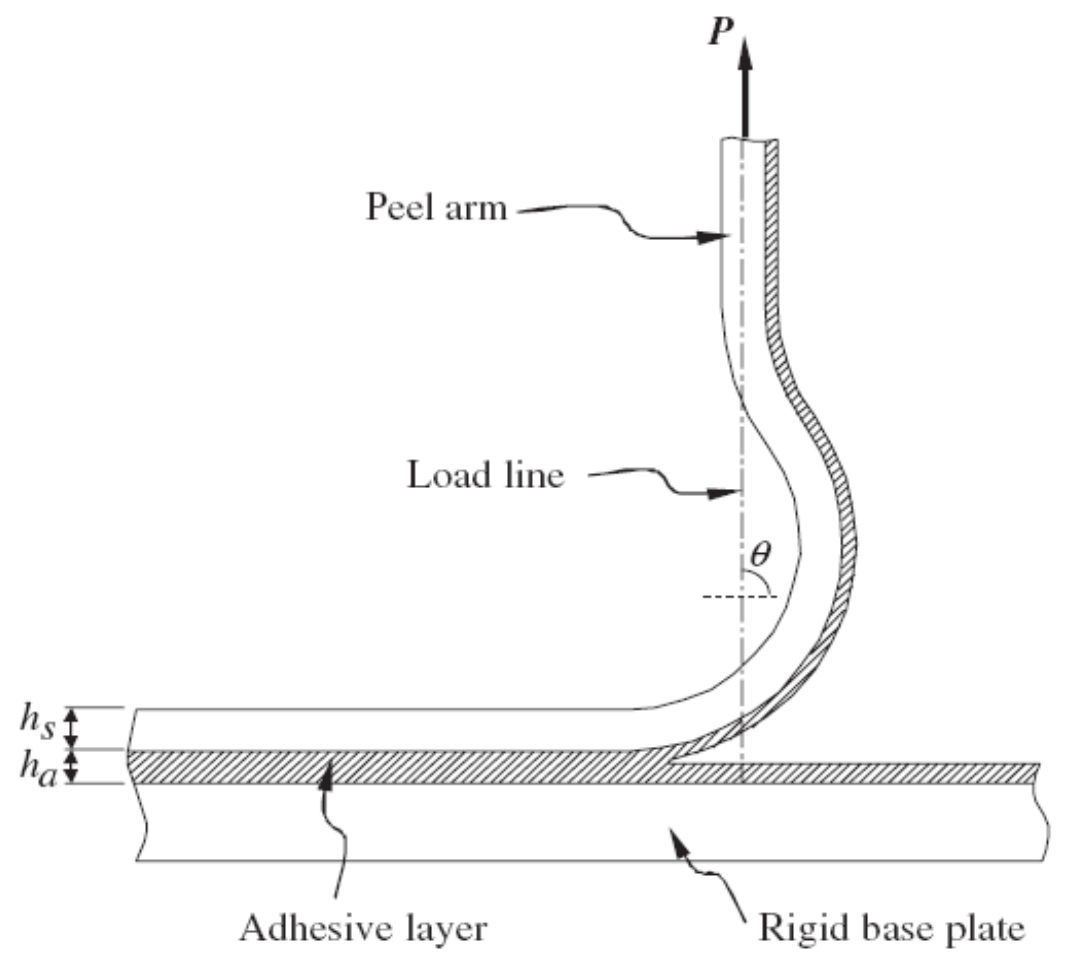

Figure 13. The single-arm $90^{\circ}$ peel test. The height of the adhesive and peel arm are represented by $h_{a}$ and $h_{s}$, respectively. The peel angle with respect to the load line is denoted by $\theta$. The load experienced when pulling the adhesive is represented by P [37]. (Reprinted from Eng. Fract. Mech., 73, H. Hadavinia, L. Kawashita, A.J. Kinloch, D.R. Moore and J.G. Williams, A numerical analysis of the elastic-plastic peel test, 23242335, 2006, with permission from Elsevier)

The second type of peel test is the T-peel test. This kind of peel test attaches the adhesive sample between the peel arms of the universal testing machine, and the peel 
arms are allowed to rotate freely [37]. Unlike the single-arm $90^{\circ}$ peel test, the T-peel test has both peel arms pull apart from the vertical axis and the force required to fracture the adhesive bond is measured [37]. The crosshead speed remains constant measured in millimeters per minute. Figure 14 illustrates how the T-peel test works.

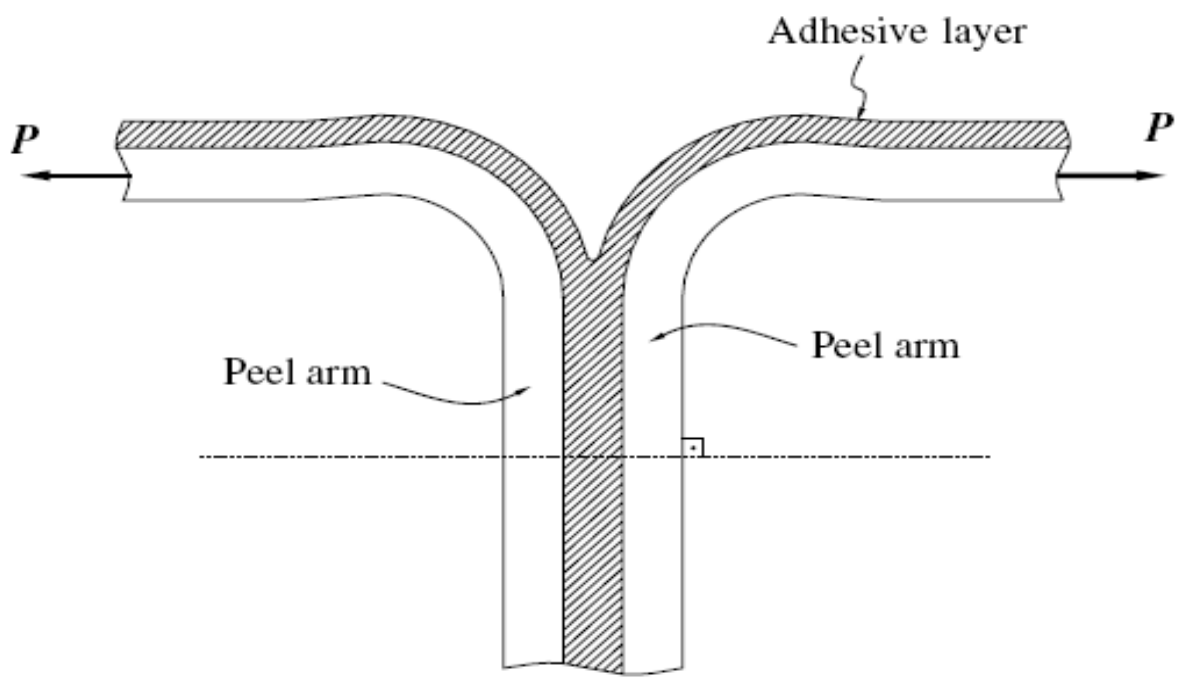

Figure 14. The T-peel test. The peel arms are perpendicular to the horizontal axis. The load experienced when pulling the adhesive is represented by P [37]. (Reprinted from Eng. Fract. Mech., 73, H. Hadavinia, L. Kawashita, A.J. Kinloch, D.R. Moore and J.G. Williams, A numerical analysis of the elastic-plastic peel test, 2324-2335, 2006, with permission from Elsevier)

Lee and Tsao used the single-arm $90^{\circ}$ peel test to measure the adhesive force. They used a Lloyd LRX Universal Tester to measure the adhesive force and set the crosshead speed at $30 \mathrm{~mm} / \mathrm{min}$ [25]. The adhesive force for various concentrations of silver nanoparticles in the hydrogel is tabulated in Table 5. The results from the test showed that the increase of silver nanoparticle concentration yields a slight decrease in adhesive force. 
Table 5. The adhesive force for various concentrations of silver nanoparticles in the hydrogel. As there was an increase of silver nanoparticle concentration in parts per million in the hydrogel, the adhesive force slightly decreased [25]. (Reprinted from J. Mater. Sci., 45, W-F. Lee and K-T. Tsao, Effect of silver nanoparticles content on the various properties of nanocomposite hydrogels by in situ polymerization, 89-97, 2010, with permission from Springer Science and Business Media)

\begin{tabular}{|l|l|}
\hline Silver Nanoparticle Concentration $(\mathrm{ppm})$ & Adhesive Force $\left(\mathrm{g} / \mathrm{cm}^{2}\right)$ \\
\hline 0 & $16.73 \pm 0.3 \%$ \\
\hline 55.6 & $16.32 \pm 1.6 \%$ \\
\hline 83.4 & $16.22 \pm 1.3 \%$ \\
\hline 111.2 & $15.61 \pm 0.7 \%$ \\
\hline 139 & $14.99 \pm 0.2 \%$ \\
\hline
\end{tabular}

Chivers et al. evaluated the adhesive properties of several common tissue adhesives, such as cyanoacrylate, gelatin-based adhesive, and fibrin [38]. They tested the adhesive strength of the adhesive to porcine skin, bone, and cartilage. Porcine skin is a common substrate used for measuring adhesive properties of an adhesive. Adhesive was applied in between overlapping skin and then allowed to cure. This specimen was then clamped by the grips of the universal testing machine and pulled at $5 \mathrm{~mm} / \mathrm{min}$ until the bond completely failed [38]. The strength of the adhesive was highly dependent on the test substrate. As shown in Table 6, cyanoacrylate displayed the greatest adhesive strength over gelatin-based adhesive and fibrin [38].

Table 6. The mean adhesive force for the three adhesives bonded to the three different substrates. Cyanoacrylate showed the greatest adhesive strength [38]. (Reprinted from Int. J. Adhes. Adhes., 17, R.A. Chivers and R.G. Wolowacz, The strength of adhesive-bonded tissue joints, 127-132, 1997, with permission from Elsevier)

\begin{tabular}{|l|l|l|l|}
\hline \multirow{2}{*}{} & \multicolumn{4}{|l|}{ Adhesive Strength $(\mathrm{MPa})$} \\
\cline { 2 - 4 } & Cartilage & Bone & Skin \\
\hline n-Butyl-2-cyanoacrylate & 1.00 & 1.40 & 1.20 \\
\hline Gelatin/resorcinol/formaldehyde & 0.15 & 0.20 & 0.07 \\
\hline Fibrin & 0.0049 & 0.0110 & 0.0190 \\
\hline
\end{tabular}




\subsection{Curing Time}

Cyanoacrylate tissue adhesives polymerize on contact with moisture such as water and blood $[10,11]$. Upon contact with liquid substances, a strong bond is formed between the adhesive and tissue. The application of one drop of 2-octyl cyanoacrylate as a smooth single layer on the wound takes 15 to $30 \mathrm{~s}$ to fully polymerize and dry [11]. When increasing the droplet amount of 2-octyl cyanoacrylate to two to three drops, it takes two minutes to fully polymerize and dry as a thin, uniform layer on the wound [10].

\subsection{Transparency}

After the polymerization and drying time of 2-octyl cyanoacrylate, Meskin et al. reported that a gray-to-white meshwork of the adhesive formed on the corneal wound as a barrier [11]. The 51 patients involved with this study did not report any obstruction of vision or decline of visual acuity after the adhesive was applied. During the second postoperative visit after cataract surgery, 8 of the 51 patients experienced mild staining on the clear corneal wound edges or a mildly irregular epithelium [11]. Nevertheless, Meskin and his group reported that all patients met the safety criteria and regained their vision soon after the procedure.

\subsection{Summary}

Tissue adhesives are a safe and effective alternative to sutures when treating wounds around the body. Due to the delicate nature of ocular tissue, tissue adhesives will not inflict any mechanical damage onto the eye. The desirable mechanical and antibacterial properties suggest that a silver nanoparticle-infused tissue adhesive would minimize wound healing time and reduce the possibility of infection. 
The areas investigated in this literature review offer insights on how to develop a silver nanoparticle-infused tissue adhesive for ophthalmic use. The tissue adhesive with a short curing time and favorable sealing and mechanical properties is 2-octyl cyanoacrylate. The size, shape, and concentration need to be considered because of its relevance in determining the antibacterial effectiveness of silver nanoparticles. With these parameters discussed in this chapter, a functional silver nanoparticle-infused tissue adhesive for ophthalmic use was developed in this research. 


\section{CHAPTER THREE}

\section{OBJECTIVE}

\subsection{Objective}

The objective of this research was to evaluate the effects of silver nanoparticle infusion on the antibacterial efficacy, adhesive strength, and breaking strength of a 2octyl cyanoacrylate tissue adhesive as a function of nanoparticle size and concentration. Before evaluating the antibacterial and mechanical properties of the silver nanoparticleinfused tissue adhesive, uniform distribution of the silver nanoparticles in the adhesive needed to be achieved. The antibacterial effectiveness of the composite adhesive was determined via the Kirby-Bauer disk diffusion susceptibility test and CFU counting. The adhesive force to a porcine sclera and breaking load of the silver nanoparticle-infused 2octyl cyanoacrylate tissue adhesive were the mechanical properties evaluated. Generated results from these tests were compared to the results of a control sample composed of an unaltered version of the 2-octyl cyanoacrylate tissue adhesive.

\subsection{Justification}

Tissue adhesives are safe alternatives to mechanical fasteners when treating ocular wounds. Using sutures on delicate ocular tissue or allowing self-healing increases the risk of infection and healing time. Currently, tissue adhesives are used for ophthalmic applications; however, the potential for infection is still present if the wound is not properly cleansed. The addition of silver nanoparticles to a 2-octyl cyanoacrylate tissue adhesive was proposed to reduce the potential for infection. 


\section{CHAPTER FOUR}

\section{MATERIALS AND METHODS}

\subsection{Overview}

A 2-octyl cyanoacrylate tissue adhesive provides a safe alternative to using mechanical fixtures when treating wounds. Using mechanical fixtures on tissue causes discomfort to patients and occasionally inflicts damage beyond what is necessary [6]. Furthermore, there is a risk of inflammation or infection on the wound when using mechanical fixtures. If a tissue adhesive is used to treat an improperly cleansed wound, there is also a possibility of inflammation and infection. The infusion of silver nanoparticles into a 2-octyl cyanoacrylate was proposed to reduce the potential for infection because of the notable bactericidal effect of silver nanoparticles.

\subsection{Materials}

The two main materials tested in this experiment were silver nanoparticles and a 2-octyl cyanoacrylate tissue adhesive. The $4 \mathrm{~nm}$ and $10 \mathrm{~nm}$ size silver nanoparticles (NanoXact, nanoComposix) were dried powders redispersed in $99.7+\%$ chloroform (IBI Scientific) and $99.5+\%$ anhydrous ethanol (Fisher Scientific), respectively. The brand of the 2-octyl cyanoacrylate tissue adhesive was Dermabond ${ }^{\circledR}$ (Ethicon, Inc.), which is a high viscosity tissue adhesive that comes in individual $0.5 \mathrm{~mL}$ vials. All samples that needed to be specifically shaped for their respective tests were formed in a polyacrylamide mold, which was composed of $99.9 \%$ N,N'-methylenebisacrylamide (bisacrylamide; UltraPure ${ }^{\mathrm{TM}}$, Life Technologies), 98.5+\% acrylamide (Fisher Scientific), 98\% ammonium persulfate (APS; Fisher Scientific), 95+\% N,N,N',N'- 
tetramethylethylenediamine (TEMED; Fisher Scientific), and deionized water. For the antibacterial testing, E. coli (San José State University, Department of Biological Sciences) were the bacteria used and were incubated on a solid LB agar (Miller, Fisher Scientific) and LB broth (Lennox, Fisher Scientific) filled culturing dish. In the breaking load testing of the experiment, the silver nanoparticle-infused tissue adhesive was molded into a dog-bone shaped specimen. For the adhesive force testing, the composite adhesive was applied onto the sclera of a porcine eye (Mi Pueblo Food Center). The porcine eyes were kept in sterile Ringer's solution and were stored in a refrigerator. The Ringer's solution was composed of sodium chloride, potassium chloride, and calcium chloride. The handling and disposal of porcine eyes was in compliance with the regulations set forth by the San José State University Institutional Animal Care and Use Committee (IACUC).

\subsection{Equipment}

The silver nanoparticles were dispersed into the adhesive with a vortex $\left(\mathrm{S} / \mathrm{P}{ }^{\circledR}\right.$ Vortex Mixer, Baxter Diagnostics Inc.) and indirect sonicator. The composite adhesive sample container was placed in a cold water bath and ultrasonic energy was propagated through the medium via the sonicator. Transmission electron microscopy (1010, JEOL) produced high resolution images of the sample to ensure the uniform distribution of the silver nanoparticles within the adhesive.

An autoclave (SS-320, Tomy) sterilized the liquid media used for the experiments. The antibacterial testing portion of the experiment required the handling of bacteria in a biosafety cabinet (1100, Forma Scientific). An incubator (B 5060, Heraeus 
Instruments) was used to grow the bacterial colonies and also incubate the bacteria with the silver nanoparticle-doped adhesive. An inverted microscope (Eclipse Ti, Nikon) was used to observe the inhibition halos surrounding the adhesive samples for the KirbyBauer disk diffusion susceptibility test. To test the breaking load and adhesive force of the adhesive, an Instron (4204) universal testing machine was the analytical instrument used. The adhesive force setup also included securing a porcine eye in a vacuum eye holder that was connected to an Edwards (RV12) rotary vane pump for vacuum suction. The vacuum eye holder was comprised of everyday items, such as a wooden frame, tubing, $1 / 2 " \times 3 / 4 "$ pipe adapter, and $1 / 2$ " barb elbow fitting that are typically used for a water sprinkler system (Orbit Sprinklers). The pipe adapter held the eye while the barb elbow fitting connected the adapter to the tubing connected to the rotary vane pump. The experiments were performed at San José State University.

\subsection{Materials and Equipment Safety}

Personal protective equipment (PPE) was worn when handling all of the materials involved in this experiment. The PPE worn included nitrile gloves, goggles, lab coat, long sleeve shirt, pants, and closed-toe shoes. Before preparing and conducting any of the experiments, training for using the equipment and materials was conducted. Table 7 organizes the safety precautions for the materials necessary for this experiment. 
Table 7. Safety precautions for each material used in this experiment. These precautions include hazards, handling, storage, emergency response plan, spill and leak procedures, and waste disposal procedures.

\begin{tabular}{|c|c|c|c|c|c|c|}
\hline Material & Hazards & Handling & Storage & \begin{tabular}{|l|} 
Emergency \\
Response Plan
\end{tabular} & $\begin{array}{l}\text { Spill and Leak } \\
\text { Procedures }\end{array}$ & $\begin{array}{l}\text { Waste Disposal } \\
\text { Procedure }\end{array}$ \\
\hline \begin{tabular}{l|} 
Silver \\
nanoparticles
\end{tabular} & $\begin{array}{l}\text { Skin, eyes, } \\
\text { respiratory, } \\
\text { digestive tract } \\
\text { irritant [39] } \\
\end{array}$ & $\begin{array}{l}\text { PPE, avoid } \\
\text { inhalation and } \\
\text { ingestion [39] }\end{array}$ & $\begin{array}{l}\text { Store in closed } \\
\text { bottle, store at 2- } \\
25^{\circ} \mathrm{C} \text { away from } \\
\text { light }[40]\end{array}$ & \begin{tabular}{|l|} 
For fire, use \\
water, carbon \\
dioxide [39]
\end{tabular} & \begin{tabular}{|l|} 
Sweep, dilute \\
with water, wipe \\
surface with \\
cleaner [39] \\
\end{tabular} & $\begin{array}{l}\text { Dispose of } \\
\text { according to } \\
\text { regulations [39] }\end{array}$ \\
\hline $\begin{array}{l}\text { 2-octyl } \\
\text { cyanoacrylate } \\
\text { Dermabond } \AA\end{array}$ & $\mid \begin{array}{l}\text { Polymerizes } \\
\text { rapidly on contact } \\
\text { with tissue }[41,42]\end{array}$ & PPE [41] & $\begin{array}{l}\text { Store below } \\
30^{\circ} \mathrm{C} \text { away from } \\
\text { moisture, heat } \\
{[41,42]}\end{array}$ & \begin{tabular}{|l|} 
Use petroleum \\
jelly to loosen \\
bond on skin \\
{$[41]$}
\end{tabular} & $\begin{array}{l}\text { Polymerize with } \\
\text { water, pick up } \\
\text { with inert } \\
\text { material }[41,42]\end{array}$ & $\begin{array}{l}\text { Dispose in non- } \\
\text { hazardous solid } \\
\text { waste [41] }\end{array}$ \\
\hline $\begin{array}{l}\text { LB agar and } \\
\text { LB broth }\end{array}$ & $\begin{array}{l}\text { Skin, respiratory, } \\
\text { digestive tract } \\
\text { irritant }[43,44]\end{array}$ & $\begin{array}{l}\text { PPE, avoid } \\
\text { inhaling vapors, } \\
\text { eye and skin } \\
\text { contact }[43,44] \\
\end{array}$ & $\begin{array}{l}\text { Store in closed } \\
\text { container in a } \\
\text { dry, ventilated } \\
\text { area }[43,44] \\
\end{array}$ & \begin{tabular}{|l|} 
Wash eyes, \\
skin with water \\
{$[43,44]$}
\end{tabular} & \begin{tabular}{|l|} 
Sweep up and \\
dispose in \\
closed container \\
{$[43,44]$}
\end{tabular} & $\begin{array}{l}\text { Give product to } \\
\text { disposal } \\
\text { company } \\
{[43,44]}\end{array}$ \\
\hline $\begin{array}{l}\text { Escherichia } \\
\text { coli }\end{array}$ & $\begin{array}{l}\text { Causes } \\
\text { hemorrhagic } \\
\text { colitis, abdominal } \\
\text { pain }[45]\end{array}$ & $\begin{array}{l}\text { PPE, frequent } \\
\text { hand washing } \\
{[45]}\end{array}$ & $\begin{array}{l}\text { Store in } \\
\text { appropriately } \\
\text { labeled sealed } \\
\text { containers [45] }\end{array}$ & \begin{tabular}{|l|} 
Electrolyte \\
fluid therapy, \\
use antibiotics \\
in severe cases \\
{$[45]$} \\
\end{tabular} & \begin{tabular}{|l|} 
Absorb spill \\
with paper \\
towel, sodium \\
hypochlorite \\
[45] \\
\end{tabular} & $\begin{array}{l}\text { Decontaminate, } \\
\text { sterilize, } \\
\text { disinfect [45] }\end{array}$ \\
\hline Porcine eyes & $\begin{array}{l}\text { Biohazard if not } \\
\text { handled properly }\end{array}$ & $\begin{array}{l}\text { PPE, frequent } \\
\text { hand washing }\end{array}$ & $\begin{array}{l}\text { Refrigerate in } \\
\text { Ringer's solution }\end{array}$ & \begin{tabular}{|l|} 
Contact \\
physician if \\
become sick \\
\end{tabular} & $\begin{array}{l}\text { Dispose in } \\
\text { biohazard } \\
\text { container }\end{array}$ & $\begin{array}{l}\text { Dispose in } \\
\text { biohazard } \\
\text { container }\end{array}$ \\
\hline $\begin{array}{l}\text { Anhydrous } \\
\text { Ethanol }\end{array}$ & \begin{tabular}{|l|} 
Flammable, \\
carcinogen. Skin, \\
eye, respiratory \\
irritant [46] \\
\end{tabular} & $\begin{array}{l}\text { PPE, avoid } \\
\text { inhaling vapors } \\
\text { or mist [46] }\end{array}$ & \begin{tabular}{|l|} 
Store in closed \\
container away \\
from flammables \\
{$[46]$}
\end{tabular} & $\begin{array}{l}\text { For fire, use } \\
\text { water, carbon } \\
\text { dioxide [46] }\end{array}$ & \begin{tabular}{|l|} 
Contain spillage, \\
place in \\
appropriate \\
container [46] \\
\end{tabular} & $\begin{array}{l}\text { Dispose via } \\
\text { waste disposal } \\
\text { service }[46]\end{array}$ \\
\hline Chloroform & $\begin{array}{l}\text { Carcinogen. Skin } \\
\text { and eye irritant } \\
{[47]}\end{array}$ & $\begin{array}{l}\text { PPE, avoid } \\
\text { inhaling vapors } \\
{[47]}\end{array}$ & $\begin{array}{l}\text { Store in closed } \\
\text { container away } \\
\text { from light [47] } \\
\end{array}$ & \begin{tabular}{|l|} 
Wash skin and \\
eyes with \\
water [47]
\end{tabular} & $\begin{array}{l}\text { Contain spillage, } \\
\text { place in } \\
\text { container }[47]\end{array}$ & \begin{tabular}{|l} 
Dispose of \\
according to \\
regulations [47]
\end{tabular} \\
\hline Acrylamide & $\begin{array}{l}\text { Causes genetic } \\
\text { damage, infertility, } \\
\text { allergic reaction. } \\
\text { Neurotoxin, } \\
\text { carcinogen [48] }\end{array}$ & \begin{tabular}{|l} 
PPE, use fume \\
hood, avoid eye \\
and skin contact, \\
inhalation [48]
\end{tabular} & $\begin{array}{l}\text { Store in closed } \\
\text { container, } \\
\text { refrigerate, away } \\
\text { from sunlight } \\
{[48]}\end{array}$ & \begin{tabular}{|l|} 
Rinse eyes, \\
wash skin with \\
soap and \\
water $[48]$
\end{tabular} & $\begin{array}{l}\text { Wear breathing } \\
\text { apparatus, } \\
\text { protective suit. } \\
\text { Sweep into } \\
\text { container [48] }\end{array}$ & $\begin{array}{l}\text { Dispose of } \\
\text { according to } \\
\text { regulations [48] }\end{array}$ \\
\hline Bisacrylamide & \begin{tabular}{|l|} 
Eye, skin irritant. \\
Causes \\
reproductive harm \\
{$[49]$}
\end{tabular} & \begin{tabular}{|l|} 
PPE, use fume \\
hood, avoid eye \\
and skin contact, \\
inhalation [49] \\
\end{tabular} & \begin{tabular}{|l|} 
Keep in a cool, \\
dry, ventilated \\
area [49]
\end{tabular} & \begin{tabular}{|l|} 
Rinse eyes, \\
wash skin with \\
soap and \\
water [49] \\
\end{tabular} & $\begin{array}{l}\text { Sweep or } \\
\text { vacuum into } \\
\text { suitable } \\
\text { container [49] } \\
\end{array}$ & $\begin{array}{l}\text { Dispose of } \\
\text { according to } \\
\text { regulations [49] }\end{array}$ \\
\hline $\begin{array}{l}\text { Ammonium } \\
\text { persulfate }\end{array}$ & \begin{tabular}{|l|} 
Combustible, \\
organic material. \\
Respiratory, skin, \\
eye irritant $[50]$ \\
\end{tabular} & \begin{tabular}{|l|} 
PPE, use fume \\
hood, avoid eye \\
and skin contact, \\
inhalation [50] \\
\end{tabular} & \begin{tabular}{|l|} 
Keep in a cool, \\
dry, ventilated \\
area, away from \\
flammables [50]
\end{tabular} & \begin{tabular}{|l|} 
Rinse eyes, \\
wash skin with \\
soap and \\
water [50] \\
\end{tabular} & $\begin{array}{l}\text { Sweep, vacuum } \\
\text { into suitable } \\
\text { container }[50]\end{array}$ & $\begin{array}{l}\text { Dispose of } \\
\text { according to } \\
\text { regulations [50] }\end{array}$ \\
\hline TEMED & \begin{tabular}{|l|} 
Causes burns, \\
pulmonary edema. \\
Harmful if inhaled, \\
ingested. \\
Flammable [51]
\end{tabular} & \begin{tabular}{|l} 
PPE, use fume \\
hood, avoid eye \\
and skin contact, \\
inhalation [51]
\end{tabular} & $\begin{array}{l}\text { Keep in a dry, } \\
\text { ventilated area, } \\
\text { away from } \\
\text { flammables [51] }\end{array}$ & $\begin{array}{l}\text { Rinse eyes, } \\
\text { wash skin with } \\
\text { soap and } \\
\text { water [51] }\end{array}$ & \begin{tabular}{|l} 
Absorb with \\
inert material. \\
Keep in suitable \\
container [51]
\end{tabular} & $\begin{array}{l}\text { Dispose of } \\
\text { according to } \\
\text { regulations [51] }\end{array}$ \\
\hline
\end{tabular}


Formal training before operating the equipment used in this experiment was conducted to educate the operator of potential hazards and to teach proper usage. When using a sonicator, the operator needed to wear earplugs to protect his ears from the high frequency of the ultrasonic energy. The autoclave also possesses hazards if not properly used. Since a high temperature and pressure were set during sterilization, the autoclave was allowed to cool before opening [52]. The operator needed to stand back and open the door slowly to let the extra steam escape [52]. Once these precautions were taken, thick gloves were used to remove the hot items [52].

The rotary vane pump created a vacuum by the rotation of the pump-motor inside the containing cavity [53]. Oil was used to lubricate the moving parts of the pump and posed as a safety hazard. The operator needed to avoid prolonged skin contact and inhaling the oil mist [53]. Furthermore, the instrument casing was hot during and after operation and can cause burns if carried [53]. The operator needed to be careful of moving parts when using the universal testing machine.

\subsection{Experimental Methodology}

\subsubsection{Experimental Matrix}

To fulfill the objective of this research, the antibacterial effectiveness, breaking load, and adhesive force of the silver nanoparticle-infused tissue adhesive were measured. The two measured factors were the silver nanoparticle concentration and size. These factors were each measured at a high and low level. For the silver nanoparticle concentration, the high and low level concentrations were $10 \mu \mathrm{g} / \mathrm{mL}$ and $1 \mu \mathrm{g} / \mathrm{mL}$, respectively. The high and low silver nanoparticle size levels were $10 \mathrm{~nm}$ and $4 \mathrm{~nm}$, 
respectively. These factors and levels are organized in an experimental matrix in Table 8 to aid in designing an experiment that demonstrates the effect of silver nanoparticle concentration and size on the antibacterial efficacy, breaking load, and adhesive force of the 2-octyl cyanoacrylate tissue adhesive.

Table 8. The experimental matrix containing varying levels of each factor. Since there were two factors being varied, there were four runs that were conducted for each test. A control sample was also evaluated for each test. The plus (+) sign represents a high level, and the minus (-) sign represents a low level.

\begin{tabular}{|l|l|l|}
\hline Standard Order & Silver Nanoparticle Concentration & Silver Nanoparticle Size \\
\hline 1 & - & - \\
\hline 2 & + & - \\
\hline 3 & - & + \\
\hline 4 & + & + \\
\hline
\end{tabular}

Each of the three tests used 2-octyl cyanoacrylate alone as a control. The experiment was conducted five times to ensure reliability of the data. Repeating the experiment provided varying ranges of response data and allowed for the determination of errors in each run. Data analysis was performed to conclude the effect silver nanoparticle concentration and size has on the adhesive's antibacterial and mechanical properties. Additionally, the responses of the tissue adhesive containing varying factors were compared to the responses generated by the tissue adhesive alone. These response comparisons established if the infusion of silver nanoparticles into the 2-octyl cyanoacrylate tissue adhesive was advantageous over the tissue adhesive alone. To summarize the steps involved in this experiment, Figure 15 shows a flowchart depicting each step of the experimental process. 


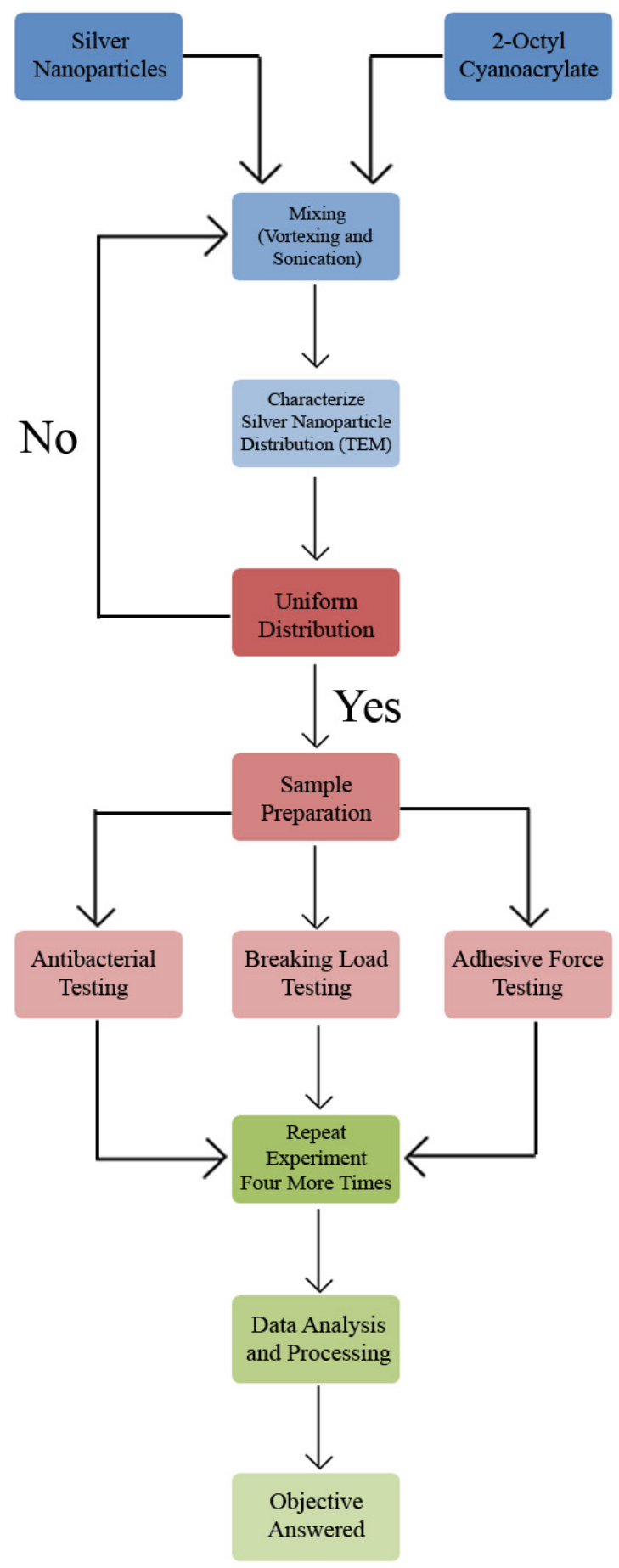

Figure 15. Flowchart illustrating the steps involved with this experiment. 


\subsubsection{Infusion of Silver Nanoparticles into the Tissue Adhesive}

Varying concentrations and sizes of silver nanoparticles were added to a 2-octyl cyanoacrylate tissue adhesive via vortexing and indirect sonication. Vortexing provided initial mixing of the silver nanoparticles into the liquid tissue adhesive. Indirect sonication was used because the ultrasonic energy evenly disperses the nanoparticles within the tissue adhesive. Results will be subject to additional variability and will not be repeatable if the silver nanoparticles were not evenly distributed within the tissue adhesive. These dispersion techniques were important to this experiment because of the relatively quick polymerization of 2-octyl cyanoacrylate on contact with moisture. Typically, dried silver nanoparticles must first be added to a solvent and vortexed and sonicated to be dispersed and unagglomerated.

The $10 \mathrm{~nm}$ silver nanoparticle surfaces were received from the manufacturer coated with polyvinylpyrrolidone to prevent agglomeration after dispersion into a polar solvent. There are a variety of polar solvents in which silver nanoparticles are soluble. Since 2-octyl cyanoacrylate quickly polymerizes when in contact with moisture, an anhydrous solvent was the best choice to slow the polymerization and allow for more control of the adhesive. An anhydrous, 200 proof, $99.5+\%$ ethanol was used as the solvent to allow high solubility for the silver nanoparticles. The $4 \mathrm{~nm}$ silver nanoparticles has a dodecanethiol capping agent. These organically functionalized silver nanoparticles can be redispersed in various polar organic solvents. A $99.7+\%$ chloroform was the selected solvent because of the high solubility of silver nanoparticles in this solvent and its relative safety compared to other polar organic solvents. These coatings 
should displace from the silver nanoparticles when added to the appropriate solvent [54]. The solvents were added to their respective silver nanoparticle containers and were vortexed for $10 \mathrm{~s}$ and sonicated for $30 \mathrm{~s}$ to produce a homogenous solution. The solvents were not added to the unaltered adhesive control samples.

Vortexing and indirect sonication were ideal methods to disperse the small amounts of 2-octyl cyanoacrylate and silver nanoparticles used in these experiments. This was because vortexing and sonicating provided quick and homogeneous mixing of the silver nanoparticles into the adhesive. Indirect sonication was also ideal because of the reduction of heat resulting from direct ultrasonic energy. Indirect sonication involved the immersion of the liquid sample container into a cold water bath while ultrasonic waves were sent through the bath [29]. Continuous mode operation was adequate for dispersing the nanoparticles within the adhesive. The tissue adhesive and redispersed silver nanoparticles were added to a $1.5 \mathrm{~mL}$ microcentrifuge tube and were vortexed for $10 \mathrm{~s}$ and indirectly sonicated for $30 \mathrm{~s}$ to obtain a homogeneous solution. If the nanoparticle and adhesive mixture was not homogeneous, additional vortexing and sonication was performed. Figure 16 shows the addition of silver nanoparticles to the adhesive before and after vortexing and sonication. 

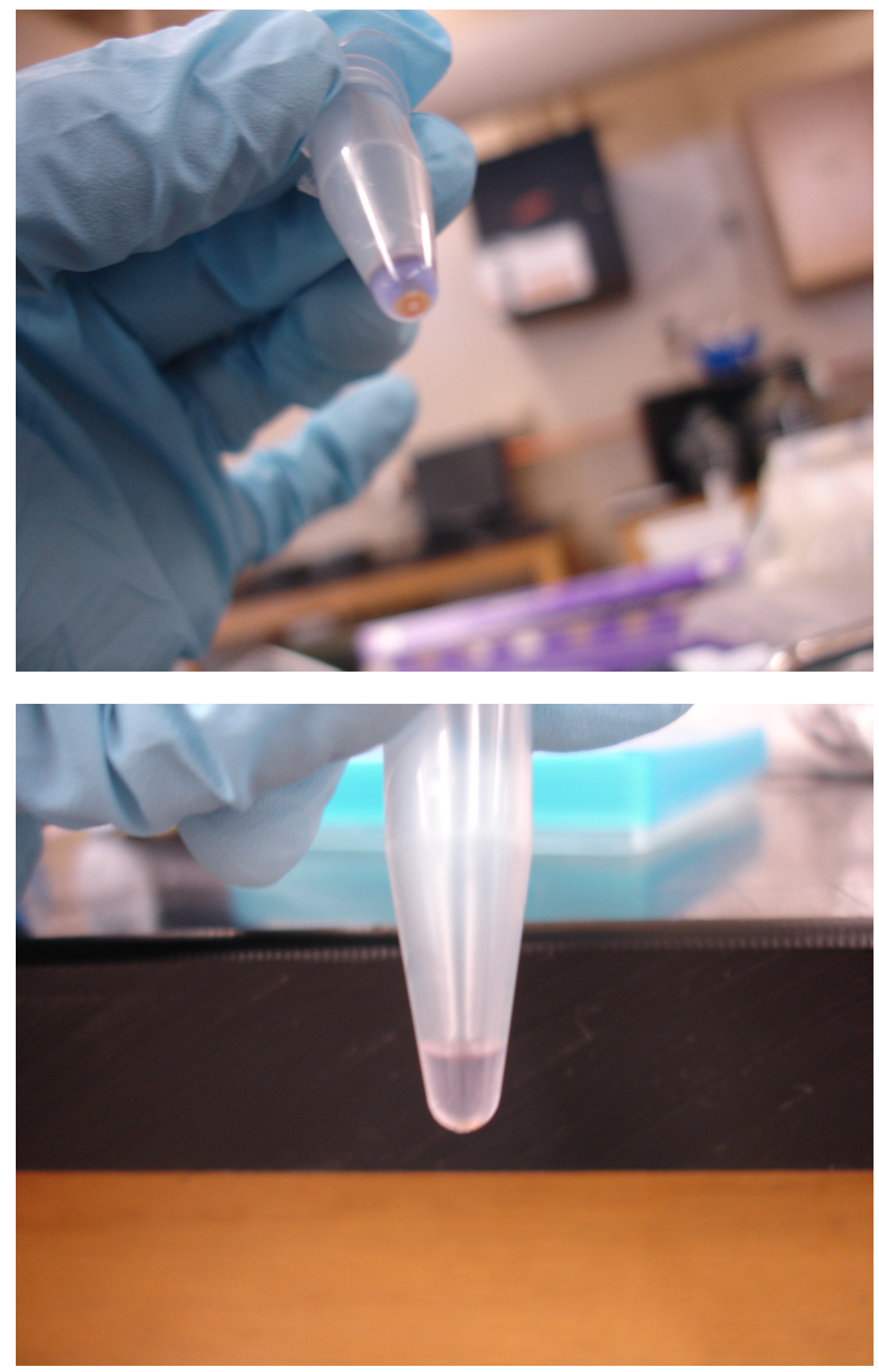

Figure 16. The addition of silver nanoparticles to the tissue adhesive prior (top) and after (bottom) vortexing and sonication. 


\subsubsection{Silver Nanoparticle Distribution Within Adhesive}

The distribution of silver nanoparticles within the tissue adhesive was observed with a TEM. The TEM images the transmitted beam of electrons through the sample to generate an image of the silver nanoparticles within the tissue adhesive [55]. A $0.5 \mathrm{~mL}$ vial of the adhesive and $0.5 \mathrm{mg}$ container of dried $10 \mathrm{~nm}$ silver nanoparticles were sent for TEM analysis (nanoComposix). The anhydrous ethanol was not sent along with the adhesive and nanoparticles because of the possible container breakage and exposure of the flammable ethanol to an ignition source. The silver nanoparticles were redispersed in anhydrous ethanol by the tester. We provided instructions on how to prepare the composite sample as we would for our testing. The silver nanoparticle composite adhesive was prepared by adding $50 \mu \mathrm{L}$ of adhesive to a container holding $10 \mu \mathrm{g} / \mathrm{mL}$ of silver nanoparticles, vortexing for $10 \mathrm{~s}$, and indirectly sonicating for $30 \mathrm{~s}$ to obtain a homogeneous solution. Image acquisition was performed and images were sent back for our use. ImageJ, which is an image processing and analyzing program developed by the National Institutes of Health $(\mathrm{NIH})$, was used to evaluate the distribution of particle spacing. First, the scale was set to the length of the scale bar from the provided image. The Line tool was used to draw a line from the center of a particle to the center of an adjacent particle. The length of the line was measured by ImageJ and the results of the analysis were displayed. Measuring the spacing between particles were performed for all particles and ultimately summarized by the ImageJ software. 


\subsubsection{Preparing Samples in Polyacrylamide Mold}

A polyacrylamide mold was used to shape the samples for their respective testing. Polyacrylamide was chosen due to its water content, which aids in the polymerization of the 2-octyl cyanoacrylate adhesive when poured into the mold and can be rehydrated if needed. Polyacrylamide was also chosen to be the mold because of its flexibility that allowed easy removal of samples from the mold. The mold formed the disks and dogbone shaped specimens for the Kirby-Bauer test and breaking load test, respectively. This polyacrylamide mold was created by being formed on an inverted solid mold. The disk and dog-bone shapes on the solid mold were extruded outward to form the polyacrylamide mold, which allowed the adhesive to be poured into the mold. The disks used for the Kirby-Bauer test had a diameter of $6.35 \mathrm{~mm}$ and a thickness of $1.5875 \mathrm{~mm}$. The dog-bone specimens used for the breaking load test have a reduced section of 6.35 , 1.5875 , and $1.5875 \mathrm{~mm}$ as the length, width, and thickness, respectively. Bulk highdensity polyethylene (HDPE) was machined to create the solid mold and is pictured in Figure 17. 


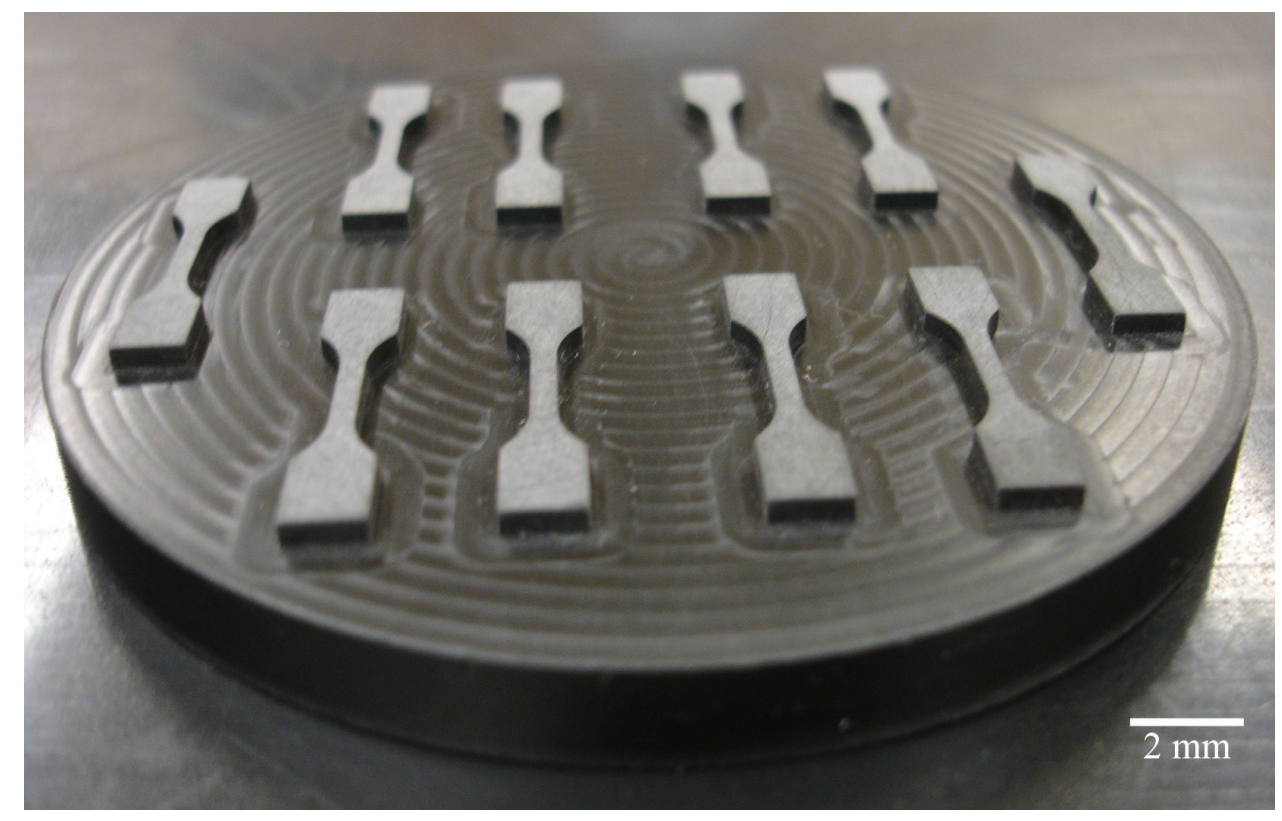

Figure 17. Machined high-density polyethylene (HDPE) solid mold used to form the polyacrylamide mold for preparing samples for the breaking load test.

Refining the formulation of the polyacrylamide mold to the desired flexibility and durability required multiple attempts. Since unpolymerized acrylamide is a neurotoxin, every step of this procedure was performed in a fume hood. The bottom of the solid mold was taped to a $100 \mathrm{~mm}$ diameter culturing dish using double-sided tape before preparing the polyacrylamide solution. In order to create a $20 \mathrm{~mL}$ solution of acrylamide, $0.0199 \mathrm{~g}$ of bisacrylamide was added to $3.9801 \mathrm{~g}$ of acrylamide and mixed with deionized water until reaching $20 \mathrm{~mL}$. In a separate container, $0.2 \mathrm{~g}$ of APS was added to $2 \mathrm{~mL}$ of deionized water. The APS was then mixed with the acrylamide solution.

Quickly afterward, $7 \mu \mathrm{L}$ of TEMED was dispensed into the acrylamide and APS mixture and stirred vigorously before being poured into the culturing dish containing the solid 
mold. APS and TEMED catalyzed the polymerization of acrylamide and generated the polyacrylamide in 30 min. Figure 18 depicts the freshly made polyacrylamide mold.

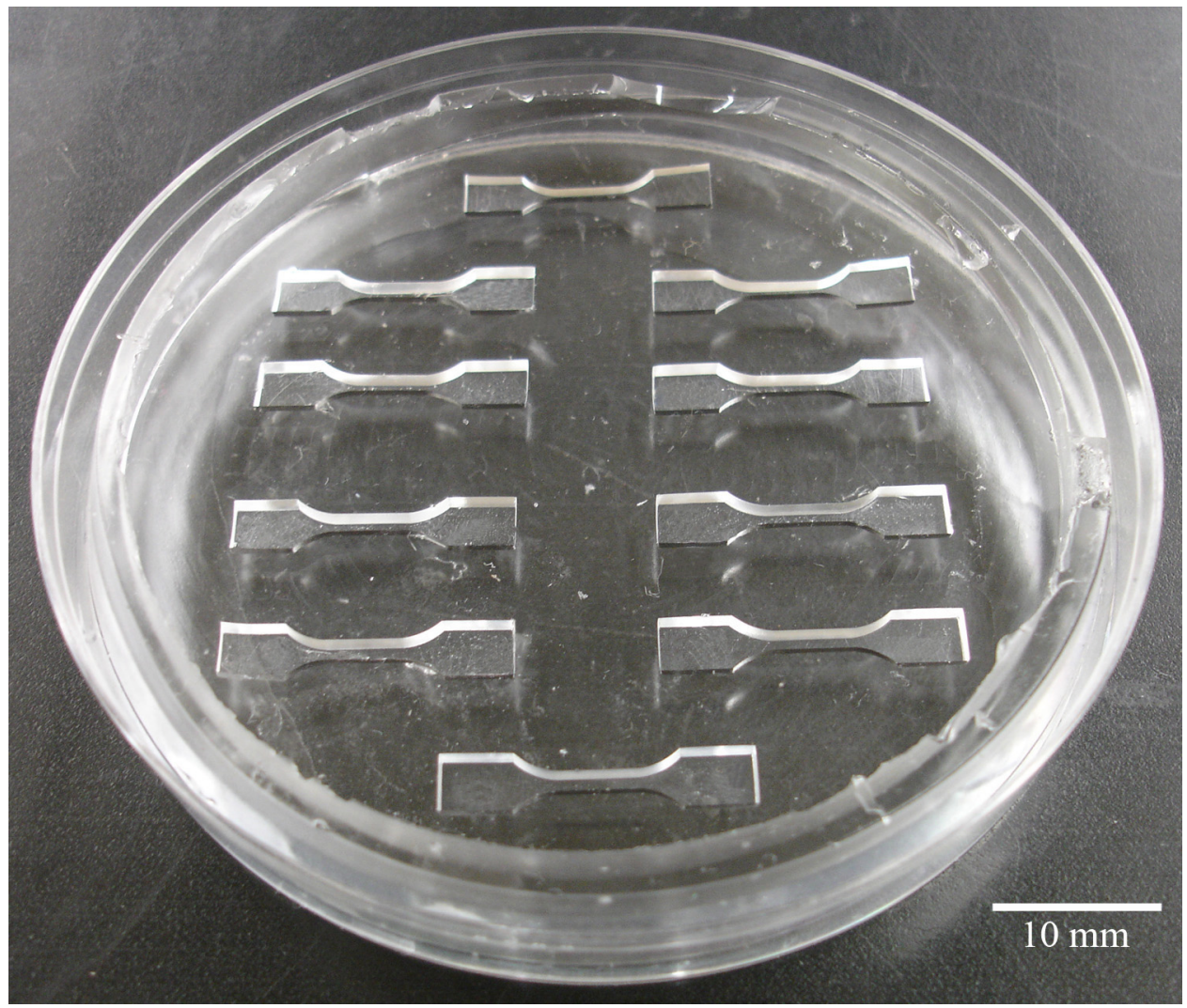

Figure 18. The polyacrylamide mold used to form the samples used for breaking load testing. The mold was placed in a $100 \mathrm{~mm}$ diameter culturing dish.

\subsubsection{Antibacterial Effectiveness Testing}

Before testing the antibacterial efficacy of the composite tissue adhesive, E. coli fed with LB broth was grown on sterilized solid agar within a culturing dish. LB broth was prepared by mixing $25 \mathrm{~g}$ of the powder to $1,000 \mathrm{~mL}$ of deionized water. Similarly, LB agar was prepared by mixing $37 \mathrm{~g}$ of the powder to $1,000 \mathrm{~mL}$ of deionized water. These amounts and volumes were general ratios and were scalable to whatever final volume of material needed. The LB broth and LB agar were then placed into the 
autoclave for $20 \mathrm{~min}$ at $121^{\circ} \mathrm{C}$ to be sterilized. Upon completion of sterilization, the containers of broth and agar were removed and set aside to be cooled down. The agar was poured into $60 \mathrm{~mm}$ diameter culturing dishes when the agar was slightly cooled to be safely held and poured but remained at low viscosity. The agar gradually solidified and was placed into the refrigerator along with the LB broth.

The Kirby-Bauer test sample preparation started by adding a colony of E. coli to $10 \mathrm{~mL}$ of LB broth within a $15 \mathrm{~mL}$ conical centrifuge tube and placed in an incubator at $37^{\circ} \mathrm{C}$ for $16 \mathrm{~h}$. The conical centrifuge tube was taken out after the time has elapsed and vortexed for five seconds. A single-channel adjustable pipet was used to pipet $25 \mu \mathrm{L}$ of the E. coli in LB broth solution onto the solidified agar within the culturing dish. The narrow portion of a glass Pasteur pipet was flamed and bent into a L-shape to be used to spread the E. coli in LB broth solution on the agar. Next, the adhesive samples were prepared on a polyacrylamide mold. After the $6.35 \mathrm{~mm}$ diameter by $1.5875 \mathrm{~mm}$ thick disk-shaped sample was formed, the sample was placed onto the culturing dish and incubated for $16 \mathrm{~h}$ at $37^{\circ} \mathrm{C}$. During the $16 \mathrm{~h}$ of incubation, the sample absorbs water from the agar plate while the silver diffuses into the surrounding agar [26,34]. If the bacteria were susceptible to the antibacterial property of silver nanoparticles, then an inhibition halo formed around the composite adhesive sample. To prove the antibacterial effectiveness of the silver nanoparticles, a disk of unaltered tissue adhesive served as a control, which should not produce an inhibition halo. We hypothesized that altering silver nanoparticle concentration and size will affect the diameter of the inhibition halo, thus indicating variation in antibacterial efficacy. The determination of the presence of 
an inhibition halo surrounding the samples was observed after $16 \mathrm{~h}$. All inhibition halo diameters of the samples were measured with a caliper and recorded.

CFU counting was another quantitative measurement of antibacterial effectiveness of the silver nanoparticle-imbued 2-octyl cyanoacrylate tissue adhesive. The samples from the Kirby-Bauer test were prepped to be used for the CFU counting test. The samples from that test were first added to $10 \mathrm{~mL}$ of $\mathrm{LB}$ broth within a $15 \mathrm{~mL}$ conical centrifuge tube, which was vortexed for $10 \mathrm{~s}$ and indirectly sonicated for $30 \mathrm{~s}$. Vortexing and sonication was repeated two more times. This solution was diluted to five different orders of magnitude: $10^{-1}, 10^{-2}, 10^{-3}, 10^{-4}$, and $10^{-5}$. To dilute the solution to $10^{-}$ ${ }^{1}, 100 \mu \mathrm{L}$ of the sample solution from the conical centrifuge tube was drawn by a singlechannel adjustable pipet and dispensed into a $1.5 \mathrm{~mL}$ microcentrifuge tube containing $900 \mu \mathrm{L}$ of LB broth. The new diluted solution was aspirated and dispensed three times in the microcentrifuge tube to ensure thorough mixing. Next, $100 \mu \mathrm{L}$ of this diluted solution was drawn, dispensed, and mixed into another $1.5 \mathrm{~mL}$ microcentrifuge tube containing $900 \mu \mathrm{L}$ of LB broth to produce the $10^{-2}$ diluted solution. This process was repeated until reaching the $10^{-5}$ diluted solution. After all dilutions were completed, 25 $\mu \mathrm{L}$ of the $10^{-5}$ diluted solution was dispensed onto solid agar within a culturing dish and was spread with a flamed, L-shaped glass Pasteur pipet. This spreading of diluted sample solution was repeated for the $10^{-4}$ dilution all the way to $10^{-1}$ in that sequential order. The culturing dishes were then placed into the incubator for $18 \mathrm{~h}$ at $37^{\circ} \mathrm{C}$. This entire sample preparation process was repeated for all adhesive samples. After the incubation time, the culturing dishes were removed from the incubator and the E. coli colonies of each dish 
were counted. There should be a noticeable reduction of colonies as the samples were more diluted. We hypothesized that an unaltered version of 2-octyl cyanoacrylate will produce a higher CFU count than the silver nanoparticle-doped tissue adhesive samples. Pictures of the samples were taken with a camera (DSC-P200, Sony) at 1X magnification to be processed and analyzed in ImageJ.

\subsubsection{Breaking Load Testing}

The breaking load of the silver nanoparticle-infused tissue adhesive was measured with the universal testing machine. Samples were prepared by dispensing the adhesive into the individual dog-bone shaped mold on the polyacrylamide mold to polymerize and dry. After the adhesive polymerized, each end of the sample was clamped by the pneumatic grips of the universal testing machine, which is shown in Figure 19. The user entered $6.35,1.5875$, and $1.5875 \mathrm{~mm}$ as the length, width, and thickness of the reduced section of the adhesive sample into Instron's Bluehill ${ }^{\circledR} 3$ instrument software before the test began. The universal testing machine was equipped with a $100 \mathrm{~N}$ load cell to detect the breaking load of the composite adhesive, which was found when the sample fractured and completely separated. The sample was pulled apart by the universal testing machine at a rate of $1 \mathrm{~mm} / \mathrm{min}$ until the sample fractured. The raw data was recorded and initially analyzed by the Bluehill ${ }^{\circledR} 3$ software. The raw data was obtained and further analyzed in Microsoft Excel to assess the effects of silver nanoparticles on the breaking load of the tissue adhesive. 


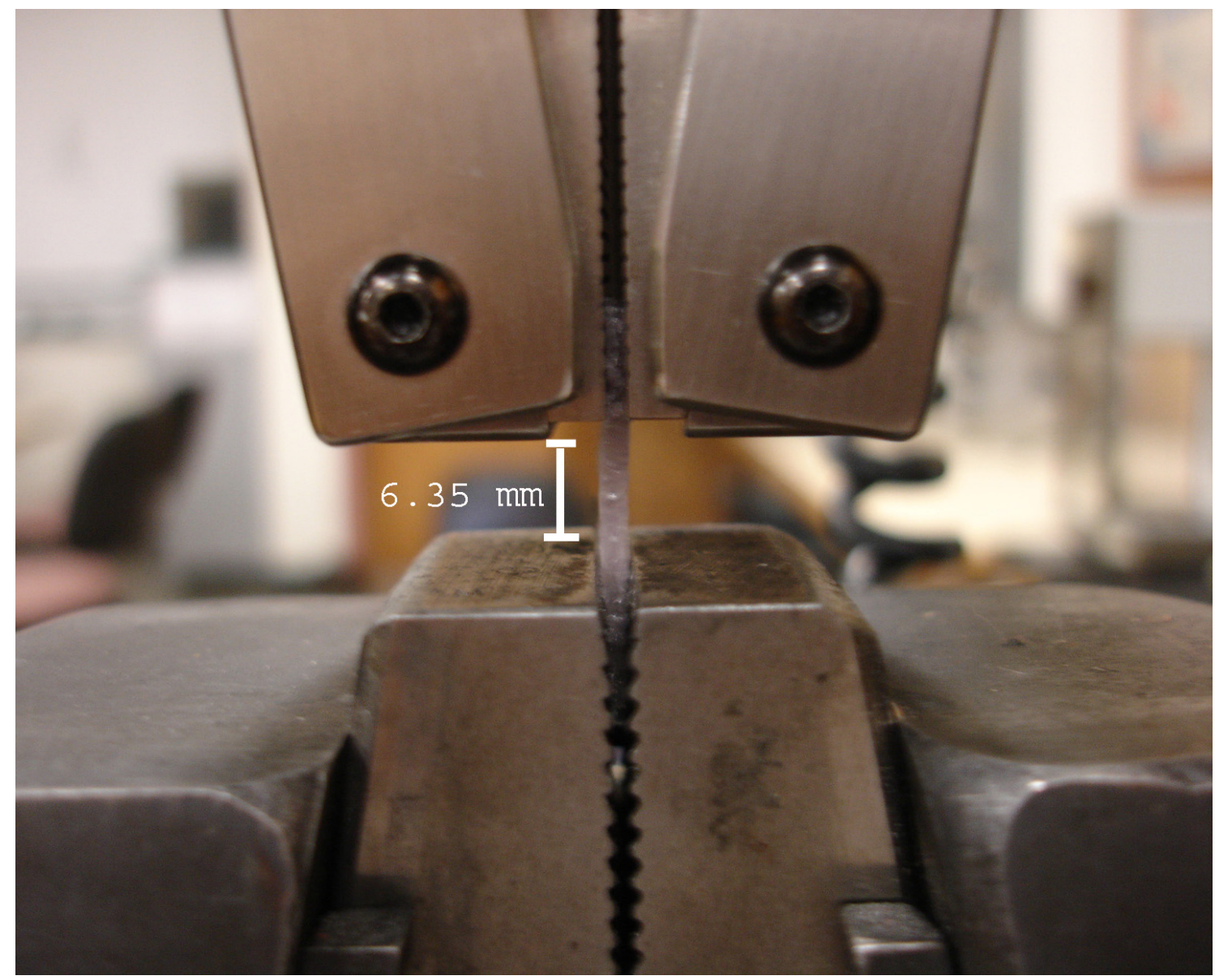

Figure 19. Dog-bone shaped specimen clamped by the grips of the universal testing machine. The adhesive sample's length, width, and thickness of the reduced section were $6.35 \mathrm{~mm}, 1.5875 \mathrm{~mm}$, and $1.5875 \mathrm{~mm}$, respectively.

\subsubsection{Adhesive Force Testing}

This test examined the adhesive force of the composite tissue adhesive on porcine eye tissue. First, a $3.0 \mathrm{~mm}$ incision was made on the sclera of the porcine eye. A $50 \mu \mathrm{L}$ amount of adhesive was then applied as a smooth single layer to the incised ends of the sclera while the two ends of the tissue were held together. A machined T-structure was attached to the other side of the adhesive and the operator applied force to the bonded area for five minutes to allow the adhesive to polymerize. Figure 20 shows the T- 
structure attached to the porcine sclera. The T-structure was wooden because the wood will not fracture before the adhesive bond fractures. The eye was then placed into a vacuum eye holder and rotated in a way such that the area of the incised sclera was not secured by the eye holder. The eye holder is pictured in Figure 21. The eye holder was tightened by the lower grip of the universal testing machine and connected with a tube to the rotary vane pump that provided vacuum suction. Figure 22 illustrates the setup for the adhesive force testing.

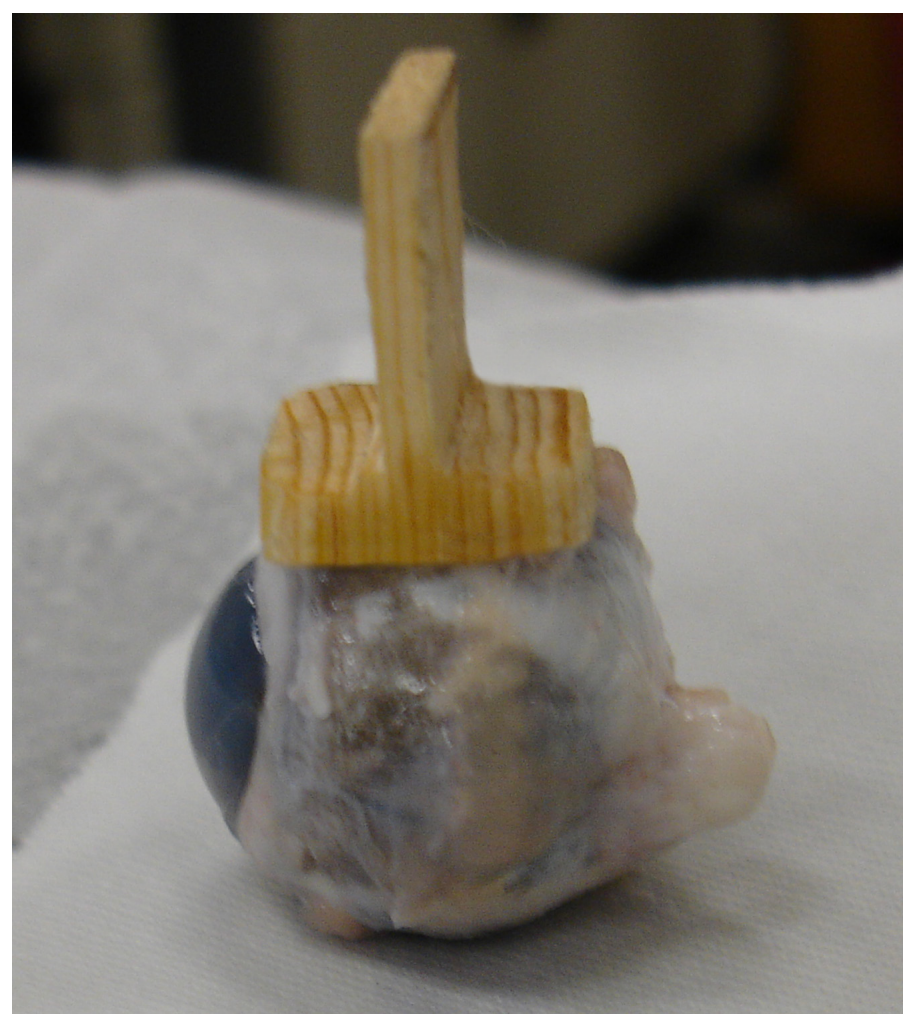

Figure 20. The T-structure adhered to the porcine sclera prior to placing into the vacuum eye holder. The bonding surface of the T-structure was $13 \mathrm{~mm}$ wide and $13 \mathrm{~mm}$ long. 


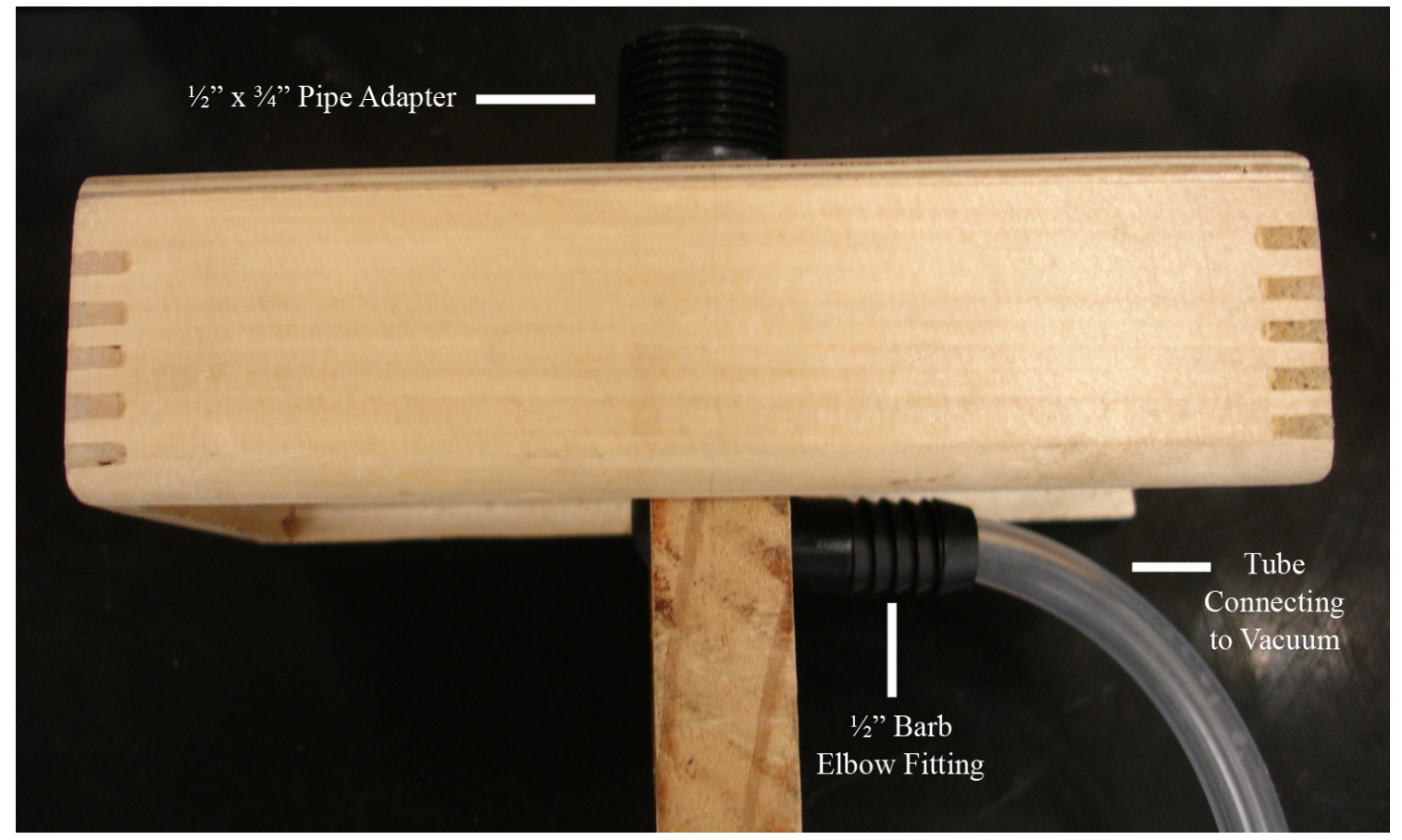

Figure 21. The eye holder that held the eye in the pipe adapter. The tube connected the eye holder to the rotary vane pump to provide vacuum suction. 


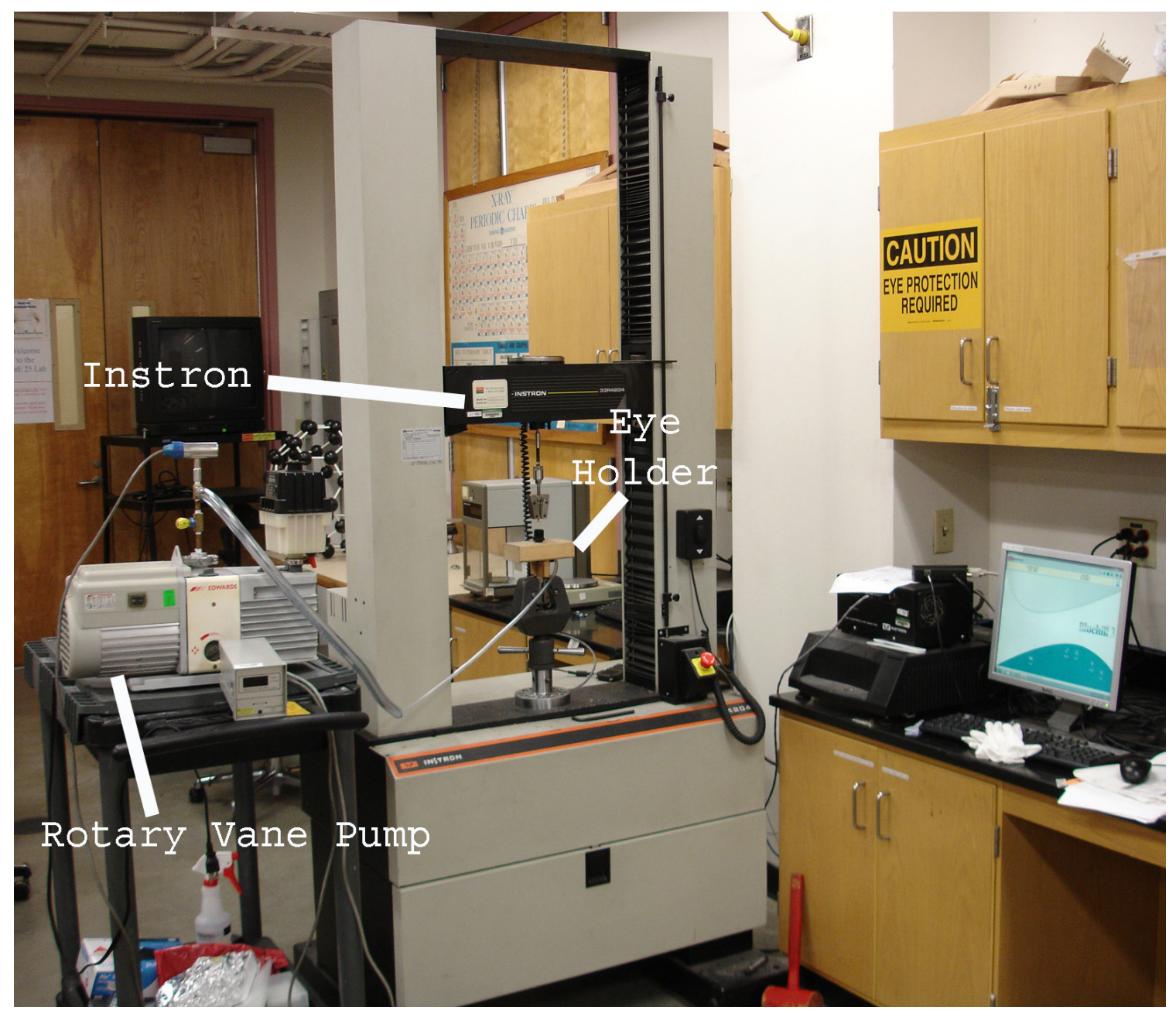

Figure 22. The adhesive force experimental setup. The rotary vane pump was positioned on the cart (far left), while the eye holder was clamped onto the universal testing machine.

The upper pneumatic grip was lowered until the vertical section of the T-structure was clamped to the grips. The operator entered the length, width, and thickness of the bonded area of the adhesive to the eye into the Bluehill@ 3 software before testing started. The $100 \mathrm{~N}$ load cell was also used for this test and was pulled at a rate of 5 $\mathrm{mm} / \mathrm{min}$ until the adhesive bonds between the porcine eye and the adhesive fractured. The force required to break the adhesive bonds is called the adhesive force. Similar to 
the other performed tests, an unaltered tissue adhesive was used as a control. The raw data was generated by the Bluehill® 3 software and Microsoft Excel was used to evaluate the effects the silver nanoparticles has on the adhesive force of the tissue adhesive when tested on porcine eyes. 


\section{CHAPTER FIVE}

RESULTS

5.1 Silver Nanoparticle Distribution within Tissue Adhesive

The TEM images showed uniform distribution of the silver nanoparticles within the 2-octyl cyanoacrylate. Figure 23 displays the distribution of the $10 \mathrm{~nm}$ silver nanoparticles within the tissue adhesive. The spacing between the particles for four TEM images was on average $37.2 \mathrm{~nm}$, with a standard deviation of $14.4 \mathrm{~nm}$. The raw data for the ImageJ analysis of the spacing between particles are located in Appendix A. The 4 $\mathrm{nm}$ and $10 \mathrm{~nm}$ silver nanoparticles were also imaged to confirm the particle size. The 4 $\mathrm{nm}$ particle size is pictured in Figure 24, while the $10 \mathrm{~nm}$ particle size is shown in Figure 25. The $4 \mathrm{~nm}$ and $10 \mathrm{~nm}$ particle sizes represented the median sizes. In terms of the silver nanoparticle size distribution, the $10 \mathrm{~nm}$ nanoparticles exhibited a $12.3 \%$ coefficient of variation, while the $4 \mathrm{~nm}$ nanoparticles exhibited a $15.6 \%$ coefficient of variation. 


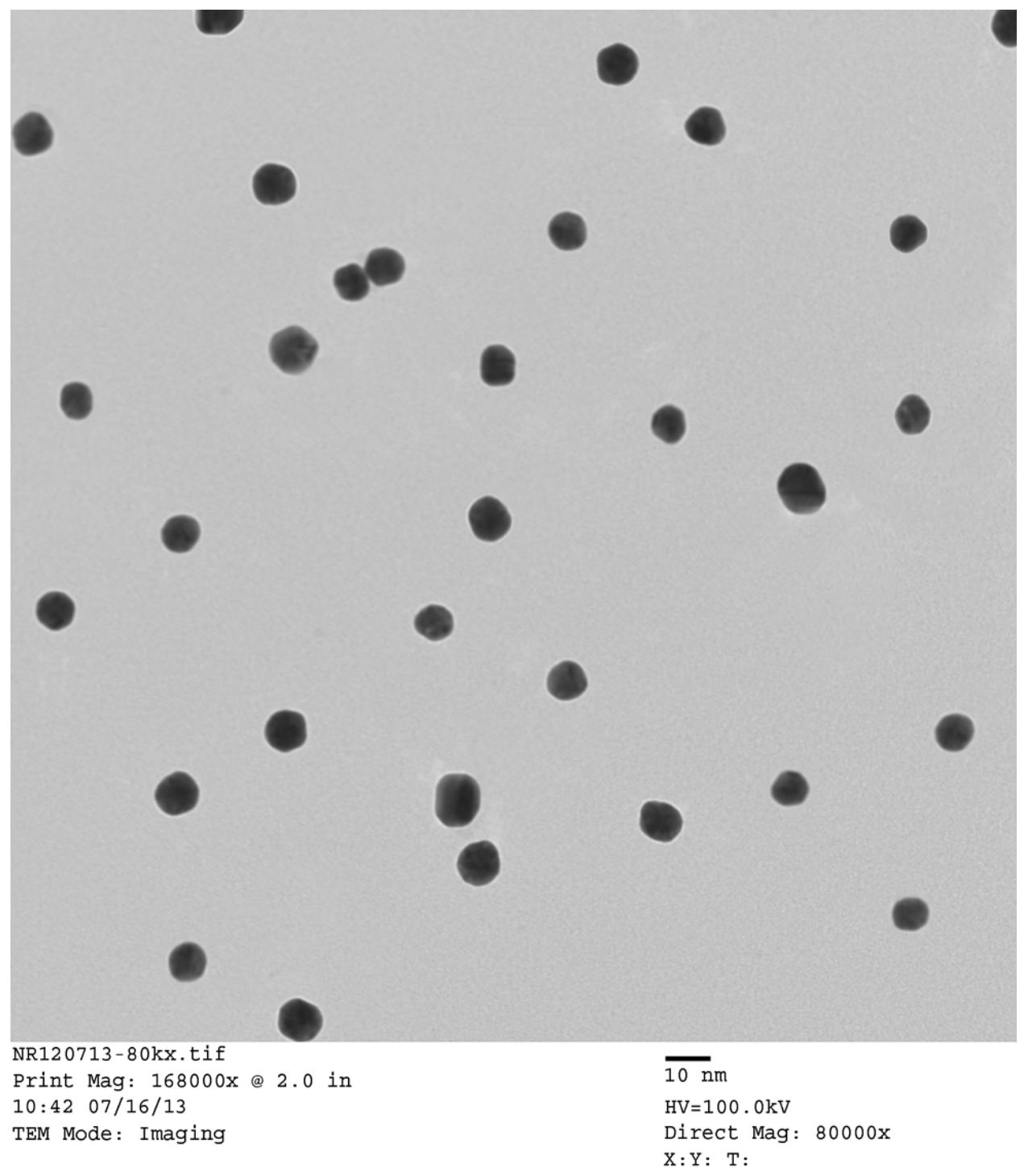

Figure 23. TEM image of the $10 \mathrm{~nm}$ silver nanoparticles distributed within 2-octyl cyanoacrylate. The image is at $80,000 \mathrm{X}$ magnification. 


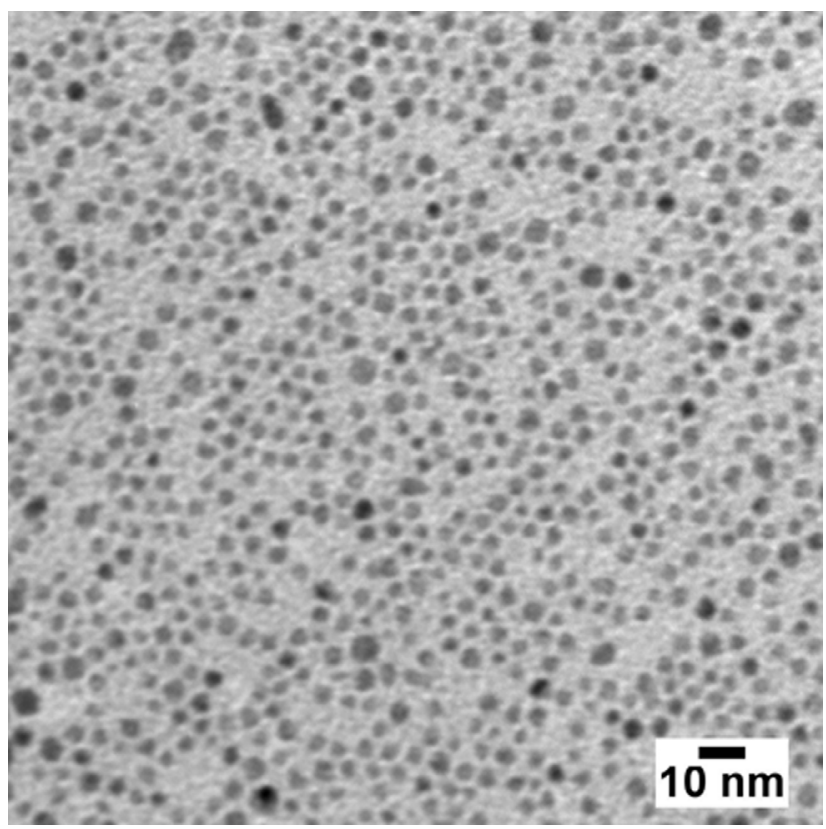

Figure 24. TEM image of the $4 \mathrm{~nm}$ silver nanoparticles to confirm the particle size. The image is at $100,000 \mathrm{X}$ magnification.

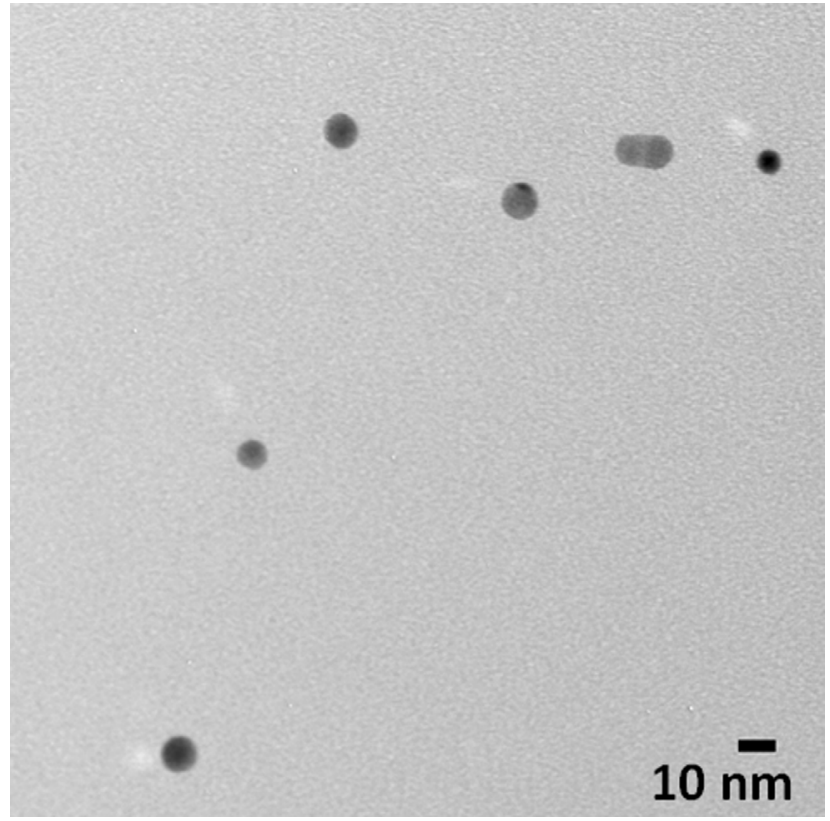

Figure 25. TEM image of the $10 \mathrm{~nm}$ silver nanoparticles to confirm the particle size. The image is at $80,000 \mathrm{X}$ magnification. 


\subsection{Antibacterial Efficacy}

We hypothesized that the infusion of silver nanoparticles into the 2-octyl cyanoacrylate tissue adhesive imbues an antibacterial effect to the adhesive. The KirbyBauer disk diffusion susceptibility test and CFU counting were performed to examine this composite adhesive and compared it to an unaltered version of the tissue adhesive.

Results indicate that the composite adhesive was characterized by a notable decrease of bacterial growth than compared to the tissue adhesive alone. The following sections describe the results of the individual antibacterial tests.

\subsubsection{Kirby-Bauer Disk Diffusion Susceptibility Test}

The objective of this test was to observe if an inhibition halo was present around the disk-shaped sample that was placed on top of a culturing dish filled with E. coli. As expected, none of the unaltered 2-octyl cyanoacrylate samples produced a surrounding inhibition halo. The absence of an inhibition halo is seen in Figure 26. Figure 27 is a magnified view of an unaltered adhesive sample using an inverted microscope. 


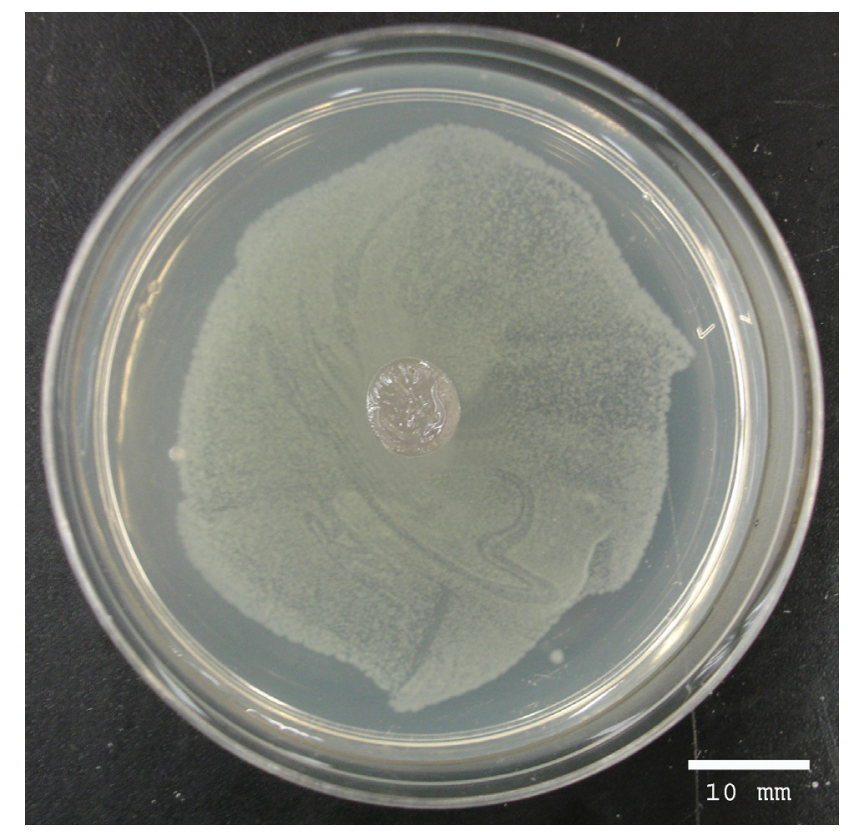

Figure 26. An inhibition halo was not formed around the unaltered adhesive.

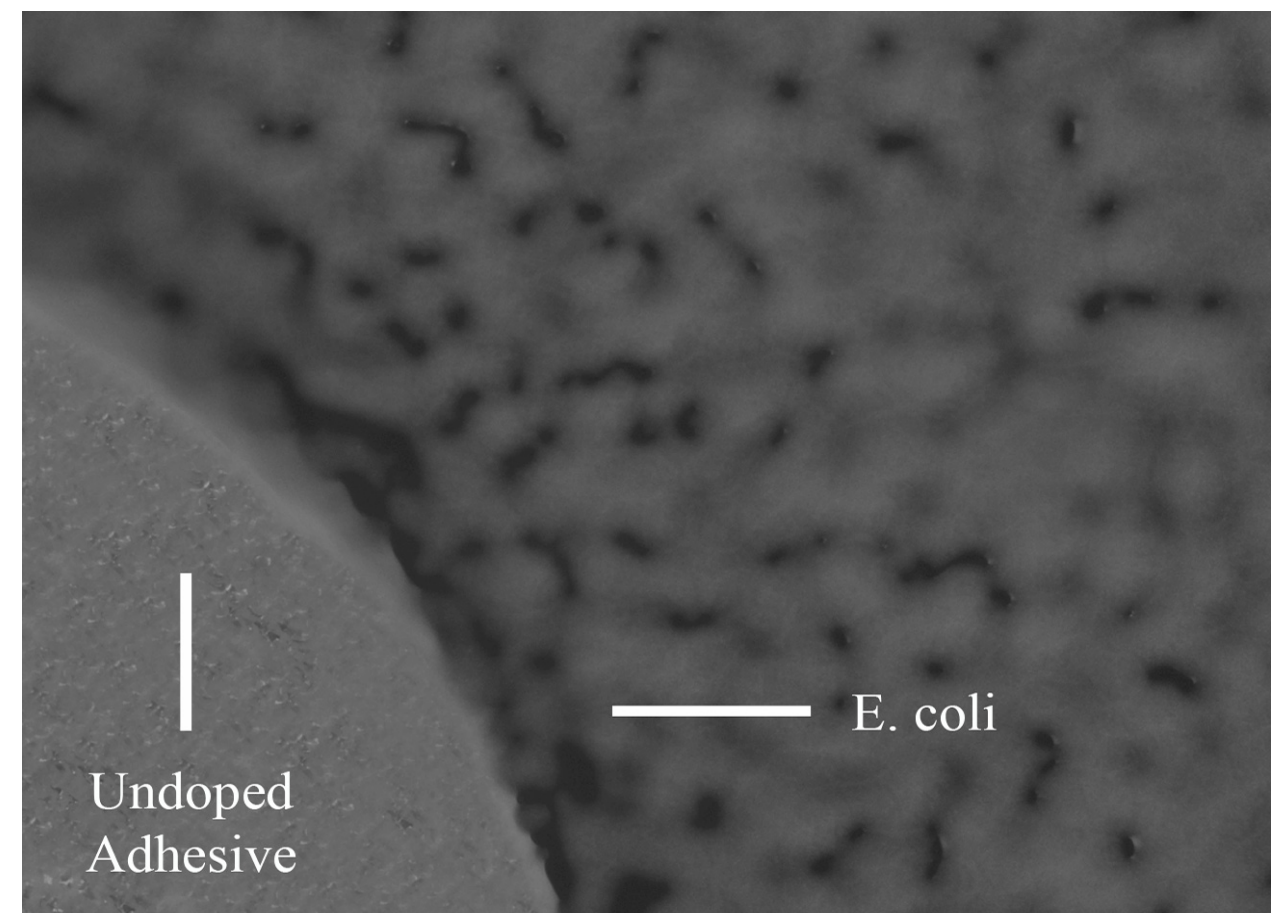

Figure 27. Magnified view of an unaltered adhesive sample at $2 \mathrm{X}$ magnification. The $E$. coli was confluent around the sample. 
The silver nanoparticle-infused tissue adhesive samples generated a distinct inhibition halo surrounding each sample. This distinct inhibition halo appeared for all the varying tested silver nanoparticle concentrations and sizes. The diameter of the inhibition halo was measured with a caliper. Figure 28 shows a composite sample surrounded by a distinct inhibition halo. An inverted microscope magnified the view of the inhibition halo surrounding the sample, which is shown in Figure 29. Table 9 tabulates the average inhibition halo of the tested samples. The raw data for the KirbyBauer test are located in Appendix B. Figure 30 organizes the average inhibition halo diameters by their respective sample combination. The error bars depict the standard deviation of the set of data for each sample. Table 10 summarizes the results of a 2-way analysis of variance (ANOVA) test from the responses generated in the Kirby-Bauer test. 


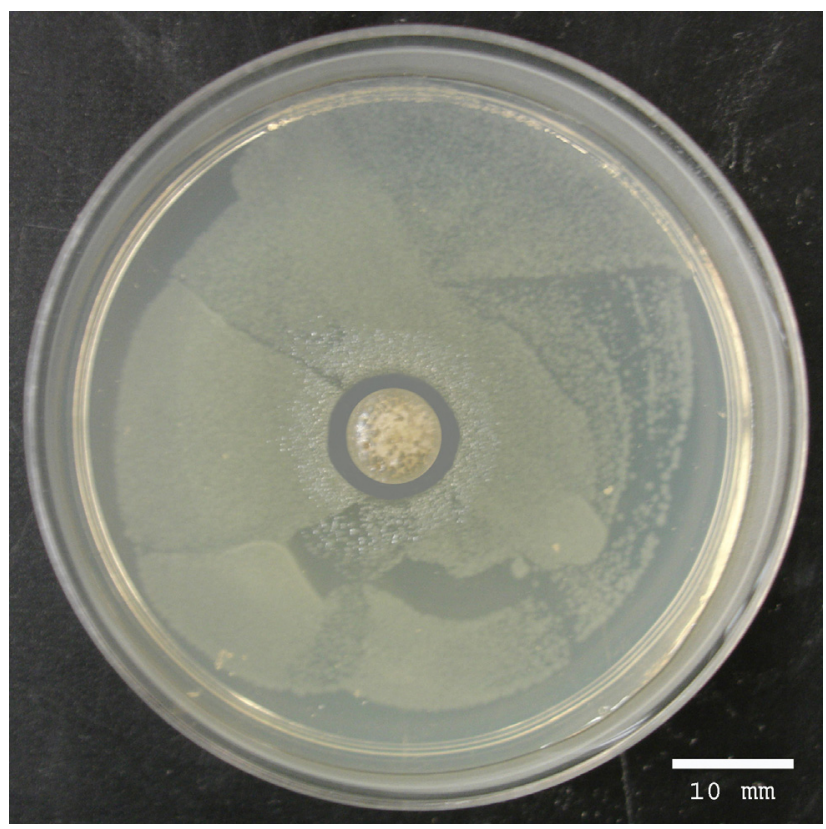

Figure 28. A composite sample displaying the presence of an inhibition halo.

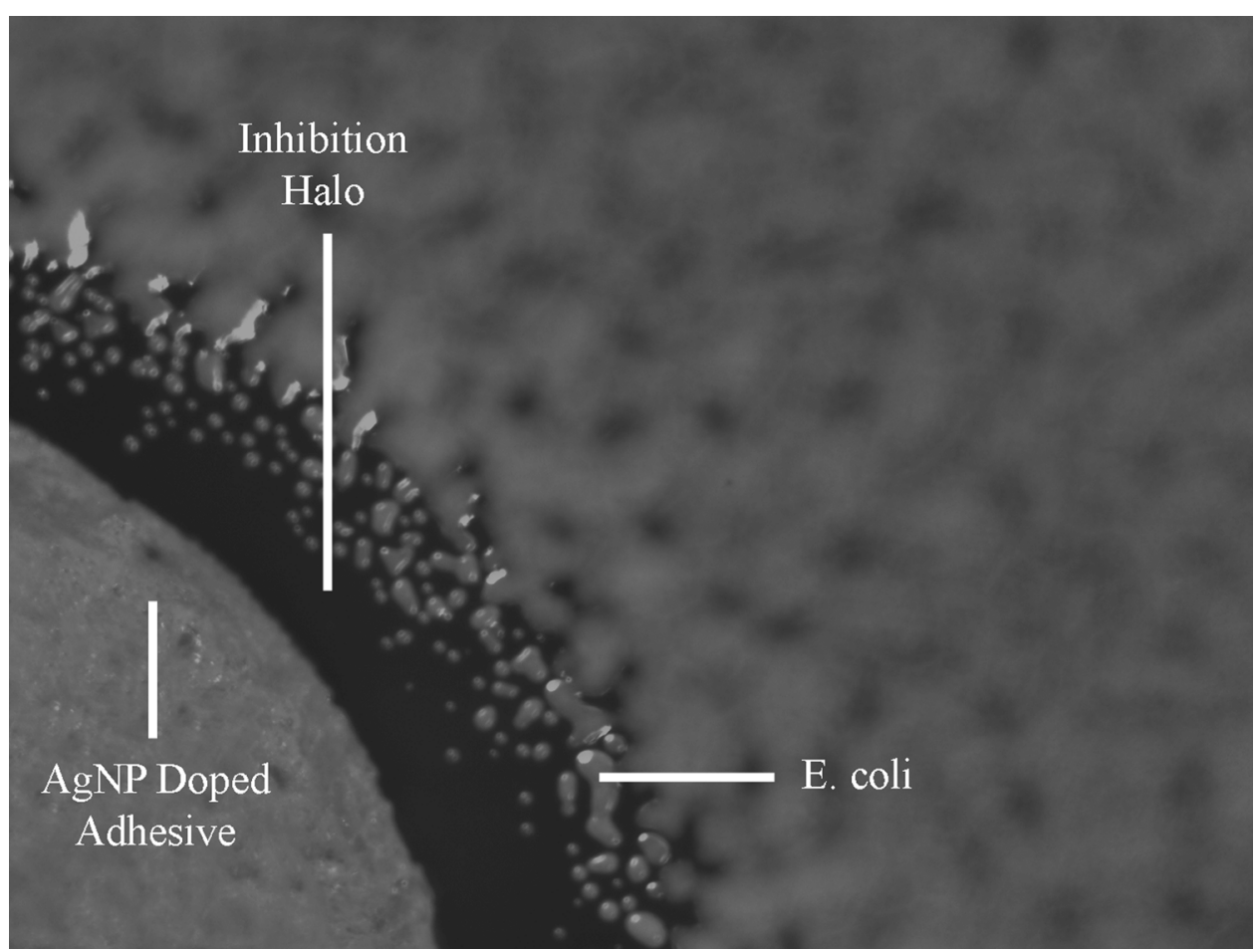

Figure 29. Magnified view of a composite adhesive sample's inhibition halo at $2 \mathrm{X}$ magnification. Notice the distinct halo between the sample and E. coli. 
Table 9. The average diameter of the inhibition halos around the various samples. All runs were performed five times.

\begin{tabular}{|l|l|l|l|}
\hline Name & $\begin{array}{l}\text { Average Inhibition Halo } \\
\text { Diameter }(\mathrm{mm})\end{array}$ & $\begin{array}{l}\text { Standard } \\
\text { Deviation }\end{array}$ & $p$-value \\
\hline Adhesive Alone & 0 & 0 & N/A \\
\hline $\begin{array}{l}1 \mu \mathrm{g} / \mathrm{mL}, 4 \mathrm{~nm} \\
\text { AgNP }+ \text { Adhesive }\end{array}$ & 11.0 & 0.71 & $2.55 \mathrm{E}-10$ \\
\hline $\begin{array}{l}10 \mu \mathrm{g} / \mathrm{mL}, 4 \mathrm{~nm} \\
\text { AgNP }+ \text { Adhesive }\end{array}$ & 15.2 & 1.79 & $3.05 \mathrm{E}-08$ \\
\hline $\begin{array}{l}1 \mu \mathrm{g} / \mathrm{mL}, 10 \mathrm{~nm} \\
\text { AgNP }+ \text { Adhesive }\end{array}$ & 12.2 & 0.84 & $4.27 \mathrm{E}-10$ \\
\hline $\begin{array}{l}10 \mu \mathrm{g} / \mathrm{mL}, 10 \mathrm{~nm} \\
\text { AgNP }+ \text { Adhesive }\end{array}$ & 12.0 & 0.71 & $1.28 \mathrm{E}-10$ \\
\hline
\end{tabular}

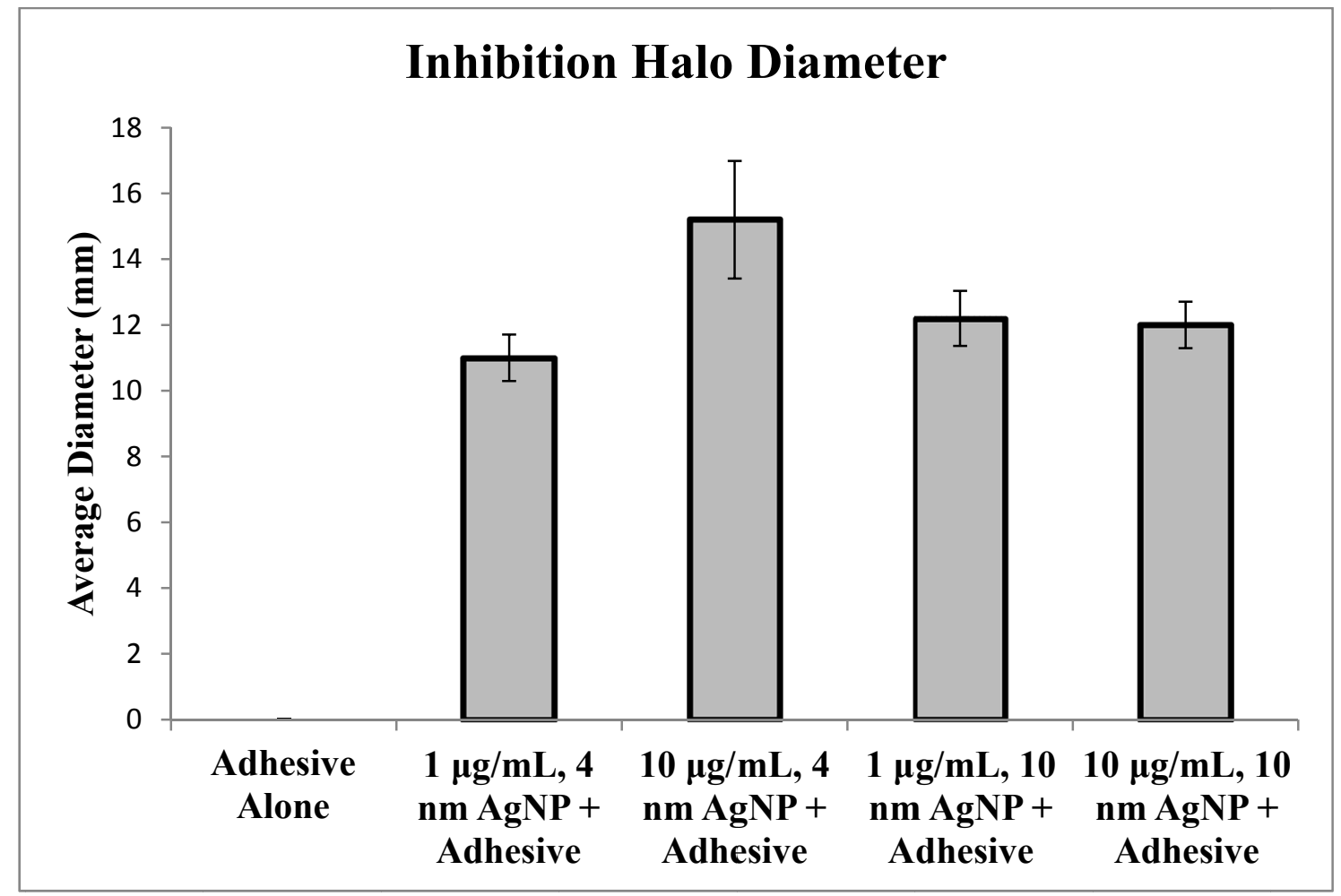

Figure 30. The average inhibition halo diameter for various silver nanoparticle-doped and undoped adhesives. Error bars represent the standard deviation for each sample combination. 
Table 10. The results of a 2-way ANOVA test from the responses generated in the Kirby-Bauer disk diffusion susceptibility test. The test statistic $(F)$, critical value $(F$ $c r i t$ ), and $p$-value are shown for the size and concentration factors. The interaction of the size and concentration factors is also shown.

\begin{tabular}{|l|l|l|l|}
\hline Source of Variation & $F$ & $F$ crit & $p$-value \\
\hline Concentration & 16.3 & 4.49 & $9.48 \mathrm{E}-04$ \\
\hline Size & 4.08 & 4.49 & $6.04 \mathrm{E}-02$ \\
\hline Interaction & 19.8 & 4.49 & $4.08 \mathrm{E}-04$ \\
\hline
\end{tabular}

\subsubsection{CFU Counting}

CFU counting provided another test to measure the antibacterial effectiveness of the silver nanoparticle-imbued 2-octyl cyanoacrylate tissue adhesive. This test was conducted after the completion of the Kirby-Bauer disk diffusion susceptibility test by taking the samples from that test and adding them to LB broth to be diluted to their respective order of magnitude. The samples were diluted to five different orders of magnitude: $10^{-1}, 10^{-2}, 10^{-3}, 10^{-4}$, and $10^{-5}$. CFU counting allowed for quantitative assessment of the degree of bacterial growth. The E. coli colonies were counted with ImageJ. ImageJ detected the various colors of the image and allowed the user to adjust the color threshold and pixel size to be counted. Allowing the operator to adjust these parameters excluded artifactual pixels that possibly greatly alter the colony count. When the user was not able to distinguish the number of distinct colonies in a densely populated area on the solid agar, ImageJ separated touching colonies into segments using the program's Watershed algorithm and added the segmentations into the colony count. This analysis with ImageJ was not perfect but does provide a reliable estimate of the number of colonies. Figure 31 compiles the various samples and their respective ImageJ analysis 
that provided a better resolution of the CFU counts. Figure 32 shows the serial dilution of an unaltered adhesive sample, while Figure 33 shows the serial dilution of a doped adhesive sample.
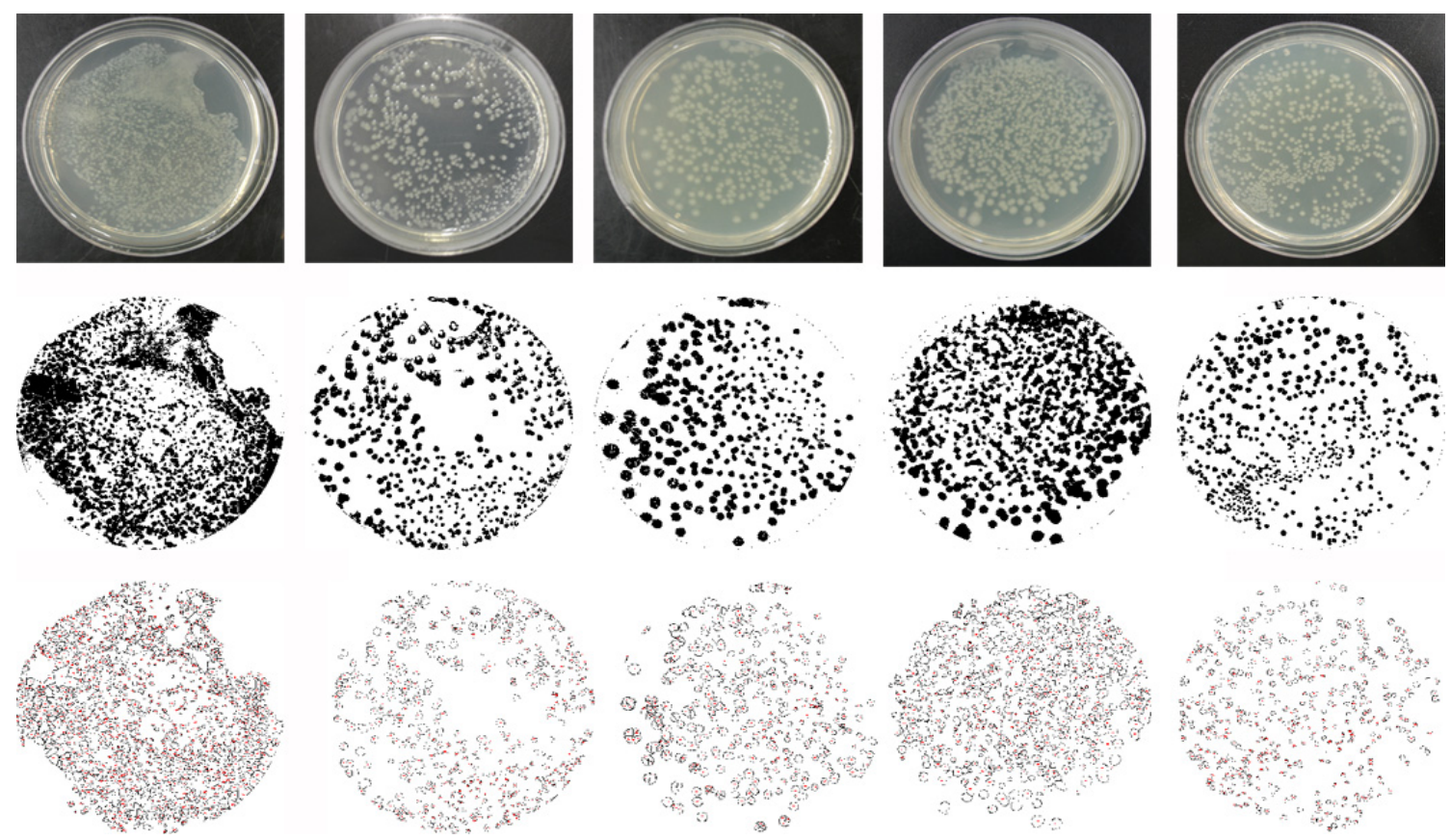

Figure 31. CFU counts for each of the different tested samples. The pictures on the top were the colonies formed on a culturing dish after incubation. The pictures in the middle were the adjusted color threshold that detected the desired colony colors in ImageJ. The pictures on the bottom were the results after ImageJ analyzed the number of colonies in the culturing dish. From left to right, the unaltered adhesive diluted to $10^{-2}$ had 1225 colonies, $1 \mu \mathrm{g} / \mathrm{mL}$ of $4 \mathrm{~nm}$ silver nanoparticles within the adhesive diluted to $10^{-1}$ had 520 colonies, $10 \mu \mathrm{g} / \mathrm{mL}$ of $4 \mathrm{~nm}$ silver nanoparticles within the adhesive diluted to $10^{-1}$ had 410 colonies, $1 \mu \mathrm{g} / \mathrm{mL}$ of $10 \mathrm{~nm}$ silver nanoparticles within the adhesive diluted to $10^{-1}$ had 610 colonies, and $10 \mu \mathrm{g} / \mathrm{mL}$ of $10 \mathrm{~nm}$ silver nanoparticles within the adhesive diluted to $10^{-1}$ had 463 colonies. 


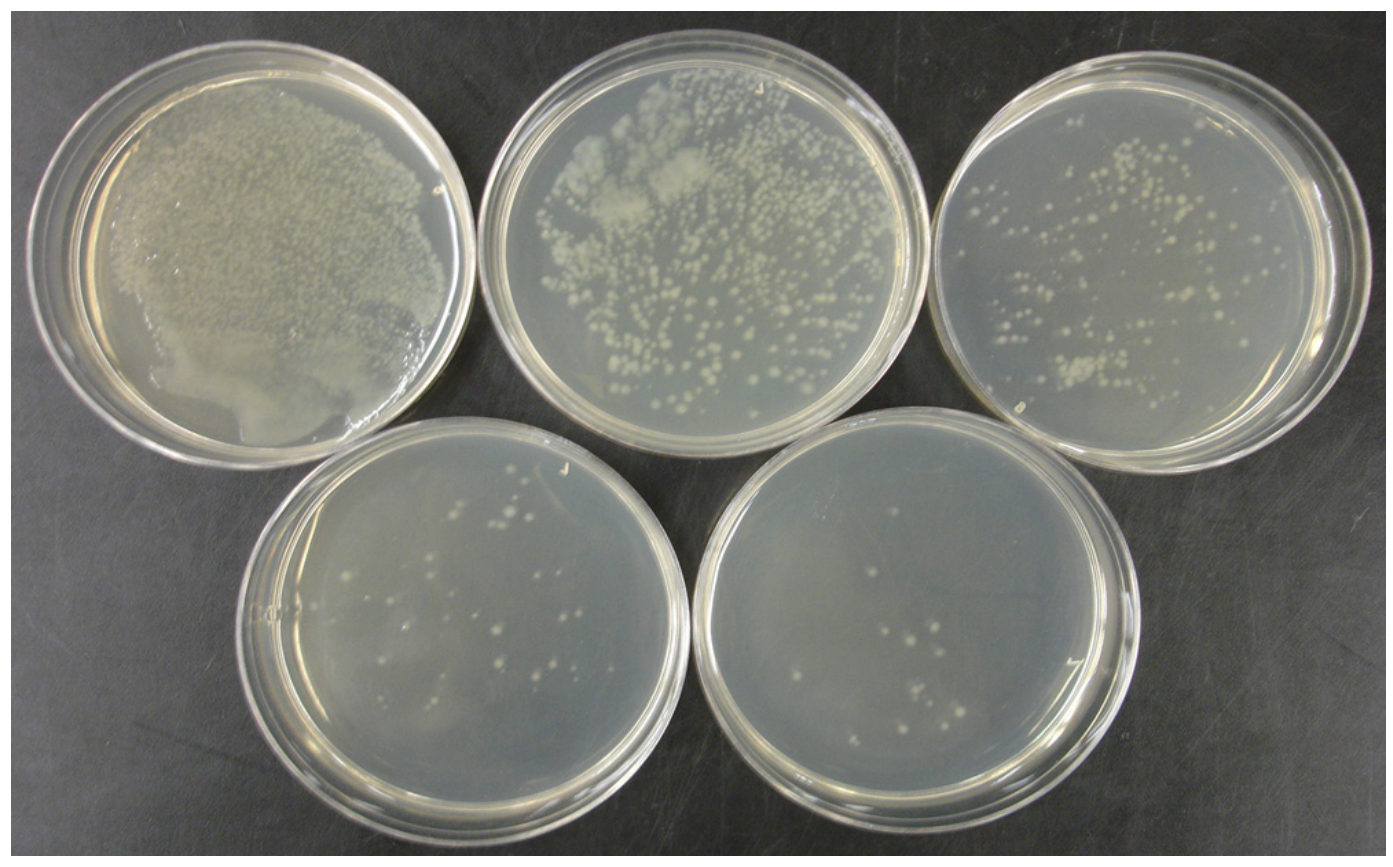

Figure 32. The serial dilution of an undoped tissue adhesive.

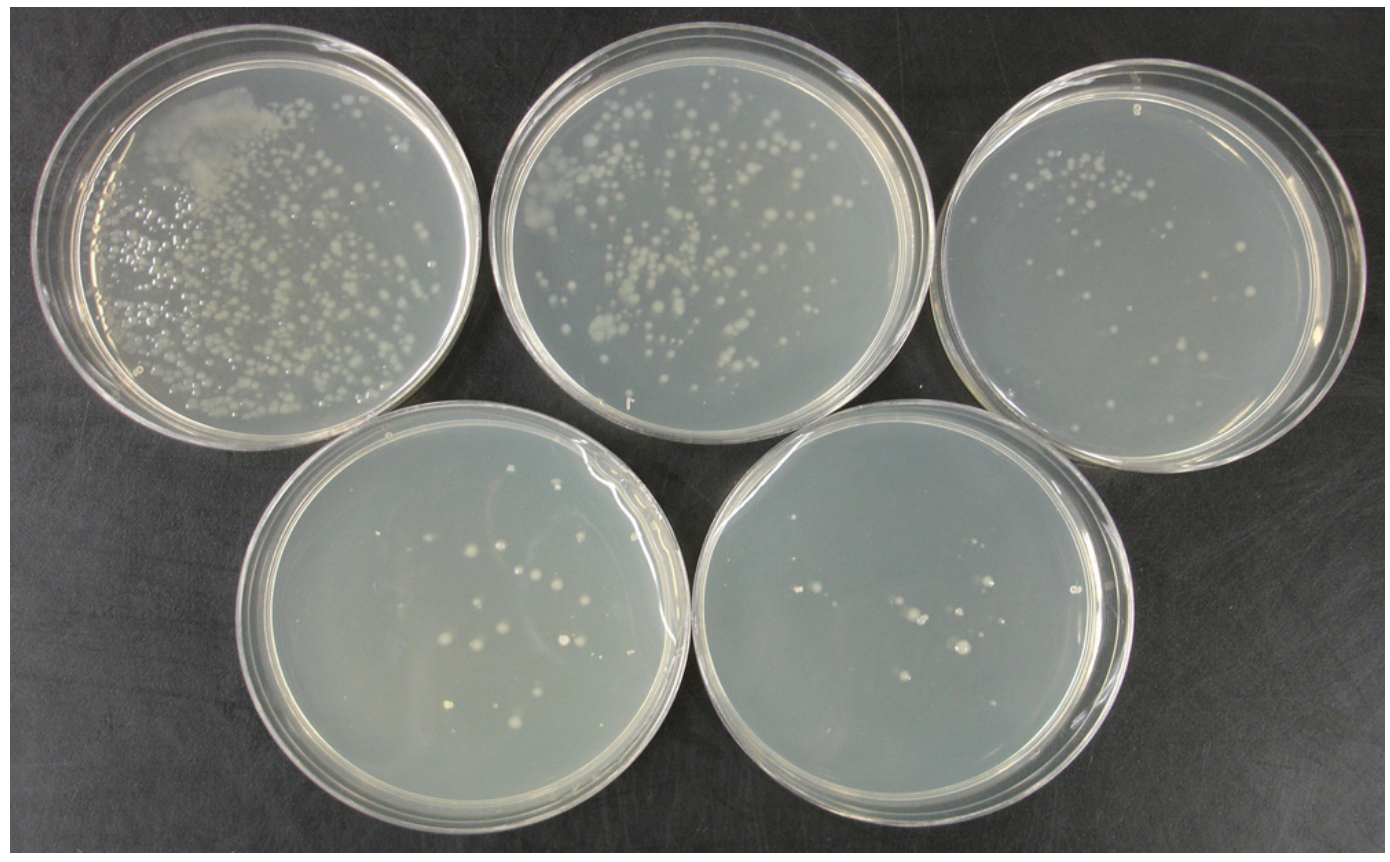

Figure 33. The serial dilution of a silver nanoparticle-doped adhesive. 
Based on the results from the Kirby-Bauer disk diffusion susceptibility test, an unaltered version of 2-octyl cyanoacrylate was found to have a higher CFU count than the silver nanoparticle-infused tissue adhesive. Table 11 displays the average logarithmic amount of E. coli colonies present on the different culturing dishes. The colony counts were calculated in the logarithmic scale for simpler and clearer comparison. The standard deviation and $p$-values were also computed. The raw data for the CFU counts are located in Appendix C. Figure 34 compares varying concentrations and sizes of silver nanoparticles within the tissue adhesive to the original 2-octyl cyanoacrylate. The error bars depict the standard deviation of the set of data for each sample. Table 12 summarizes the results of a 2-way ANOVA test from the responses produced in the CFU counting.

Table 11. The average logarithmic amount of E. coli colonies for the different types of samples. The logarithmic values were in base 10. All runs were performed five times.

\begin{tabular}{|l|l|l|l|}
\hline Name & $\begin{array}{l}\text { Average Number of } \\
\text { Colonies (Logarithmic) }\end{array}$ & Standard Deviation & $\begin{array}{l}p \text {-value } \\
(\text { Logarithmic) }\end{array}$ \\
\hline Adhesive Alone & 4.88 & 0.16 & N/A \\
\hline $\begin{array}{l}1 \mu \mathrm{g} / \mathrm{mL}, 4 \mathrm{~nm} \\
\mathrm{AgNP}+\text { Adhesive }\end{array}$ & 3.89 & 0.13 & $2.44 \mathrm{E}-06$ \\
\hline $\begin{array}{l}10 \mu \mathrm{g} / \mathrm{mL}, 4 \mathrm{~nm} \\
\mathrm{AgNP}+\text { Adhesive }\end{array}$ & 3.81 & 0.13 & $1.38 \mathrm{E}-06$ \\
\hline $\begin{array}{l}1 \mu \mathrm{g} / \mathrm{mL}, 10 \mathrm{~nm} \\
\text { AgNP }+ \text { Adhesive }\end{array}$ & 3.90 & 0.11 & $1.67 \mathrm{E}-06$ \\
\hline $\begin{array}{l}10 \mu \mathrm{g} / \mathrm{mL}, 10 \mathrm{~nm} \\
\mathrm{AgNP}+\text { Adhesive }\end{array}$ & 3.87 & 0.16 & $3.66 \mathrm{E}-06$ \\
\hline
\end{tabular}




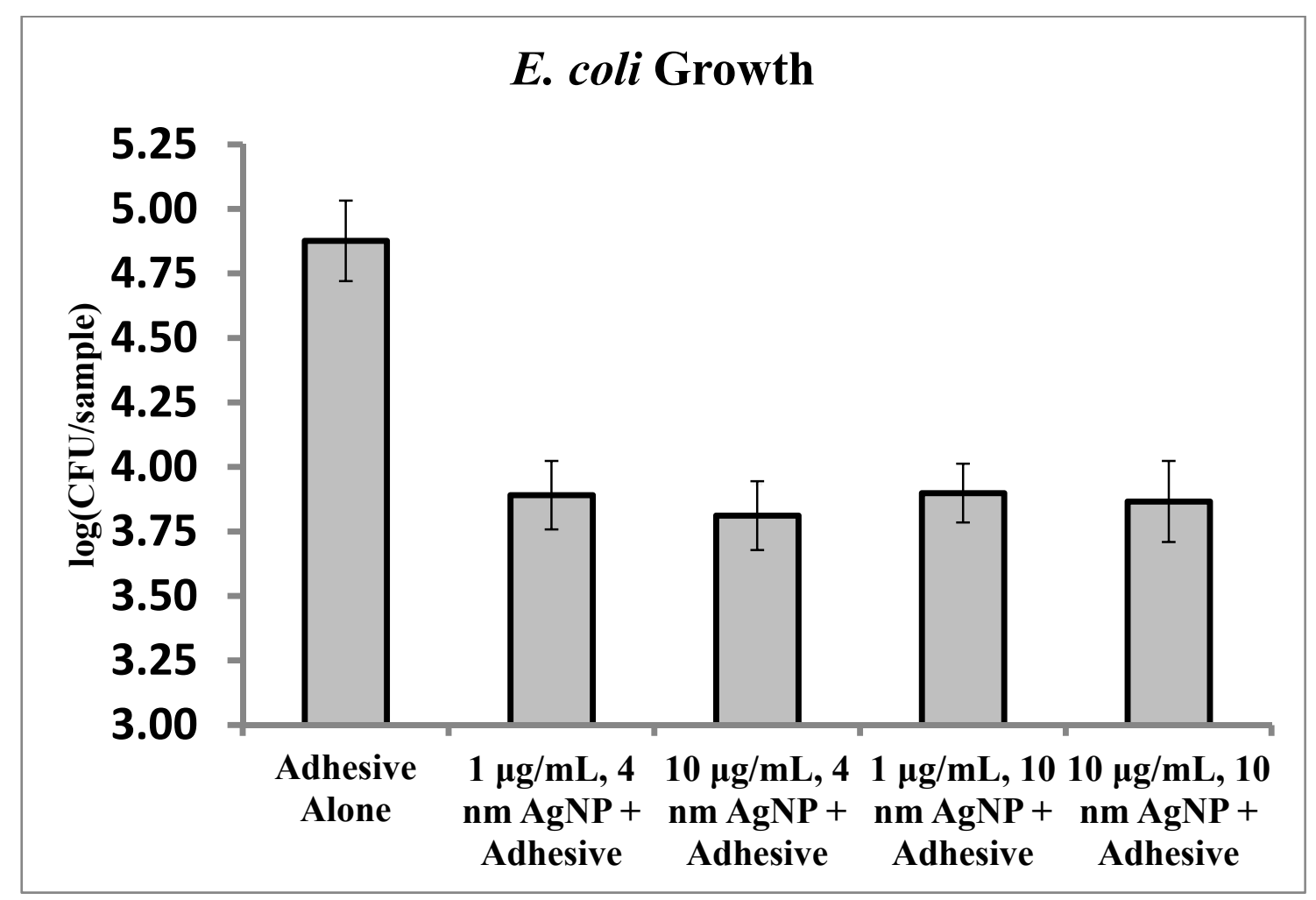

Figure 34. The average CFU counts of various silver nanoparticle concentration and size combinations within the 2-octyl cyanoacrylate tissue adhesive. Average CFU counts are depicted on a logarithmic scale. Error bars represent the standard deviation for each sample combination.

Table 12. The results of a 2-way ANOVA test from the responses produced in the CFU counting. The test statistic, critical value, and $p$-value are shown for the size and concentration factors. The interaction of the size and concentration factors is also shown.

\begin{tabular}{|l|l|l|l|}
\hline Source of Variation & $F$ & $F$ crit & $p$-value \\
\hline Concentration & 0.85 & 4.49 & $3.71 \mathrm{E}-01$ \\
\hline Size & 0.27 & 4.49 & $6.12 \mathrm{E}-01$ \\
\hline Interaction & 0.15 & 4.49 & $7.05 \mathrm{E}-01$ \\
\hline
\end{tabular}




\subsection{Breaking Load Testing}

The breaking load of the 2-octyl cyanoacrylate increased when silver nanoparticles were added to the adhesive. The samples were affixed to the universal testing machine clamps and were pulled until the reduced section fractured. The raw data recorded by the Bluehill@ 3 software was obtained and analyzed in Microsoft Excel. Table 13 displays the average breaking load for each silver nanoparticle concentration and size combination, standard deviation, and $p$-values. The raw data for the breaking load test are located in Appendix D. Figure 35 is a graph comparing the average breaking load of the unaltered adhesive and different composite adhesives with each other. The error bars depict the standard deviation of the set of data for each sample.

Table 14 summarizes the results of a 2-way ANOVA test from the responses generated in the breaking load testing.

Table 13. The average breaking loads for the different factor combinations. All runs were performed five times.

\begin{tabular}{|l|l|l|l|}
\hline Name & $\begin{array}{l}\text { Average Breaking } \\
\text { Load }(\mathrm{MPa})\end{array}$ & $\begin{array}{l}\text { Standard } \\
\text { Deviation }\end{array}$ & $p$-value \\
\hline Adhesive Alone & 0.46 & 0.09 & N/A \\
\hline $\begin{array}{l}1 \mu \mathrm{g} / \mathrm{mL}, 4 \mathrm{~nm} \\
\text { AgNP }+ \text { Adhesive }\end{array}$ & 0.75 & 0.09 & $4.47 \mathrm{E}-04$ \\
\hline $\begin{array}{l}10 \mu \mathrm{g} / \mathrm{mL}, 4 \mathrm{~nm} \\
\text { AgNP }+ \text { Adhesive }\end{array}$ & 1.07 & 0.29 & $9.89 \mathrm{E}-04$ \\
\hline $\begin{array}{l}1 \mu \mathrm{g} / \mathrm{mL}, 10 \mathrm{~nm} \\
\text { AgNP }+ \text { Adhesive }\end{array}$ & 0.76 & 0.19 & $6.68 \mathrm{E}-03$ \\
\hline $\begin{array}{l}10 \mu \mathrm{g} / \mathrm{mL}, 10 \mathrm{~nm} \\
\text { AgNP }+ \text { Adhesive }\end{array}$ & 1.46 & 0.33 & $9.46 \mathrm{E}-05$ \\
\hline
\end{tabular}




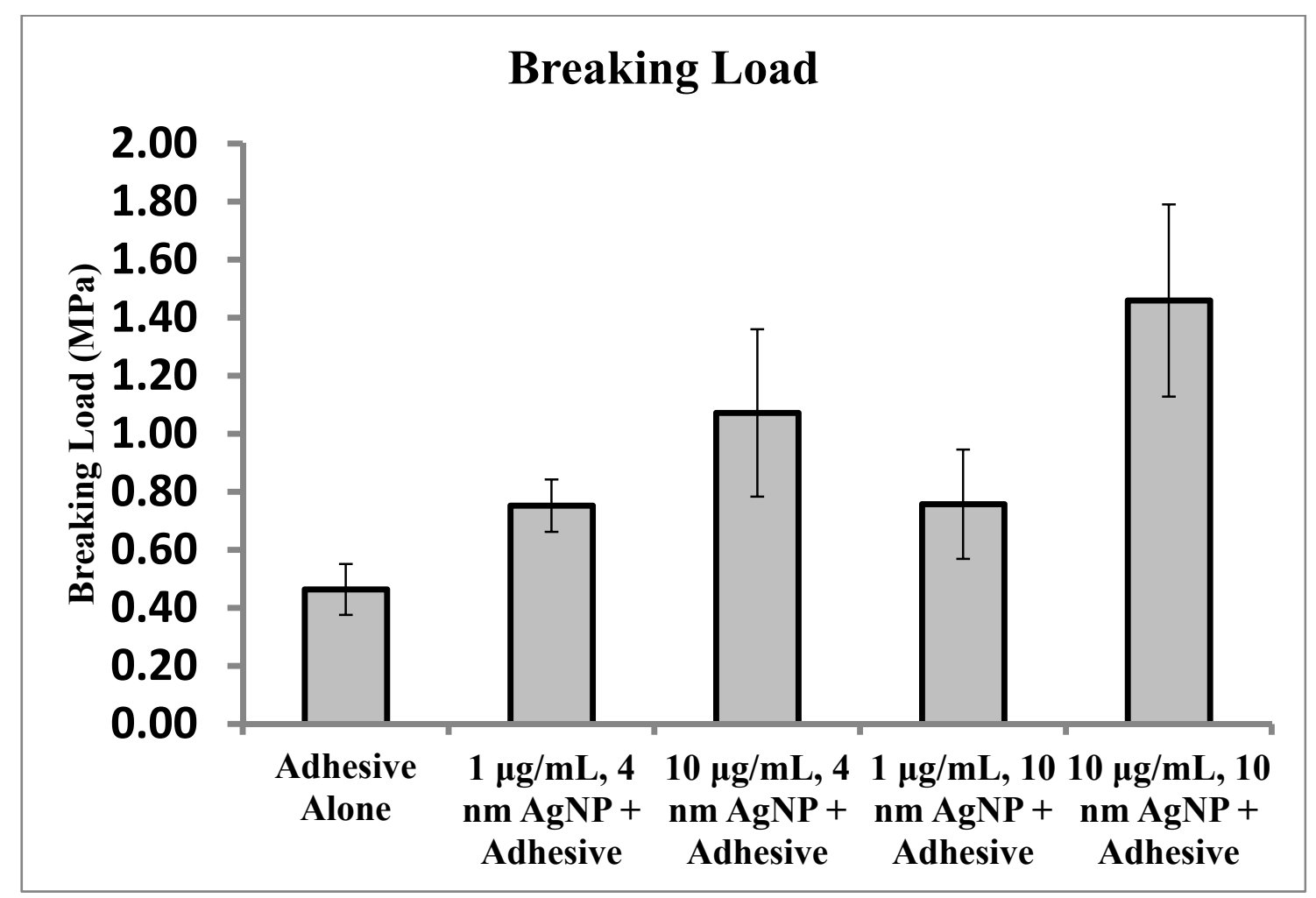

Figure 35. The breaking load results of the different silver nanoparticle concentration and size combinations within the tissue adhesive. Error bars represent the standard deviation for each sample combination.

Table 14. The results of a 2-way ANOVA test from the responses generated in the breaking load testing. The test statistic, critical value, and $p$-value are shown for the size and concentration factors. The interaction of the size and concentration factors is also shown.

\begin{tabular}{|l|l|l|l|}
\hline Source of Variation & $F$ & $F$ crit & $p$-value \\
\hline Concentration & 22.0 & 4.49 & $2.44 \mathrm{E}-04$ \\
\hline Size & 3.26 & 4.49 & $9.01 \mathrm{E}-02$ \\
\hline Interaction & 3.09 & 4.49 & $9.80 \mathrm{E}-02$ \\
\hline
\end{tabular}

\subsection{Adhesive Force Testing on Porcine Eyes}

When silver nanoparticles were added to the 2-octyl cyanoacrylate adhesive, the adhesive force increased. Figure 36 shows the fracturing of the adhesive bonds. The 
adhesive force was determined by using Microsoft Excel to analyze the raw data generated by the Bluehill ${ }^{\circledR} 3$ software. Table 15 tabulates the average adhesive force for each silver nanoparticle concentration and size combination, standard deviation, and $p$ values. The raw data for the adhesive force test are located in Appendix E. Figure 37 compares the average adhesive force of the unaltered adhesive samples to the different composite adhesives. The error bars depict the standard deviation of the set of data for each sample. Table 16 summarizes the results of a 2-way ANOVA test from the responses produced in the adhesive force testing.

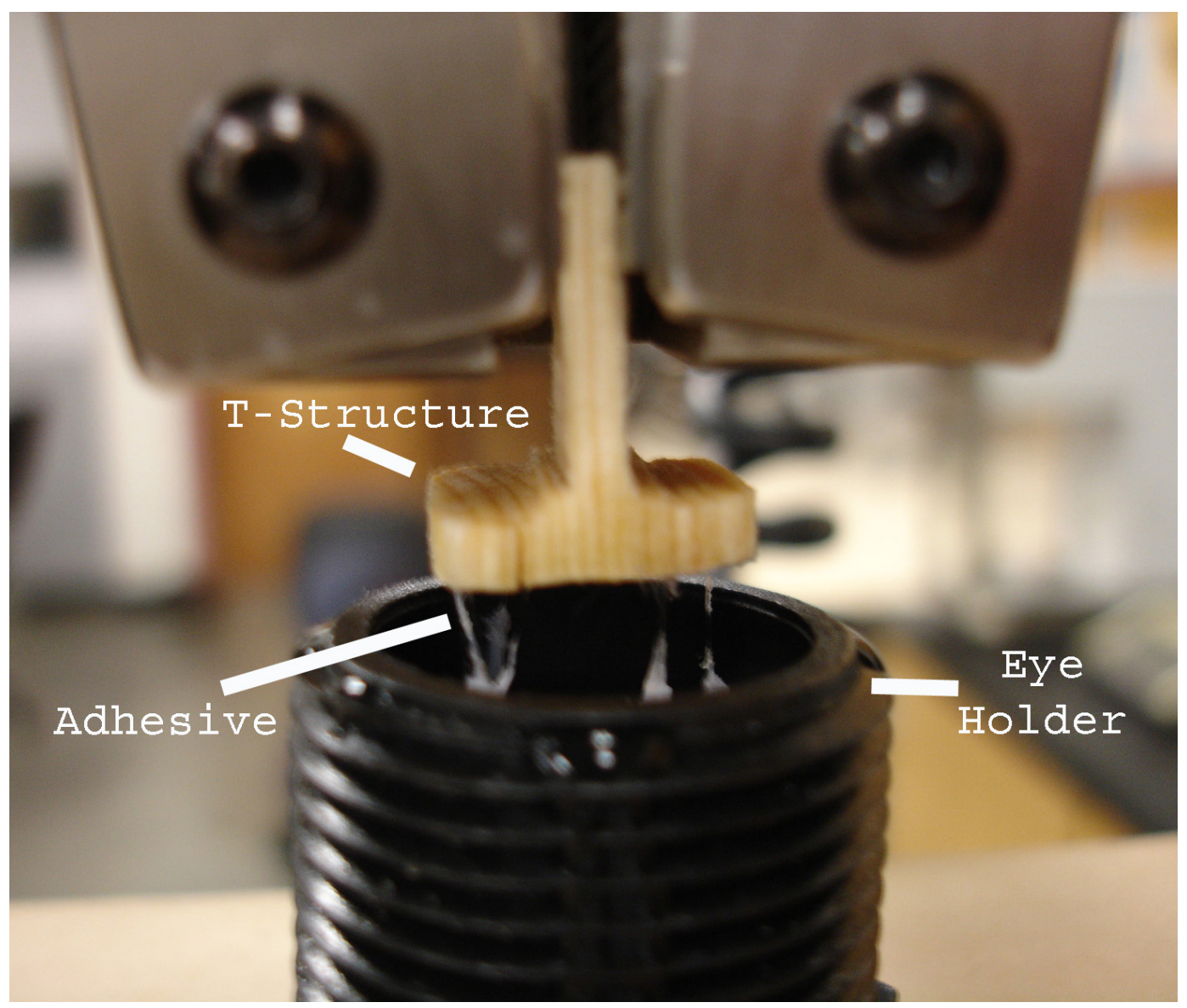

Figure 36. The broken adhesive bonds after adhesive force testing. 
Table 15. The average adhesive forces for the various factor combinations. All runs were performed five times.

\begin{tabular}{|l|l|l|l|}
\hline Name & $\begin{array}{l}\text { Average Adhesive } \\
\text { Force (MPa) }\end{array}$ & $\begin{array}{l}\text { Standard } \\
\text { Deviation }\end{array}$ & $p$-value \\
\hline Adhesive Alone & 0.008 & 0.002 & N/A \\
\hline $\begin{array}{l}1 \mu \mathrm{g} / \mathrm{mL}, 4 \mathrm{~nm} \text { AgNP } \\
+ \text { Adhesive }\end{array}$ & 0.010 & 0.001 & $4.462 \mathrm{E}-02$ \\
\hline $\begin{array}{l}10 \mu \mathrm{g} / \mathrm{mL}, 4 \mathrm{~nm} \\
\text { AgNP }+ \text { Adhesive }\end{array}$ & 0.023 & 0.006 & $4.922 \mathrm{E}-04$ \\
\hline $\begin{array}{l}1 \mu \mathrm{g} / \mathrm{mL}, 10 \mathrm{~nm} \\
\text { AgNP }+ \text { Adhesive }\end{array}$ & 0.018 & 0.004 & $7.816 \mathrm{E}-04$ \\
\hline $\begin{array}{l}10 \mu \mathrm{g} / \mathrm{mL}, 10 \mathrm{~nm} \\
\text { AgNP }+ \text { Adhesive }\end{array}$ & 0.025 & 0.007 & $4.367 \mathrm{E}-04$ \\
\hline
\end{tabular}

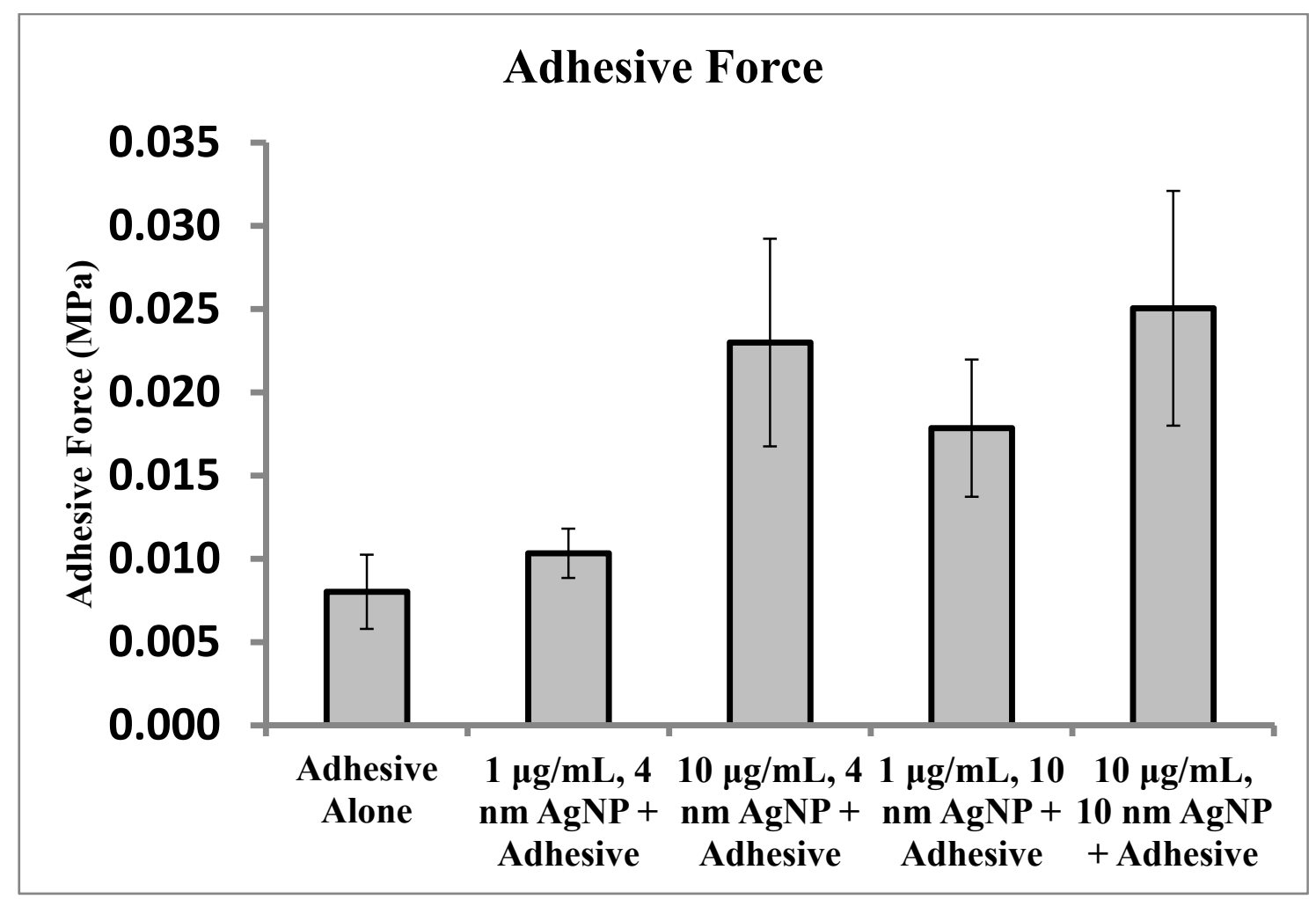

Figure 37. The adhesive force results of the various doped and undoped adhesives. Error bars represent the standard deviation for each sample combination. 
Table 16. The results of a 2-way ANOVA test from the responses produced in the adhesive force testing. The test statistic, critical value, and $p$-value are shown for the size and concentration factors. The interaction of the size and concentration factors is also shown.

\begin{tabular}{|l|l|l|l|}
\hline Source of Variation & $F$ & $F$ crit & $p$-value \\
\hline Concentration & 18.3 & 4.49 & $5.77 \mathrm{E}-04$ \\
\hline Size & 4.26 & 4.49 & $5.57 \mathrm{E}-02$ \\
\hline Interaction & 1.38 & 4.49 & $2.57 \mathrm{E}-01$ \\
\hline
\end{tabular}




\section{CHAPTER SIX}

\section{DISCUSSION}

\subsection{Silver Nanoparticle Distribution within Tissue Adhesive}

The distribution of the silver nanoparticles within the 2-octyl cyanoacrylate tissue adhesive can possibly affect the variability of the results. When mixing the silver nanoparticles into the adhesive, silver nanoparticles were positioned in the polymer matrix such that it affected the mechanical strength of the adhesive $[31,56,57]$. If the nanoparticles were not uniformly distributed within the polymer matrix, portions of the composite sample could possibly possess higher concentrations of the nanoparticles whereas other portions could possess lower or minimal concentrations of nanoparticles within the matrix. For the adhesive force testing, the higher nanoparticle concentration portion of the sample should require more force to break the adhesive bonds to the porcine sclera. For the breaking load testing, a higher nanoparticle concentration portion at the reduced section of the dog-bone specimen should withstand more tensile force when the specimen is pulled apart until the reduced section fractures. In contrast, samples containing negligible amounts of silver nanoparticles distributed at certain portions of the polymer matrix should experience similar mechanical strength as an unaltered version of the tissue adhesive.

\subsection{Antibacterial Efficacy}

Both the Kirby-Bauer disk diffusion susceptibility test and CFU counting test revealed that the silver nanoparticles imbued antibacterial properties to the 2-octyl cyanoacrylate tissue adhesive when mixed together. For the Kirby-Bauer test, an evident 
inhibition halo surrounded the composite samples where E. coli colonies were not found. For the CFU counting test, the silver nanoparticle-doped adhesive significantly reduced the number of $E$. coli colonies grown on the culturing dish. The difference between composite samples and unaltered samples was statistically significant with a $p$-value less than 0.01 .

\subsubsection{Kirby-Bauer Disk Diffusion Susceptibility Test}

There was no inhibition halo surrounding the undoped adhesive samples. Imbuing the antibacterial property of silver nanoparticles into the adhesive produced a notably clear and distinct inhibition halo around the composite sample. This is due to the absorption of water by the composite adhesive while the silver diffuses into the surrounding agar during incubation [26,34]. The silver interacts with the bacterial cells to inhibit several cell functions and injure the cells $[8,58]$. The growth of $E$. coli was inhibited surrounding the sample because the bacteria experienced the antibacterial property of the silver nanoparticles. The magnified microscope images of the samples confirmed the inhibition halo around the composite sample and the E. coli growth surrounding the unaltered tissue adhesive. The difference between doped and undoped samples was statistically significant with a $p$-value less than 0.01 .

The results show that the $10 \mu \mathrm{g} / \mathrm{mL}$ of $4 \mathrm{~nm}$ silver nanoparticle-doped adhesive demonstrated the greatest bactericidal effect. With the exception of the inhibition halo diameters of the $10 \mu \mathrm{g} / \mathrm{mL}$ of $4 \mathrm{~nm}$ silver nanoparticle-doped adhesive, the difference between inhibition halo diameters of the all samples was minimal. A 2-way ANOVA test was executed in Microsoft Excel and found that the silver nanoparticle concentration had 
a significant effect on the inhibition halo diameter results, while there was no significant difference between the silver nanoparticle sizes on the results. The 2-way ANOVA test results also showed that there was interaction between silver nanoparticle size and concentration, which means that the response to size was dependent on the concentration and vice versa. The effect of silver nanoparticle concentration on antibacterial efficacy supported previous research that found an increase of silver nanoparticle concentration enhanced antibacterial effectiveness [25]. The minimal difference in antibacterial efficacy when varying silver nanoparticle size from $4 \mathrm{~nm}$ to $10 \mathrm{~nm}$ was possibly due to the relatively small difference in nanoparticle size. Although the doped adhesives demonstrated noticeable antibacterial efficacy compared to an unaltered adhesive, a definitive conclusion cannot be drawn regarding the influence of the silver nanoparticle size on the antibacterial efficacy of the adhesive. The CFU counting test was employed to provide another quantitative measure of the influence silver nanoparticle size and concentration has on the 2-octyl cyanoacrylate tissue adhesive.

\subsubsection{CFU Counting}

The CFU counts supported the results from the Kirby-Bauer disk diffusion susceptibility test indicating that silver nanoparticles imparted their antibacterial properties to the tissue adhesive. The original tissue adhesive can only seal and protect the wound from environmental bacteria and factors. The presence of bacteria from an improperly cleansed wound will allow bacteria to continue to grow in the wound and under the sealing adhesive layer. Our results show that tissue adhesives doped with silver nanoparticles displayed a significant, order of magnitude reduction of bacterial growth 
than undoped tissue adhesives. This decrease in bacterial growth reduces the chance of bacteria in the wound producing an inflammatory response and possibly leading to infection. If a wound is currently inflamed or infected, the silver nanoparticle-infused tissue adhesive can aid in reducing the degree of inflammation or infection by preventing bacteria from continual growth and reproduction.

The $10^{-2}$ dilution of the unaltered adhesive was used for the colony counts because the $10^{-1}$ dilution culturing dishes were confluent with $E$. coli and colonies were not distinguishable to be easily counted. In contrast, the culturing dishes containing silver nanoparticle-infused adhesive samples were counted at $10^{-1}$ dilutions due to the relatively defined outline of the colonies and reasonable count. ImageJ was a reliable software to count the number of colonies on each culturing dish; however, like with all software and methods, there were some limitations. The software detected certain specified parameters that were included in the colony count. The color, size, and circularity of the colonies were set to the desired specifications. For this research, the color of the E. coli colonies was set to be detected when adjusting the color threshold. The size of the colonies was based on choosing the typical smallest colony as the minimal pixel size and including colonies larger than the smallest colony as part of the count. Small pixels displayed and detected as the same color as the colonies were considered artifactual and were excluded from the count. The acceptable circularity was set to all shapes because $E$. coli colonies are not consistently circular.

The difference in CFU counts between the composite samples and unaltered samples was statistically significant with a $p$-value less than 0.01 . Although the silver 
nanoparticle-infused tissue adhesive demonstrated an order of magnitude reduction of bacterial growth compared to the adhesive alone, the antibacterial effectiveness of the four combinations of silver nanoparticle concentration and size varied slightly between each other. A 2-way ANOVA test was performed in Microsoft Excel to determine the level of effect the silver nanoparticle size and concentration had on the antibacterial effectiveness and if there was interaction between these two factors. The 2-way ANOVA test results showed that there was no significant interaction between silver nanoparticle size and concentration, which means that the response to size was not dependent on the concentration and vice versa. There was a negligible difference in antibacterial efficacy of the varying size and concentration combinations. The slight difference in antibacterial efficacy when varying the nanoparticle size from $4 \mathrm{~nm}$ to $10 \mathrm{~nm}$ is possibly due to the relatively small difference in nanoparticle size. A larger difference between nanoparticle sizes can possibly better distinguish the effects of silver nanoparticle size on antibacterial effectiveness. The difference in antibacterial efficacy was minimal when silver nanoparticle concentration was varied for this CFU counting test. This is possibly due to after reaching certain concentration levels $E$. coli growth was the same because $E$. coli growth has essentially stopped. Increasing the silver nanoparticle concentration after reaching this concentration threshold level would not further reduce the amount of E. coli grown, which was also seen in previous research when performing CFU counts [35]. Although the difference between the various doped adhesive combinations was minimal, the CFU counts showed that a higher concentration of silver nanoparticles within the adhesive does reduce the number of bacterial colonies grown. When increasing the 
concentration from $1 \mu \mathrm{g} / \mathrm{mL}$ to $10 \mu \mathrm{g} / \mathrm{mL}$, the average logarithmic CFU count for the 4 $\mathrm{nm}$ and $10 \mathrm{~nm}$ silver nanoparticles were 3.89 to 3.81 and 3.90 and 3.87 , respectively. Our findings supported previous research that a higher concentration of silver nanoparticles increases antibacterial efficacy [25]. Furthermore, the average logarithmic CFU counts depict that the smaller silver nanoparticle size showed a greater antibacterial effect on bacteria growth than the larger nanoparticle. This supports previous research that the smaller silver nanoparticle size has a greater antibacterial effectiveness than larger nanoparticles [35]. The $10 \mu \mathrm{g} / \mathrm{mL}$ of $4 \mathrm{~nm}$ silver nanoparticles within the 2-octyl cyanoacrylate samples possesses both the high concentration and the small nanoparticle size combination. Our results supported that this combination had the greatest antibacterial efficacy among all the tested combinations.

\subsection{Breaking Load Testing}

The infusion of silver nanoparticles into the 2-octyl cyanoacrylate caused the breaking load force of the adhesive to increase. The average breaking load of the unaltered adhesive was $0.46 \mathrm{MPa}$. Increasing the silver nanoparticle concentration in the adhesive increased the breaking load. The increased concentration of $4 \mathrm{~nm}$ nanoparticles from $1 \mu \mathrm{g} / \mathrm{mL}$ to $10 \mu \mathrm{g} / \mathrm{mL}$ showed about an average $0.32 \mathrm{MPa}$ increase in breaking load, while the $10 \mathrm{~nm}$ nanoparticle concentration increase from $1 \mu \mathrm{g} / \mathrm{mL}$ to $10 \mu \mathrm{g} / \mathrm{mL}$ demonstrated about an average $0.7 \mathrm{MPa}$ increase in breaking load of the adhesive. The greatest breaking load was the $10 \mu \mathrm{g} / \mathrm{mL}$ of $10 \mathrm{~nm}$ silver nanoparticle-doped adhesive. The increased concentration of nanoparticles resulted in an increase of the adhesive's breaking strength, which supported previous research findings that increased mechanical 
strength were due to the dispersion of more nanoparticles to interact with the polymer matrix $[31,59]$.

Increasing the size of the nanoparticles from $4 \mathrm{~nm}$ to $10 \mathrm{~nm}$ at $1 \mu \mathrm{g} / \mathrm{mL}$ minimally increased the breaking load force of the adhesive. The $10 \mu \mathrm{g} / \mathrm{mL}$ of $4 \mathrm{~nm}$ and $10 \mathrm{~nm}$ showed about an average $0.39 \mathrm{MPa}$ increase in breaking load of the adhesive. This difference in average breaking load may be due to the wider range of responses of these samples. The range of responses for the $1 \mu \mathrm{g} / \mathrm{mL}$ of $4 \mathrm{~nm}$ and $10 \mathrm{~nm}$ sample combinations were narrower. The difference between the doped and undoped samples was statistically significant with a $p$-value less than 0.01. A 2-way ANOVA test was executed in Microsoft Excel and found that the silver nanoparticle concentration had a significant effect on the breaking load results, while there was no significant difference between the silver nanoparticle sizes on the results. The increase of silver nanoparticle concentration showed a clearer effect on the mechanical strength of the tissue adhesive, but the effect of silver nanoparticle size on the adhesive's mechanical strength was minimal. The 2-way ANOVA test results also showed that there was no significant interaction between silver nanoparticle size and concentration, which means that the response to size was not dependent on the concentration and vice versa.

\subsection{Adhesive Force Testing on Porcine Eyes}

The adhesive force increased when silver nanoparticles were added to the 2-octyl cyanoacrylate tissue adhesive. The average adhesive force of the unaltered adhesive was $0.008 \mathrm{MPa}$. The adhesive force slightly increased to an average of $0.010 \mathrm{MPa}$ when 1 $\mu \mathrm{g} / \mathrm{mL}$ of $4 \mathrm{~nm}$ silver nanoparticles was infused into the adhesive. Increasing the 
concentration of the silver nanoparticles in the adhesive showed a greater increase of adhesive strength. The adhesive doped with $10 \mu \mathrm{g} / \mathrm{mL}$ of $10 \mathrm{~nm}$ silver nanoparticles required the most force to fracture the adhesive bonds. On average, the adhesive strength of the adhesives containing $10 \mu \mathrm{g} / \mathrm{mL}$ of $4 \mathrm{~nm}$ nanoparticles and $1 \mu \mathrm{g} / \mathrm{mL}$ of $10 \mathrm{~nm}$ nanoparticles was also greater than the unaltered adhesive and $1 \mu \mathrm{g} / \mathrm{mL}$ of $4 \mathrm{~nm}$ composite adhesive. The increased concentration increased the interaction of the nanoparticles with the polymer matrix and was expected to enhance the adhesive strength of the adhesive [31,59].

The adhesive strength of the $1 \mu \mathrm{g} / \mathrm{mL}$ of $10 \mathrm{~nm}$ composite adhesive was higher compared to the $1 \mu \mathrm{g} / \mathrm{mL}$ of $4 \mathrm{~nm}$ doped adhesive. This was possibly due to the wider range of variability in the results for the $1 \mu \mathrm{g} / \mathrm{mL}$ of $10 \mathrm{~nm}$ composite adhesive than the 1 $\mu \mathrm{g} / \mathrm{mL}$ of $4 \mathrm{~nm}$ doped adhesive. The wider range of responses can be attributed to the uniqueness of each porcine eye and variability between each other. The shape of the test substrate can be a factor that might affect the bonding of the adhesive. Even though the flat area of the T-structure was firmly pressed and adhered to the porcine eyeball, the eyeball might have reverted to its natural spherical shape. Furthermore, the variation in surface morphology of each sclera can contribute to the broad range of responses. A 2way ANOVA test was performed in Microsoft Excel to determine the effect of silver nanoparticle concentration and size on the adhesive force and if there was interaction between these two factors. The 2-way ANOVA test results showed that there was no significant interaction between silver nanoparticle size and concentration, which means that the response to size was not dependent on the concentration and vice versa. We 
found that the silver nanoparticle concentration had a significant effect on the adhesive force results, while there was a negligible difference between the silver nanoparticle sizes on the results. Because of this 2-way ANOVA test, the results from this experiment suggest that the increase of nanoparticle concentration in the adhesive resulted in enhanced adhesive strength. The results from varying nanoparticle sizes were comparable among each other. The difference between the composite samples and unaltered samples was statistically significant with a $p$-value less than 0.05 .

An increased adhesive strength indicates that the adhesive holding together two ends of tissue requires greater force to separate the adhesive bonds. This is particularly important because the adhesive will prevent the two ends of tissue from further separation when sudden or excessive force is applied. Although doping the adhesive with silver nanoparticles increased the mechanical strength when tested on the porcine eyes, the strength of the adhesive on different tissues in the body can possibly vary because adhesive strength is highly dependent on the test substrate [38]. Since 2-octyl cyanoacrylate is already used to treat wounds from many areas of the body including the eye, the increased adhesive strength of the composite adhesive enhances the performance of the adhesive while imparting an antibacterial effect. 


\section{CHAPTER SEVEN}

\section{CONCLUSION}

The infusion of silver nanoparticles into a 2-octyl cyanoacrylate tissue adhesive does impart an antibacterial effect to the adhesive. The greatest antibacterial effect came from imbuing $10 \mu \mathrm{g} / \mathrm{mL}$ of $4 \mathrm{~nm}$ silver nanoparticles into the tissue adhesive, which was shown in both the Kirby-Bauer test and CFU counting. There were distinct inhibition halos surrounding each composite sample, whereas there were no halos surrounding unaltered samples for the Kirby-Bauer test. A significant, order of magnitude reduction of bacterial growth was seen from the doped adhesive compared to the unaltered adhesive when the CFU counting test was performed. While the addition of silver nanoparticles caused a significant reduction in the number of $E$. coli colonies for the doped adhesives, the difference among the varying silver nanoparticle size and concentration combinations was minimal.

The results of the breaking load test showed the addition of silver nanoparticles into the adhesive increased the breaking strength of the adhesive. The greatest breaking load was the $10 \mu \mathrm{g} / \mathrm{mL}$ of $10 \mathrm{~nm}$ silver nanoparticle-doped adhesive. The adhesive strength of the adhesive increased when silver nanoparticles were added and applied to the incised porcine sclera. The $10 \mu \mathrm{g} / \mathrm{mL}$ of $10 \mathrm{~nm}$ silver nanoparticle-infused adhesive also demonstrated the greatest adhesive strength. The increased adhesive strength indicates that the adhesive fastening together two ends of tissue requires greater force to break the adhesive bonds. 
With the definite antibacterial efficacy and increased mechanical strength of this silver nanoparticle-doped adhesive, this silver nanoparticle-infused 2-octyl cyanoacrylate tissue adhesive outperforms conventional tissue adhesives. Decreasing bacterial growth in a wound reduces the chance of infection at the wound site. This also reduces other complications associated with infection and minimizes healing time. Patients will experience less discomfort around the wound compared to mechanical fasteners such as sutures or staples. Furthermore, tissue adhesives are more suitable for delicate tissues such as the eye, because it is less traumatic to the tissue than rigid fasteners. Ultimately, the silver nanoparticle-infused tissue adhesive investigated in this research can be an alternative or supplement to mechanical fasteners, which allows doctors the option to select whatever tissue binding method is most appropriate for the situation. 


\section{CHAPTER EIGHT}

\section{FUTURE WORK}

Despite the noticeable antibacterial effect of the silver nanoparticle-infused tissue adhesive over the unaltered adhesive, there were small differences between the varying silver nanoparticle size and concentration combination in terms of antibacterial efficacy. Though the results suggest the $10 \mu \mathrm{g} / \mathrm{mL}$ of $4 \mathrm{~nm}$ silver nanoparticles within the 2-octyl cyanoacrylate possesses a greater bactericidal effect, the antibacterial efficacy was marginally better than the other factor combinations. Future research can be conducted to determine if larger size silver nanoparticles in the adhesive continue to affect antibacterial efficacy positively or negatively.

Future research can also be performed to determine the effect of larger size silver nanoparticles on the mechanical strength of the adhesive. Further testing can involve examining what silver nanoparticle size and concentration will provide the optimal antibacterial and mechanical adhesive composition. There are many other characteristics of this tissue adhesive that can be tested to further understand its properties and its effect on other tissue. This tissue adhesive can be developed to be safe for in vivo use upon the completion of additional in-depth research. 


\section{REFERENCES}

1. A.P. Duarte, J.F. Coelho, J.C. Bordado, M.T. Cidade and M.H. Gil, "Surgical adhesives: Systematic review of the main types and development forecast," Prog. Polym. Sci. 37, 1031-1050 (2012).

2. H.C. Fark, R. Champakalakshmi, P.P. Panengrad, M. Raghunath and J.S. Mehta, “Tissue Adhesives in Ocular Surgery," Expert Rev. Ophthalmol. 6, 631-655 (2011).

3. D. Sierra and R. Saltz, Surgical Adhesives and Sealants: Current Technology and Applications, $1^{\text {st }}$ ed. (Technomic Publishing Co., Inc. Lancaster, U.S.A., 1996), pp. 3-6.

4. H.E. Kaufman, M.S. Insler, H.A. Ibrahim-Elzembely and S.C. Kaufman, "Human Fibrin Tissue Adhesive for Sutureless Lamellar Keratoplasty and Scleral Patch Adhesion: A Pilot Study," Ophthalmology, 110, 2168-2172 (2003).

5. X. Chen and H.J. Schluesener, "Nanosilver: A nanoproduct in medical application," Toxicol. Lett. 176, 1-12 (2008).

6. M.W. Grinstaff, "Designing hydrogel adhesives for corneal wound repair," Biomaterials, 28, 5205-5214 (2007).

7. M.T. Duffy, J.N. Bloom, K.M. McNally-Heintzelman, D.L. Heintzelman, E.C. Soller and G.T. Hoffman, "Sutureless Ophthalmic Surgery: A Scaffold-Enhanced Bioadhesive Technique," J. AAPOS, 9, 315-320 (2005).

8. T. Gunasekaran, T. Nigusse and M.D. Dhanaraju, "Silver Nanoparticles as Real Topical Bullets for Wound Healing," J. Am. Col. Certif. Wound Spec. 3, 82-96 (2012).

9. M. Ahamed, M.S. Alsalhi and M.K.J. Siddiqui, "Silver nanoparticle applications and human health," Clin. Chim. Acta, 411, 1841-1848 (2010).

10. D.C. Ritterband, S.W. Meskin, D.E. Shapiro, J. Kusmierczyk, J.A. Seedor and R.S. Koplin, "Laboratory Model of Tissue Adhesive (2-Octyl Cyanoacrylate) in Sealing Clear Corneal Cataract Wounds," Am. J. Ophthalmol. 140, 1039-1043 (2005).

11. S.W. Meskin, D.C. Ritterband, D.E. Shapiro, J.Kusmierczyk, S.S. Schneider, J.A. Seedor and R.S. Koplin, "Liquid Bandage (2-Octyl Cyanoacrylate) as a Temporary Wound Barrier in Clear Corneal Cataract Surgery," Ophthalmology, 112, 2015-2021 (2005). 
12. M.D. Mills, D.K. Coats, S.P. Donahue and D.T. Wheeler, "Strabismus surgery for adults: A report by the American Academy of Ophthalmology," Ophthalmology, 111, 1255-1262 (2004).

13. M. Banitt, H.K. Soong, S.I. Mian, J.B. Malta and D.C. Musch, "Wound Integrity of Clear Corneal Incisions Closed with Fibrin and N-Butyl-2-Cyanoacrylate Adhesives," Curr. Eye Res. 34, 706-710 (2009).

14. J.A. Hovanesian, "Cataract wound closure with a polymerizing liquid hydrogel ocular bandage," J. Cataract Refractive Surg. 35, 912-916 (2009).

15. I. Strehin, W.M. Ambrose, O. Schein, A. Salahuddin and J. Elisseeff, "Synthesis and characterization of a chondroitin sulfate-polyethylene glycol corneal adhesive," J. Cataract Refractive Surg. 35, 567-576 (2009).

16. T.M. Tolaymat, A.M. El Badawy, A. Genaidy, K.G. Scheckel, T.P. Luxton and M. Suidan, "An evidence-based environmental perspective of manufactured silver nanoparticle in syntheses and applications: A systematic review and critical appraisal of peer-reviewed scientific papers," Sci. Total Environ. 408, 999-1006 (2010).

17. V. Amendola, S. Polizzi and M. Meneghetti, "Free Silver Nanoparticles Synthesized by Laser Ablation in Organic Solvents and Their Easy Functionalization," Langmuir, 23, 6766-6770 (2007).

18. J. Behari, “Principles of nanoscience: An overview,” Indian J. Exp. Biol. 48, 10081019 (2010).

19. K.J. Lee, Y.I. Lee, I.K. Shim, B.H. Jun, H.J. Cho and J.W. Joung, "Large-Scale Synthesis of Polymer-Stabilized Silver Nanoparticles," Solid State Phenom. 124-126, 1189-1192 (2007).

20. D. Dorjnamjin, M. Ariunaa and Y.K Shim, "Synthesis of Silver Nanoparticles Using Hydroxyl Functionalized Ionic Liquids and Their Antimicrobial Activity," Int. J. Mol. Sci. 9, 807-820 (2008).

21. J. Yang, J.Y. Lee and H. Too, "Core-Shell Ag-Au Nanoparticles from Replacement Reaction in Organic Medium," J. Phys. Chem. B, 109, 19208-19212 (2005).

22. M. Chen, Y. Feng, X. Wang, T. Li, J. Zhang and D. Qian, "Silver nanoparticles capped by oleylamine: formation, growth, and self-organization," Langmuir, 23, 5296-5304 (2007). 
23. A.Y. Olenin, Y.A. Krutyakov, A.A. Kudrinskii and G.V. Lisichkin, "Formation of surface layers on silver nanoparticles in aqueous and water-organic media," Colloid J. 70, 71-76 (2008).

24. L. Balan, J. Malval, R. Schneider and D. Burget, "Silver Nanoparticles: new synthesis, characterization and photophysical properties," Mater. Chem. Phys. 104, 417-421 (2007).

25. W-F. Lee and K-T. Tsao, "Effect of silver nanoparticles content on the various properties of nanocomposite hydrogels by in situ polymerization," J. Mater. Sci. 45, 89-97 (2010).

26. B. Sadeghi, F.S. Garmaroudi, M. Hashemi, H.R. Nezhad, A. Nasrollahi, S. Ardalan and S. Ardalan, "Comparison of the anti-bacterial activity on the nanosilver shapes: Nanoparticles, nanorods and nanoplates," Adv. Powder Technol. 23, 22-26 (2012).

27. M.A.S. Sadjadi, B. Sadeghi, M. Meskinfam, K. Zare and J. Azizian, "Synthesis and characterization of Ag/PVA nanorods by chemical reduction method," Phys. E Low Dimens. Syst. Nanostruct. 40, 3183-3186 (2008).

28. A. Muñoz-Bonilla and M. Fernández-García, "Polymeric materials with antimicrobial activity,” Prog. Polym. Sci. 37, 281-339 (2012).

29. National Institute of Standards and Technology (2012). Preparation of Nanoparticle Dispersions from Powdered Material Using Ultrasonic Disruption [Online].

Available at http://www.nist.gov/customcf/get pdf.cfm?pub id=910680 (accessed 25 October 2012). Posted pdf file.

30. C. Radheshkumar and H. Münstedt, "Morphology and mechanical properties of antimicrobial polyamide/silver composites," Mater. Lett. 59, 1949-1953 (2005).

31. H. Deka, N. Karak, R.D. Kalita and A.K. Buragohain, "Bio-based thermostable, biodegradable and biocompatible hyperbranched polyurethane/Ag nanocomposites with antimicrobial activity," Polym. Degrad. Stab. 95, 1509-1517 (2010).

32. Y. Zhou, Y. Zhao, L. Wang, L. Xu, M. Zhai and S. Wei, "Radiation synthesis and characterization of nanosilver/gelatin/carboxymethyl chitosan hydrogel," Radiat. Phys. Chem. 81, 553-560 (2012).

33. H-W. Lin, W-H. Hwu and M-D. Ger, "The dispersion of silver nanoparticles with physical dispersal procedures," J. Mater. Process. Technol. 206, 56-61 (2008). 
34. Hudzicki, J. Kirby-Bauer Disk Diffusion Susceptibility Test Protocol [Online]. Available at http://www.microbelibrary.org/component/resource/laboratorytest/3189-kirby-bauer-disk-diffusion-susceptibility-test-protocol (accessed 3 October 2012).

35. H.L. Liu, S.A. Dai, K.Y. Fu and S.H. Hsu, "Antibacterial properties of silver nanoparticles in three different sizes and their nanocomposites with a new waterborne polyurethane," Int. J. Nanomed. 5, 1017-1028 (2010).

36. S. Kull, I. Martinelli, E. Briganti, P. Losi, D. Spiller, S. Tonlorenzi and G. Soldani, "Glubran2 Surgical Glue: In Vitro Evaluation of Adhesive and Mechanical Properties,” J. Surg. Res. 157, e15-e21 (2009).

37. H. Hadavinia, L. Kawashita, A.J. Kinloch, D.R. Moore and J.G. Williams, " $A$ numerical analysis of the elastic-plastic peel test," Eng. Fract. Mech. 73, 2324-2335 (2006).

38. R.A. Chivers and R.G. Wolowacz, "The strength of adhesive-bonded tissue joints," Int. J. Adhes. Adhes. 17, 127-132 (1997).

39. nanoComposix (2011). Material Safety Data Sheet Econix Silver Nanoparticle Powder (AGPE) [Online]. Available at http://nanocomposix.com/sites/default/files/msds/silver/NCX.MSDSEconix.Silver.PVP.Powder.pdf (accessed 20 October 2012). Posted pdf file.

40. nanoComposix (2012). Dried Nanopowder Storage and Handling Procedures [Online]. Available at http://nanocomposix.com/sites/default/files/storagehandling/NanoComposix\%20Storage\%20and\%20Handling.pdf (accessed 20 October 2012). Posted pdf file.

41. Ethicon, Inc. (2010). Dermabond Material Safety Data Sheet [Online]. Available at https://secure.mypss.com/catMaintDataServlet?existingFileId=42231 (accessed 20 October 2012). Posted pdf file.

42. Ethicon, Inc. (1998). Dermabond Topical Skin Adhesive [Online]. Available at http://hazard.com/msds/f2/cll/cllqf.html (accessed 20 October 2012). Posted pdf file.

43. Sigma-Aldrich Corporation (2012). Agar Material Safety Data Sheet [Online]. Available at http://www.sigmaaldrich.com/catalog/product/sigma/a1296?lang=en\&region=US (accessed 20 October 2012). Posted pdf file. 
44. Sigma-Aldrich Corporation (2012). Luria Broth Material Safety Data Sheet [Online]. Available at http://www.sigmaaldrich.com/catalog/product/sigma/13522?lang=en\&region=US (accessed 20 October 2012). Posted pdf file.

45. Public Health Agency of Canada (2001). Escherichia Coli Material Safety Data Sheet [Online]. Available at http://www.msdsonline.com/resources/msdsresources/free-safety-data-sheet-index/escherichia-coli-enterohemorrhagic.aspx (accessed 20 October 2012).

46. Fisher Scientific (2009). Ethanol, 200 proof Material Safety Data Sheet [Online]. Available at http://www.fishersci.com/ecomm/servlet/msdsproxy?LBCID=16020646\&productNa $\underline{\text { me}=A C 615090010}$ (accessed 20 September 2013). Posted pdf file.

47. IBI Scientific (1998). Chloroform Material Safety Data Sheet [Online]. Available at http://www.ibisci.com/images/IB05040MSDS.pdf (accessed 20 September 2013). Posted pdf file.

48. Fisher Scientific (2010). Acrylamide Material Safety Data Sheet [Online]. Available at http://www.fishersci.com/ecomm/servlet/msdsproxy?productName $=\mathrm{AC} 164835000$ (accessed 20 September 2013). Posted pdf file.

49. Life Technologies (2012). UltraPure ${ }^{\mathrm{TM}} N, N^{\prime}$-Methylenebisacrylamide Safety Data Sheet [Online]. Available at https://tools.invitrogen.com/content/sfs/msds/2011/15516024_MTR-NALT_EN.pdf (accessed 20 September 2013). Posted pdf file.

50. Fisher Scientific (2009). Ammonium Peroxydisulfate Material Safety Data Sheet [Online]. Available at http://www.fishersci.com/ecomm/servlet/msdsproxy?productName=BP17925 (accessed 20 September 2013). Posted pdf file.

51. Fisher Scientific (2010). TEMED Material Safety Data Sheet [Online]. Available at http://www.fishersci.com/ecomm/servlet/msdsproxy?productName=BP15020 (accessed 20 September 2013). Posted pdf file.

52. University of Nevada, Reno (2004). Autoclave Safety Manual [Online]. Available at http://www.ehs.unr.edu/Documents/AutoclaveSafetyManual.pdf (accessed 20 October 2012). Posted pdf file.

53. Edwards Limited (2012). RV12 Rotary Vane Pumps [Online]. Available at http://www.edwardsvacuum.com/Viewers/Document.ashx?id=1324\&lcid=2057 (accessed 3 August 2013). Posted pdf file. 
54. Z. Niu and Y. Li, "Removal and Utilization of Capping Agents in Nanocatalysis," Chem. Mater. In Press (2013).

55. Z.L. Wang, "Transmission Electron Microscopy of Shape-Controlled Nanocrystals and Their Assemblies," J. Phys. Chem. B, 104, 1153-1175 (2000).

56. J. Wie, The Effects of Nanoparticle Size on Rheological and Mechanical Properties of Polymer Nanoparticle Nanocomposites, Ph.D. Dissertation, University of Delaware, Newark, Delaware.

57. S-Y. Fu, X-Q. Feng, B. Lauke and Y-W. Mai, "Effects of particle size, particle/matrix interface adhesion and particle loading on mechanical properties of particulatepolymer composites," Composites, Part B, 39, 933-961 (2008).

58. S. Prabhu and E.K. Poulose, "Silver nanoparticles: mechanism of antimicrobial action, synthesis, medical applications, and toxicity effects," Int. Nano Lett. 2, 1-10 (2012).

59. F. Xin and L. Li, "Decoration of carbon nanotubes with silver nanoparticles for advanced CNT/polymer nanocomposites," Composites, Part A, 42, 961-967 (2011). 


\section{APPENDIX A}

\section{DISTANCES BETWEEN SILVER NANOPARTICLES}

\begin{tabular}{|c|c|c|c|c|c|c|c|}
\hline Label & Length (nm) & Label & Length (nm) & Label & Length (nm) & Label & Length (nm) \\
\hline 1 & 28.01 & 30 & 28.48 & 59 & 36.96 & 88 & 26.66 \\
\hline 2 & 36.59 & 31 & 33.07 & 60 & 26.09 & 89 & 47.52 \\
\hline 3 & 28.48 & 32 & 40.57 & 61 & 31.77 & 90 & 16.65 \\
\hline 4 & 40.16 & 33 & 32.66 & 62 & 34.02 & 91 & 50.59 \\
\hline 5 & 14.22 & 34 & 62.59 & 63 & 18.88 & 92 & 44.31 \\
\hline 6 & 41.36 & 35 & 69.79 & 64 & 15.92 & 93 & 47.05 \\
\hline 7 & 35.67 & 36 & 58.55 & 65 & 12.64 & 94 & 43.93 \\
\hline 8 & 37.27 & 37 & 27.53 & 66 & 33.87 & 95 & 27.17 \\
\hline 9 & 30.70 & 38 & 45.39 & 67 & 40.42 & 96 & 41.20 \\
\hline 10 & 37.82 & 39 & 51.03 & 68 & 46.38 & 97 & 35.83 \\
\hline 11 & 38.36 & 40 & 50.38 & 69 & 43.74 & 98 & 7.94 \\
\hline 12 & 48.24 & 41 & 11.41 & 70 & 25.06 & 99 & 18.34 \\
\hline 13 & 33.07 & 42 & 17.13 & 71 & 16.09 & 100 & 46.79 \\
\hline 14 & 36.53 & 43 & 44.71 & 72 & 41.74 & 101 & 50.53 \\
\hline 15 & 58.18 & 44 & 43.91 & 73 & 39.16 & 102 & 48.45 \\
\hline 16 & 47.95 & 45 & 8.70 & 74 & 38.19 & 103 & 18.36 \\
\hline 17 & 37.82 & 46 & 61.40 & 75 & 42.79 & 104 & 20.02 \\
\hline 18 & 36.25 & 47 & 19.64 & 76 & 52.26 & 105 & 21.17 \\
\hline 19 & 19.37 & 48 & 47.53 & 77 & 45.23 & 106 & 15.75 \\
\hline 20 & 8.40 & 49 & 17.93 & 78 & 40.75 & 107 & 37.28 \\
\hline 21 & 40.03 & 50 & 60.68 & 79 & 63.95 & 108 & 26.01 \\
\hline 22 & 32.90 & 51 & 74.46 & 80 & 40.88 & 109 & 39.69 \\
\hline 23 & 36.02 & 52 & 51.56 & 81 & 59.49 & 110 & 51.90 \\
\hline 24 & 37.82 & 53 & 57.91 & 82 & 41.36 & 111 & 62.34 \\
\hline 25 & 38.01 & 54 & 44.09 & 83 & 62.07 & & \\
\hline 26 & 23.88 & 55 & 25.68 & 84 & 49.33 & Mean & 37.20 \\
\hline 27 & 50.17 & 56 & 20.25 & 85 & 23.51 & SD & 14.41 \\
\hline 28 & 50.75 & 57 & 35.98 & 86 & 29.74 & Min & 7.94 \\
\hline 29 & 40.02 & 58 & 25.47 & 87 & 18.99 & Max & 74.46 \\
\hline
\end{tabular}




\section{APPENDIX B}

KIRBY-BAUER DISK DIFFUSION SUSCEPTIBILITY TEST

\begin{tabular}{|c|c|c|c|c|}
\hline Name & $\begin{array}{l}\text { Inhibition Halo } \\
\text { Diameter (mm) }\end{array}$ & Average (mm) & $\begin{array}{l}\text { Standard } \\
\text { Deviation }\end{array}$ & $p$-value \\
\hline \multirow{5}{*}{ Adhesive Alone } & 0 & \multirow{5}{*}{0} & \multirow{5}{*}{0} & \multirow{5}{*}{$\mathrm{N} / \mathrm{A}$} \\
\hline & 0 & & & \\
\hline & 0 & & & \\
\hline & 0 & & & \\
\hline & 0 & & & \\
\hline \multirow{5}{*}{$\begin{array}{l}1 \mu \mathrm{g} / \mathrm{mL}, 4 \mathrm{~nm} \\
\text { AgNP }+ \text { Adhesive }\end{array}$} & 10 & \multirow{5}{*}{11} & \multirow{5}{*}{0.71} & \multirow{5}{*}{$2.55 \mathrm{E}-10$} \\
\hline & 11 & & & \\
\hline & 11 & & & \\
\hline & 12 & & & \\
\hline & 11 & & & \\
\hline \multirow{5}{*}{$\begin{array}{l}10 \mu \mathrm{g} / \mathrm{mL}, 4 \mathrm{~nm} \\
\text { AgNP }+ \text { Adhesive }\end{array}$} & 14 & \multirow{5}{*}{15.2} & \multirow{5}{*}{1.79} & \multirow{5}{*}{$3.05 \mathrm{E}-08$} \\
\hline & 15 & & & \\
\hline & 17 & & & \\
\hline & 17 & & & \\
\hline & 13 & & & \\
\hline \multirow{5}{*}{$\begin{array}{l}1 \mu \mathrm{g} / \mathrm{mL}, 10 \mathrm{~nm} \\
\text { AgNP + Adhesive }\end{array}$} & 11 & \multirow{5}{*}{12.2} & \multirow{5}{*}{0.84} & \multirow{5}{*}{$4.27 \mathrm{E}-10$} \\
\hline & 12 & & & \\
\hline & 13 & & & \\
\hline & 13 & & & \\
\hline & 12 & & & \\
\hline \multirow{5}{*}{$\begin{array}{l}10 \mu \mathrm{g} / \mathrm{mL}, 10 \mathrm{~nm} \\
\text { AgNP + Adhesive }\end{array}$} & 13 & \multirow{5}{*}{12} & \multirow{5}{*}{0.71} & \multirow{5}{*}{$1.28 \mathrm{E}-10$} \\
\hline & 12 & & & \\
\hline & 11 & & & \\
\hline & 12 & & & \\
\hline & 12 & & & \\
\hline
\end{tabular}




\section{APPENDIX C}

\section{CFU COUNTS}

\begin{tabular}{|c|c|c|c|c|c|c|}
\hline Name & Colonies & $\begin{array}{l}\text { Dilution } \\
\text { Concentration }\end{array}$ & Log & Average & $\begin{array}{l}\text { Standard } \\
\text { Deviation }\end{array}$ & $\begin{array}{l}p \text {-value } \\
\text { (Logarithmic) }\end{array}$ \\
\hline \multirow{5}{*}{ Adhesive Alone } & 610 & 61000 & 4.79 & \multirow{5}{*}{4.88} & \multirow{5}{*}{0.16} & \multirow{5}{*}{ N/A } \\
\hline & \begin{tabular}{|l|}
587 \\
\end{tabular} & 58700 & 4.77 & & & \\
\hline & 554 & 55400 & 4.74 & & & \\
\hline & 1225 & 122500 & 5.09 & & & \\
\hline & 995 & 99500 & 5.00 & & & \\
\hline \multirow{5}{*}{$\begin{array}{l}1 \mu \mathrm{g} / \mathrm{mL}, 4 \mathrm{~nm} \\
\text { AgNP + Adhesive }\end{array}$} & 760 & 7600 & 3.88 & \multirow{5}{*}{3.89} & \multirow{5}{*}{0.13} & \multirow{5}{*}{ 2.44E-06 } \\
\hline & 680 & 6800 & 3.83 & & & \\
\hline & \begin{tabular}{|l|}
520 \\
\end{tabular} & 5200 & 3.72 & & & \\
\hline & 1176 & 11760 & 4.07 & & & \\
\hline & 903 & 9030 & 3.96 & & & \\
\hline \multirow{5}{*}{$\begin{array}{l}10 \mu \mathrm{g} / \mathrm{mL}, 4 \mathrm{~nm} \\
\text { AgNP + Adhesive }\end{array}$} & 830 & 8300 & 3.92 & \multirow{5}{*}{3.81} & \multirow{5}{*}{0.13} & \multirow{5}{*}{$1.38 \mathrm{E}-06$} \\
\hline & 570 & 5700 & 3.76 & & & \\
\hline & 410 & 4100 & 3.61 & & & \\
\hline & 679 & 6790 & 3.83 & & & \\
\hline & 872 & 8720 & 3.94 & & & \\
\hline \multirow{5}{*}{$\begin{array}{l}1 \mu \mathrm{g} / \mathrm{mL}, 10 \mathrm{~nm} \\
\text { AgNP + Adhesive }\end{array}$} & 860 & 8600 & 3.93 & \multirow{5}{*}{3.90} & \multirow{5}{*}{0.11} & \multirow{5}{*}{$1.67 \mathrm{E}-06$} \\
\hline & 720 & 7200 & 3.86 & & & \\
\hline & 690 & 6900 & 3.84 & & & \\
\hline & \begin{tabular}{|l|}
610 \\
\end{tabular} & 6100 & 3.79 & & & \\
\hline & 1200 & 12000 & 4.08 & & & \\
\hline \multirow{5}{*}{$\begin{array}{l}10 \mu \mathrm{g} / \mathrm{mL}, 10 \mathrm{~nm} \\
\text { AgNP + Adhesive }\end{array}$} & 463 & 44630 & 3.67 & \multirow{5}{*}{3.87} & \multirow{5}{*}{0.16} & \multirow{5}{*}{ 3.66E-06 } \\
\hline & 640 & 6400 & 3.81 & & & \\
\hline & 96 & 9600 & 3.98 & & & \\
\hline & 1158 & 11580 & 4.06 & & & \\
\hline & \begin{tabular}{|l|}
654 \\
\end{tabular} & 6540 & 3.82 & & & \\
\hline
\end{tabular}


APPENDIX D

BREAKING LOAD TESTING

\begin{tabular}{|c|c|c|c|c|}
\hline Name & $\begin{array}{l}\text { Breaking Load } \\
(\mathrm{MPa})\end{array}$ & Average (MPa) & $\begin{array}{l}\text { Standard } \\
\text { Deviation }\end{array}$ & $p$-value \\
\hline \multirow{5}{*}{ Adhesive Alone } & 0.59 & \multirow{5}{*}{0.46} & \multirow{5}{*}{0.09} & \multirow{5}{*}{$\mathrm{N} / \mathrm{A}$} \\
\hline & 0.50 & & & \\
\hline & 0.44 & & & \\
\hline & 0.36 & & & \\
\hline & 0.42 & & & \\
\hline \multirow{5}{*}{$\begin{array}{l}1 \mu \mathrm{g} / \mathrm{mL}, 4 \mathrm{~nm} \\
\text { AgNP + Adhesive }\end{array}$} & 0.77 & \multirow{5}{*}{0.75} & \multirow{5}{*}{0.09} & \multirow{5}{*}{$4.47 \mathrm{E}-04$} \\
\hline & 0.89 & & & \\
\hline & 0.66 & & & \\
\hline & 0.75 & & & \\
\hline & 0.69 & & & \\
\hline \multirow{5}{*}{$\begin{array}{l}10 \mu \mathrm{g} / \mathrm{mL}, 4 \mathrm{~nm} \\
\text { AgNP }+ \text { Adhesive }\end{array}$} & 0.84 & \multirow{5}{*}{1.07} & \multirow{5}{*}{0.29} & \multirow{5}{*}{ 9.89E-04 } \\
\hline & 0.85 & & & \\
\hline & 1.15 & & & \\
\hline & 1.54 & & & \\
\hline & 0.98 & & & \\
\hline \multirow{5}{*}{$\begin{array}{l}1 \mu \mathrm{g} / \mathrm{mL}, 10 \mathrm{~nm} \\
\text { AgNP + Adhesive }\end{array}$} & 0.78 & \multirow{5}{*}{0.76} & \multirow{5}{*}{0.19} & \multirow{5}{*}{$6.68 \mathrm{E}-03$} \\
\hline & 1.07 & & & \\
\hline & 0.71 & & & \\
\hline & 0.59 & & & \\
\hline & 0.64 & & & \\
\hline \multirow{5}{*}{$\begin{array}{l}10 \mu \mathrm{g} / \mathrm{mL}, 10 \mathrm{~nm} \\
\text { AgNP + Adhesive }\end{array}$} & 1.56 & \multirow{5}{*}{1.46} & \multirow{5}{*}{0.33} & \multirow{5}{*}{$9.46 \mathrm{E}-05$} \\
\hline & 1.70 & & & \\
\hline & 1.26 & & & \\
\hline & 0.99 & & & \\
\hline & 1.79 & & & \\
\hline
\end{tabular}




\section{APPENDIX E}

ADHESIVE FORCE TESTING

\begin{tabular}{|c|c|c|c|c|}
\hline Name & $\begin{array}{l}\text { Adhesive Force } \\
(\mathrm{MPa})\end{array}$ & Average (MPa) & $\begin{array}{l}\text { Standard } \\
\text { Deviation }\end{array}$ & $p$-value \\
\hline \multirow{5}{*}{ Adhesive Alone } & 0.012 & \multirow{5}{*}{0.008} & \multirow{5}{*}{0.002} & \multirow{5}{*}{$\mathrm{N} / \mathrm{A}$} \\
\hline & 0.009 & & & \\
\hline & 0.007 & & & \\
\hline & 0.007 & & & \\
\hline & 0.006 & & & \\
\hline \multirow{5}{*}{$\begin{array}{l}1 \mu \mathrm{g} / \mathrm{mL}, 4 \mathrm{~nm} \\
\text { AgNP }+ \text { Adhesive }\end{array}$} & 0.011 & \multirow{5}{*}{0.010} & \multirow{5}{*}{0.001} & \multirow{5}{*}{ 4.46E-02 } \\
\hline & 0.009 & & & \\
\hline & 0.010 & & & \\
\hline & 0.009 & & & \\
\hline & 0.012 & & & \\
\hline \multirow{5}{*}{$\begin{array}{l}10 \mu \mathrm{g} / \mathrm{mL}, 4 \mathrm{~nm} \\
\text { AgNP }+ \text { Adhesive }\end{array}$} & 0.014 & \multirow{5}{*}{0.023} & \multirow{5}{*}{0.006} & \multirow{5}{*}{$4.92 \mathrm{E}-04$} \\
\hline & 0.021 & & & \\
\hline & 0.024 & & & \\
\hline & 0.031 & & & \\
\hline & 0.026 & & & \\
\hline \multirow{5}{*}{$\begin{array}{l}1 \mu \mathrm{g} / \mathrm{mL}, 10 \mathrm{~nm} \\
\text { AgNP + Adhesive }\end{array}$} & 0.019 & \multirow{5}{*}{0.018} & \multirow{5}{*}{0.004} & \multirow{5}{*}{ 7.82E-04 } \\
\hline & 0.024 & & & \\
\hline & 0.016 & & & \\
\hline & 0.016 & & & \\
\hline & 0.014 & & & \\
\hline \multirow{5}{*}{$\begin{array}{l}10 \mu \mathrm{g} / \mathrm{mL}, 10 \mathrm{~nm} \\
\text { AgNP + Adhesive }\end{array}$} & 0.022 & \multirow{5}{*}{0.025} & \multirow{5}{*}{0.007} & \multirow{5}{*}{$4.37 \mathrm{E}-04$} \\
\hline & 0.018 & & & \\
\hline & 0.021 & & & \\
\hline & 0.029 & & & \\
\hline & 0.035 & & & \\
\hline
\end{tabular}

